\title{
Building Industry Reporting and Design for Sustainability (BIRDS) Neutral Environment Software Tool (NEST) Technical Manual
}

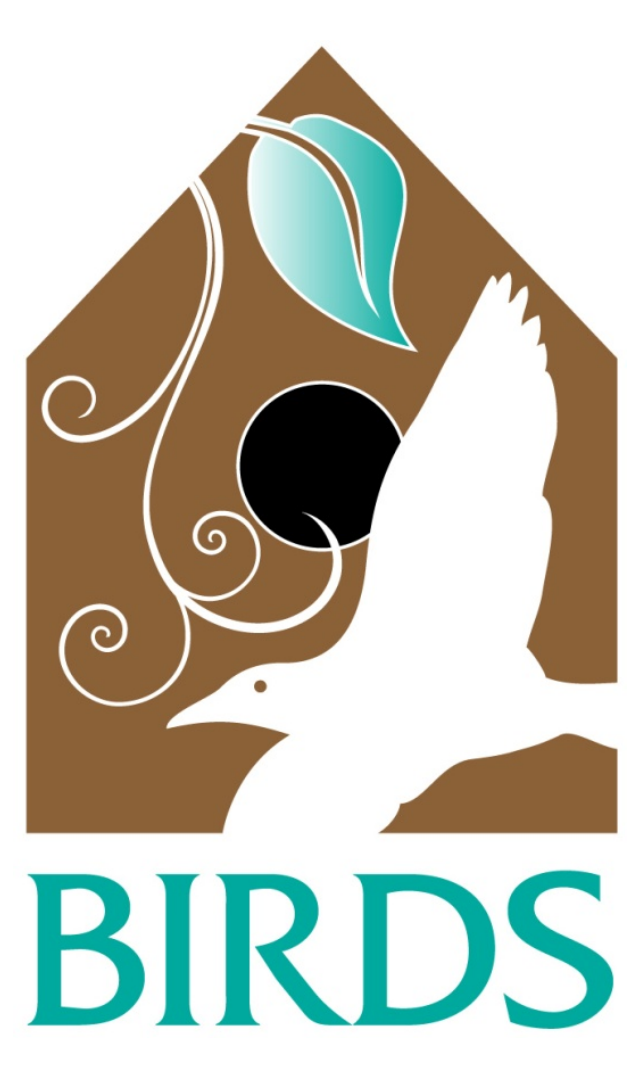

\author{
Joshua Kneifel \\ Eric O’Rear \\ Shannon Grubb \\ Priya Lavappa \\ Anne Landfield Greig
}

This publication is available free of charge from:

https://doi.org/10.6028/NIST.TN.1976

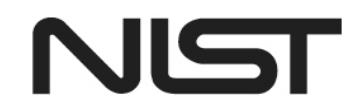

National Institute of Standards and Technology U.S. Department of Commerce 



\title{
Building Industry Reporting and Design for Sustainability (BIRDS) Neutral Environment Software Tool (NEST) Technical Manual
}

\author{
Joshua Kneifel \\ Eric O’Rear \\ Shannon Grubb \\ Priya Lavappa \\ Applied Economics Office \\ Engineering Laboratory \\ Anne Landfield Greig \\ Four Elements Consulting, LLC
}

This publication is available free of charge from:

https://doi.org/10.6028/NIST.TN.1976

October 2017

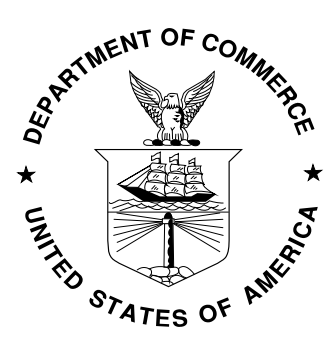

U.S. Department of Commerce

Wilbur L. Ross, Jr., Secretary

National Institute of Standards and Technology Kent Rochford, Acting NIST Director and Under Secretary of Commerce for Standards and Technology 
Certain commercial entities, equipment, or materials may be identified in this document to describe an experimental procedure or concept adequately. Such identification is not intended to imply recommendation or endorsement by the National Institute of Standards and Technology, nor is it intended to imply that the entities, materials, or equipment are necessarily the best available for the purpose.

National Institute of Standards and Technology Technical Note 1976 Natl. Inst. Stand. Technol. Tech. Note 1976, 118 pages (October 2017) CODEN: NTNOEF

This publication is available free of charge from: https:// doi.org/10.6028/NIST.TN.1976 


\begin{abstract}
Building stakeholders need practical metrics, data, and tools to support decisions related to sustainable building designs, technologies, standards, and codes. The Engineering Laboratory of the National Institute of Standards and Technology (NIST) has addressed this high priority national need by extending its metrics and tools for sustainable building products, known as Building for Environmental and Economic Sustainability (BEES), to whole-buildings through its Building Industry Reporting and Design for Sustainability (BIRDS) framework. The BIRDS framework is a sustainability measurement system consisting of whole-building sustainability metrics that are based on innovative extensions to life-cycle assessment (LCA) and life-cycle costing (LCC) approaches involving whole-building energy simulations. The measurement system evaluates the sustainability of both the materials and the energy used by a building over time. It assesses the "carbon footprint" of buildings as well as 11 other environmental performance metrics, and integrates economic performance metrics to yield science-based measures of the business case for investment choices in high-performance green buildings.

The BIRDS framework has been leveraged to assist building architects and designers to evaluate the sustainability performance of custom building designs through the development of BIRDS NEST ("Neutral Environment Software Tool”), an application programming interface (API) that allows other software tools to submit building characteristics and performance information (in a standardized format) to develop sustainability performance metrics for a customized building design.

The beta version of BIRDS NEST is focused on performing a life-cycle environmental impact assessment (LCIA) based on 12 impact categories for single-family residential buildings. The BIRDS NEST has been designed to interact with NREL's OpenStudio (OS), an open-source, cross-platform collection of software tools that supports whole building energy modeling using EnergyPlus. In collaboration with NREL’s OS Team, an OS “Measure” has been developed to successfully send and receive information to and from BIRDS NEST, allowing OS users to develop LCIA estimates for OS building models without leaving the OS application.

This technical manual describes BIRDS and its LCA and LCIA methodology and data, development of BIRDS NEST and the associated OS Measure, and BIRDS NEST's limitations, planned release, and the development of its future capabilities.
\end{abstract}

\title{
Keywords
}

life-cycle assessment; life-cycle impact assessment; energy efficiency; residential buildings; lowenergy buildings; net-zero energy performance; sustainability; software 


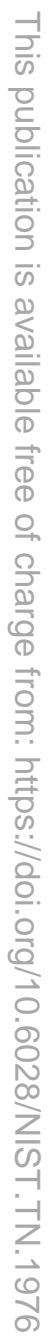




\section{Preface}

This documentation was developed by the Applied Economics Office (AEO) in the Engineering Laboratory (EL) at the National Institute of Standards and Technology (NIST). The document explains how the underlying data and software has been developed to create the Building Industry Reporting and Design for Sustainability (BIRDS) Neutral Environment Software Tool (NEST) and the associated OpenStudio (OS) Measure. The intended audience are researchers, architects, building designers, and decision makers in the residential building sector, and others interested in building sustainability.

\section{Disclaimers}

The policy of the National Institute of Standards and Technology is to use metric units in all its published materials. Because this report is intended for the U.S. construction industry which uses U.S. customary units, it is more practical and less confusing to include U.S. customary units as well as metric units. Measurement values in this report are therefore stated in metric units first, followed by the corresponding values in U.S. customary units within parentheses. 


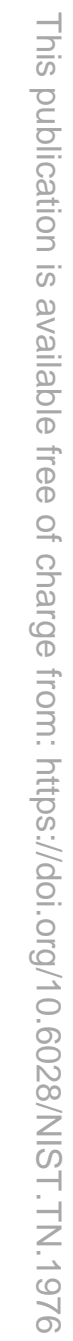




\section{Acknowledgements}

The authors wish to thank all those who contributed ideas and suggestions for this report. They include Mr. David Webb and Dr. David Butry of EL’s Applied Economics Office, Brian Polidoro of EL's Energy and Environment Division, and Dr. Nicos S. Martys of EL's Materials and Structural Systems Division. A special thanks to the Industrial Ecology Research Services team of Shivira Tomar, Christine Chen, and Matthew Leighton for their superb technical support in developing whole-building environmental life-cycle assessments for BIRDS. Thanks goes to our industry contacts that were instrumental in advising on the assumptions used to develop the product-level life-cycle impact assessments. Special thanks to our collaborators at NREL that developed the OpenStudio Measure (Andrew Parker, Nicholas Long, and Katherine Fleming) and EL Data, Software, and Technology (ELDST) that developed the interoperability component of the API and web server for BIRDS NEST (Tzong Hao Chen). Finally, the Beta testers of BIRDS NEST deserve special thanks for contributing suggestions leading to substantial improvements in the tool. 


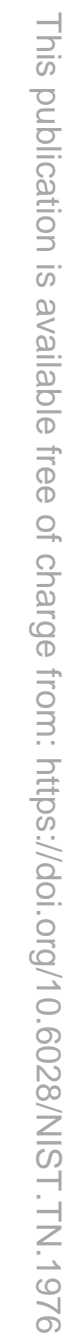




\section{Author Information}

Joshua Kneifel

Economist

National Institute of Standards and Technology

Engineering Laboratory

100 Bureau Drive, Mailstop 8603

Gaithersburg, MD 208998603

Tel.: 301-975-6857

Email: joshua.kneifel@nist.gov

Eric O’Rear

Economist

National Institute of Standards and Technology

Engineering Laboratory

100 Bureau Drive, Mailstop 8603

Gaithersburg, MD 208998603

Tel.: 301-975-4570

Email: eric.orear@nist.gov

Shannon Grubb

Engineering Trainee

National Institute of Standards and Technology

Engineering Laboratory

100 Bureau Drive, Mailstop 8603

Gaithersburg, MD 208998603

Tel.: 301-975-6857

Email: shannon.grubb@nist.gov

Priya Lavappa

Computer Specialist

National Institute of Standards and Technology

Engineering Laboratory

100 Bureau Drive, Mailstop 8603

Gaithersburg, MD 208998603

Tel.: 301-975-4522

Email: priya.lavappa@nist.gov 
Anne Landfield Greig

Principal

Four Elements Consulting, LLC

Seattle, WA

Tel: 206-935-4600

Email: anne@fourelementsllc.com 


\section{Contents}

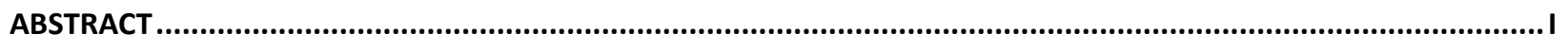

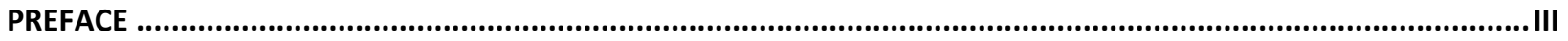

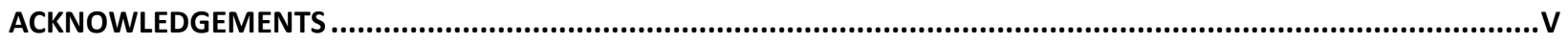

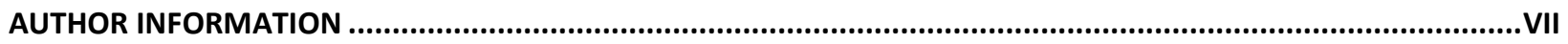

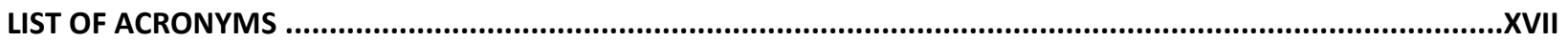

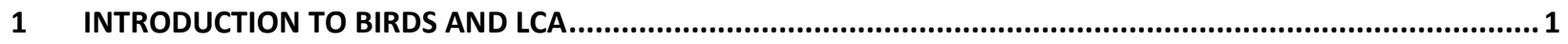

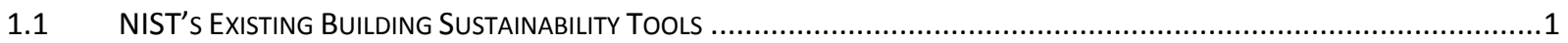

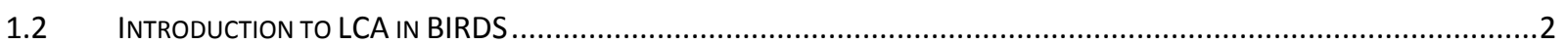

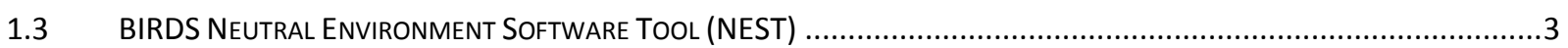

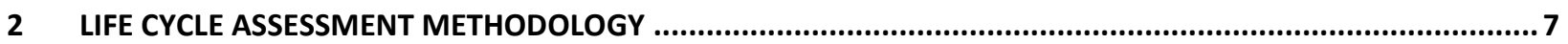

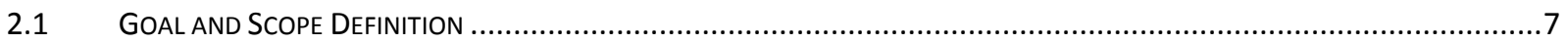

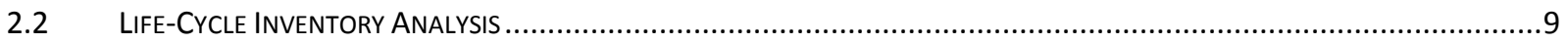

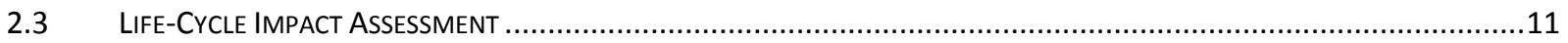

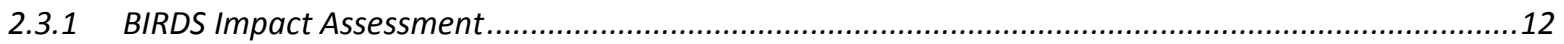

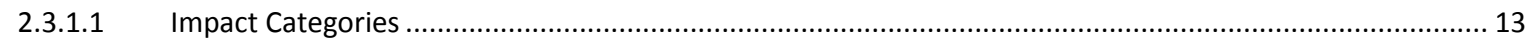

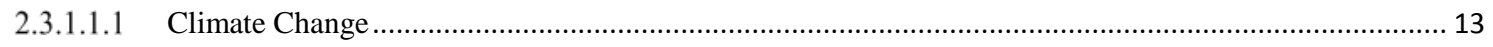

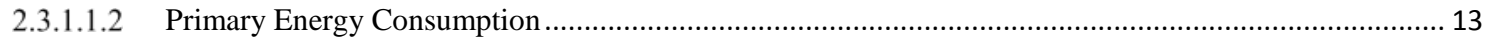

2.3.1.1.3 Human Health - Criteria Air Pollutants ……………..................................................................... 13

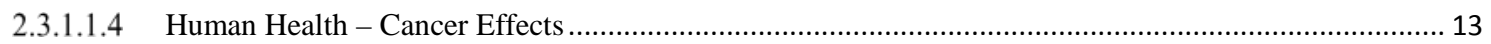

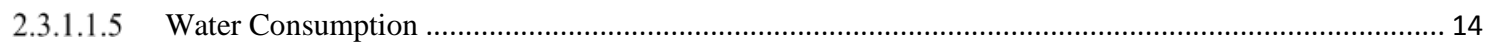

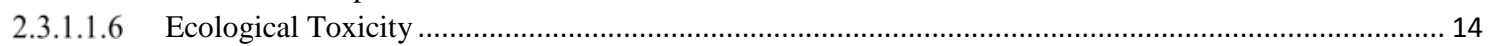

2.3.1.1.7 Eutrophication Potential.............................................................................................................. 14

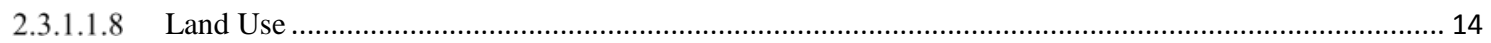

2.3.1.1.9 Human Health - Non-cancer Effects............................................................................................ 14

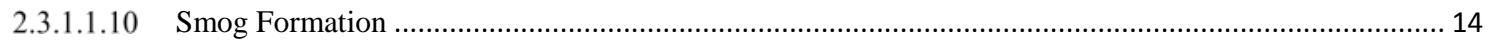

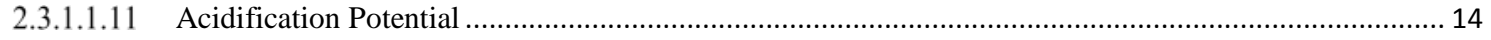

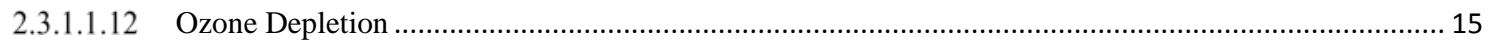

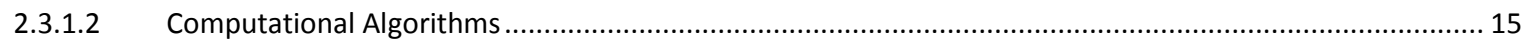

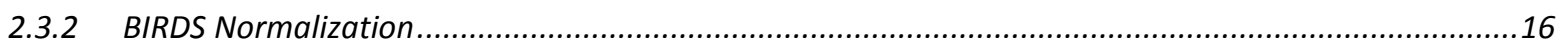

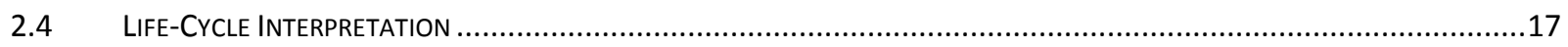

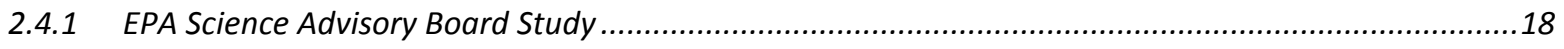

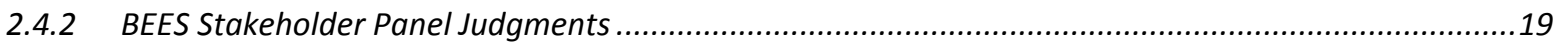

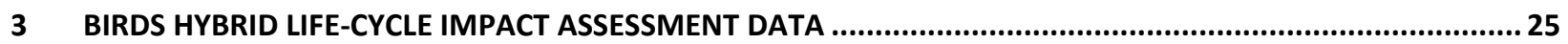

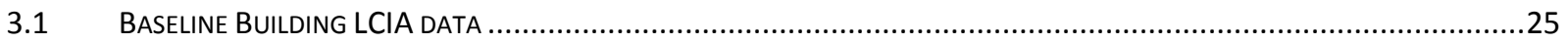

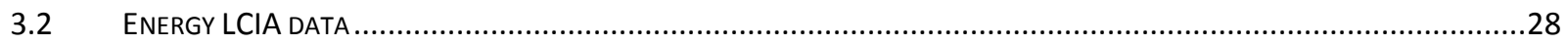

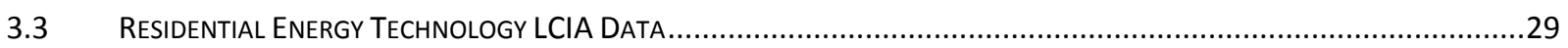

3.3.1 General Information Regarding the Energy Technology LCIs......................................................29

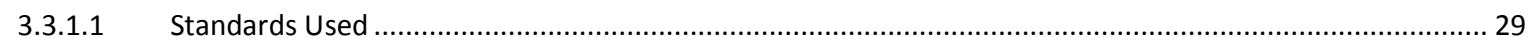

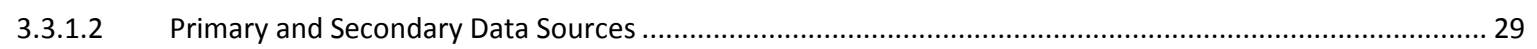

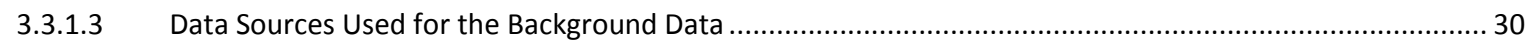

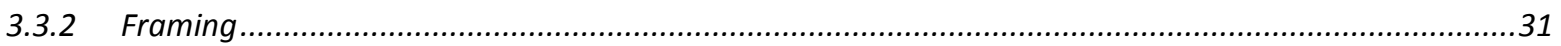

3.3.2.1 Upstream Materials Production through Manufacturing …............................................................... 32

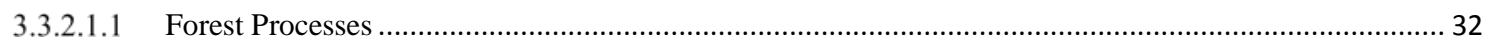

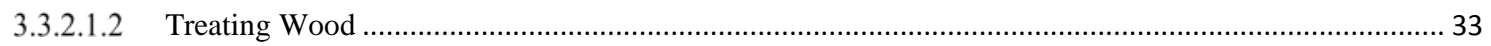




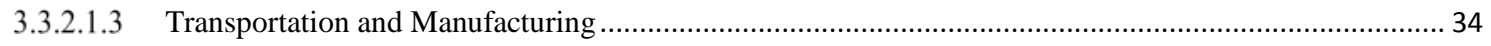

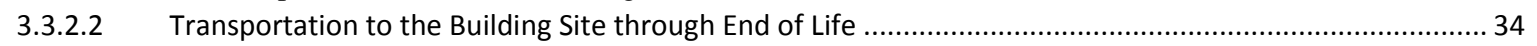

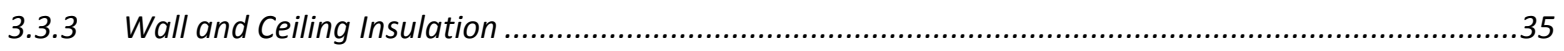

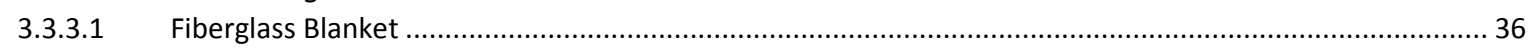

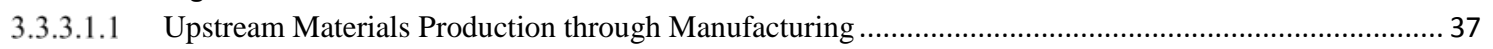

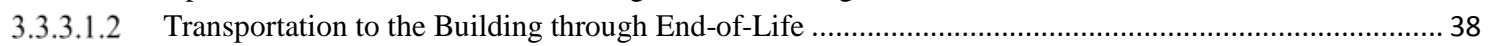

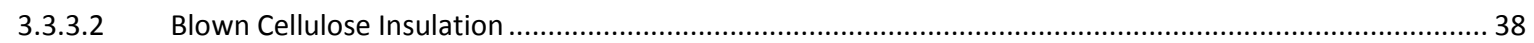

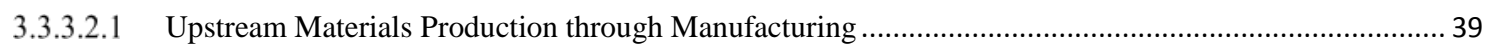

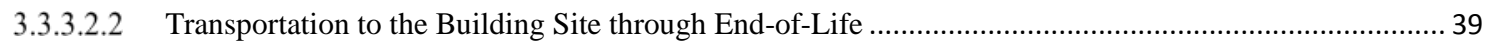

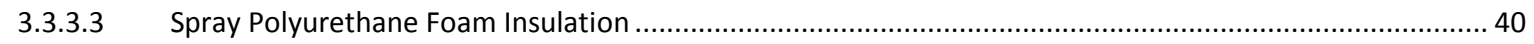

3.3.3.3.1 Upstream Materials Production through Manufacturing .......................................................................... 41

3.3.3.3.2 Transportation to the Building Site through End-of-Life ............................................................... 43

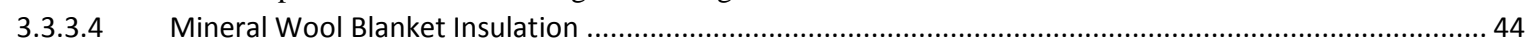

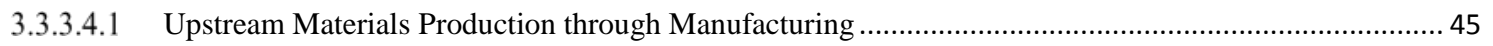

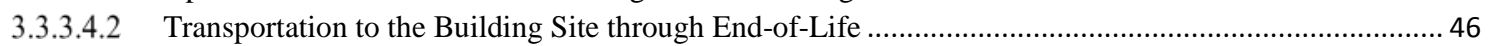

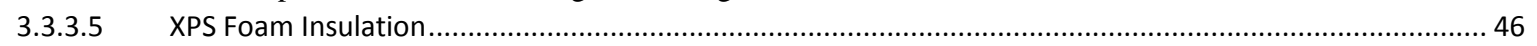

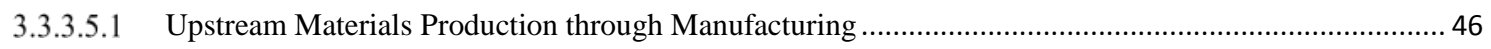

3.3.3.5.2 Transportation to the Building Site through End-of-Life ............................................................. 48

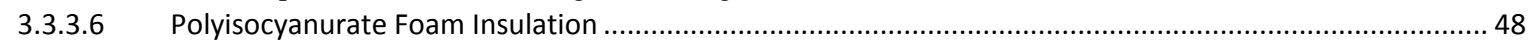

3.3.3.6.1 Upstream Materials Production through Manufacturing …............................................................. 49

3.3.3.6.2 Transportation to the Building Site through End-of-Life ................................................................ 51

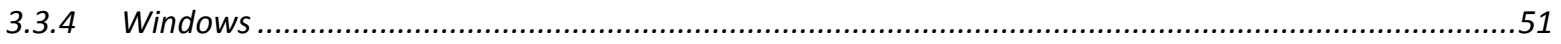

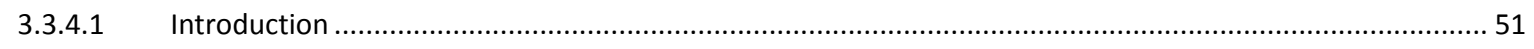

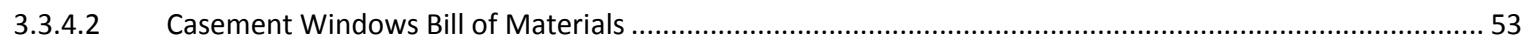

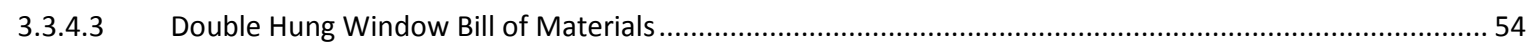

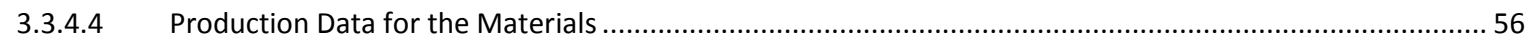

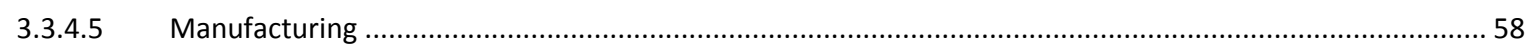

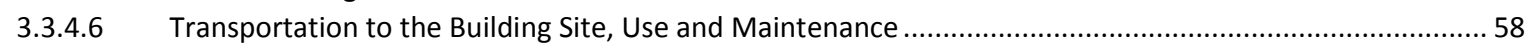

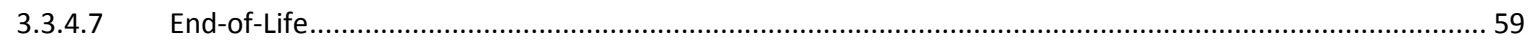

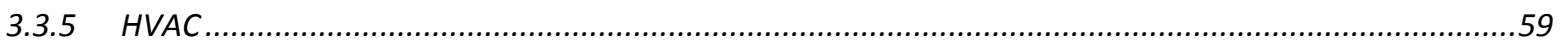

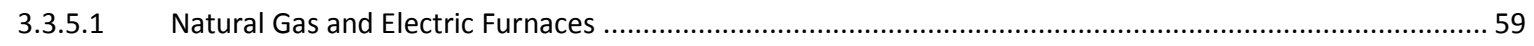

3.3.5.1.1 Upstream Materials Production through Manufacturing ..................................................................59

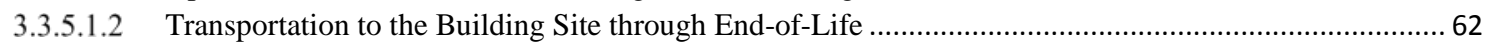

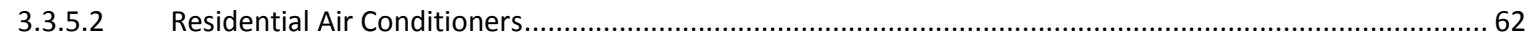

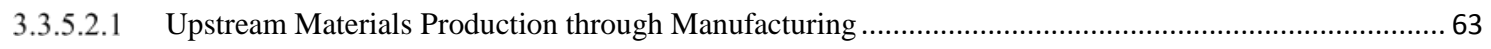

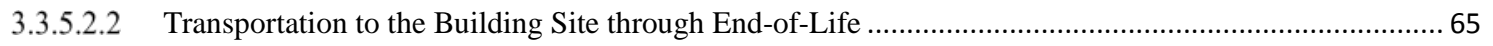

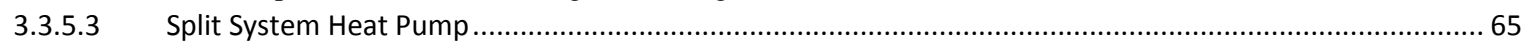

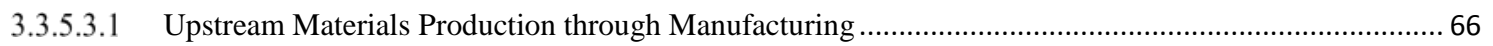

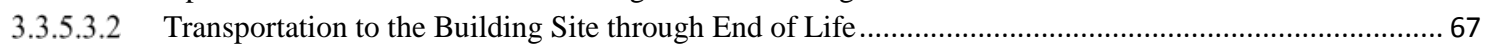

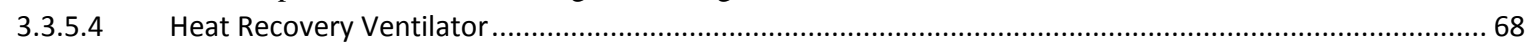

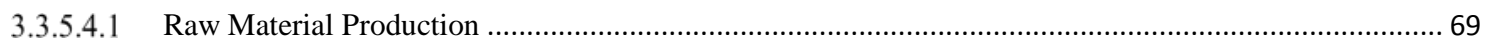

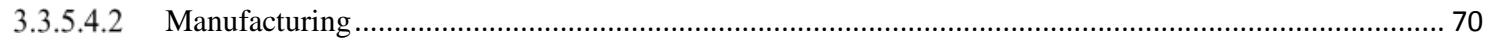

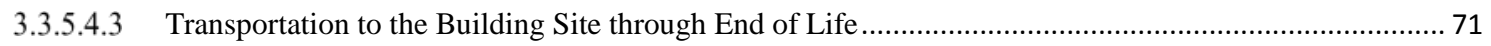

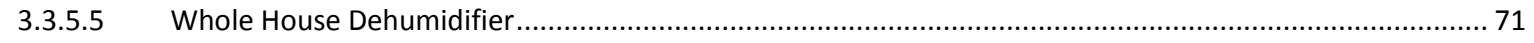

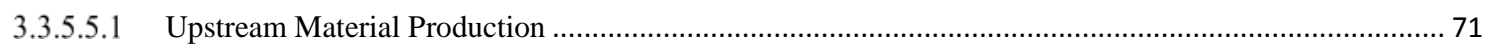

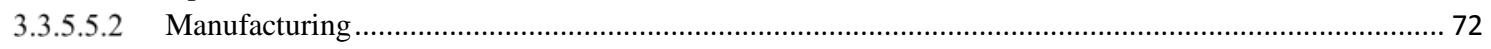

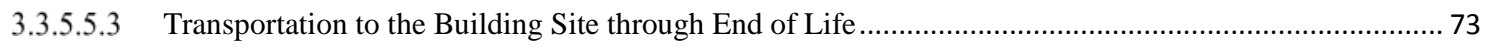

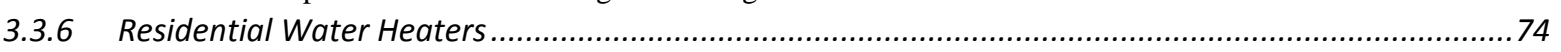

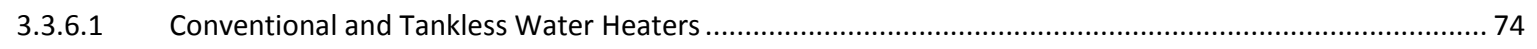

3.3.6.1.1 Upstream Materials Production through Manufacturing ................................................................. 74

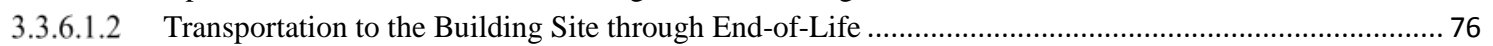

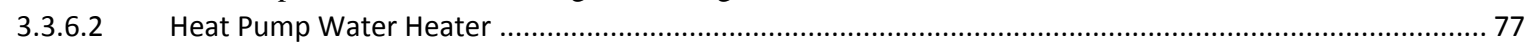

3.3.6.2.1 Upstream Materials Production through Manufacturing ................................................................. 77

3.3.6.2.2 Transportation to the Building Site through End-of-Life ............................................................ 80 


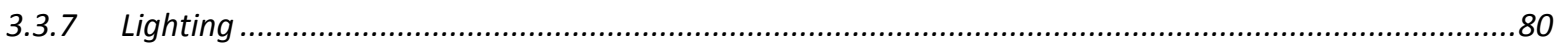

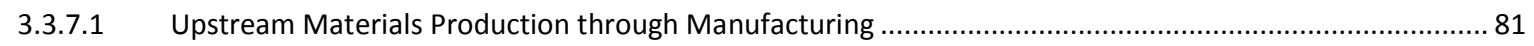

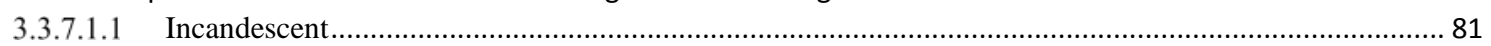

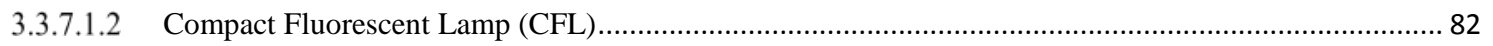

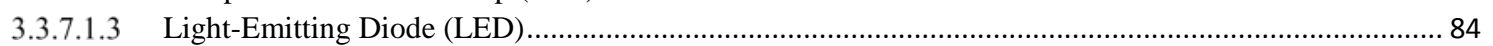

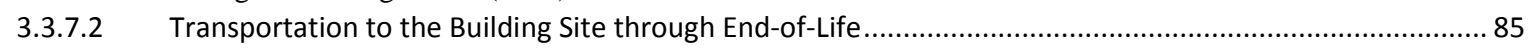

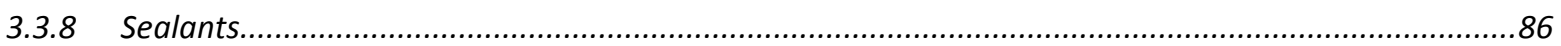

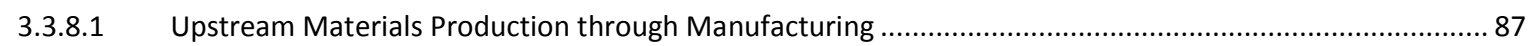

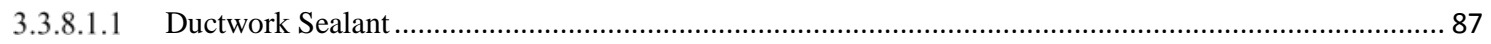

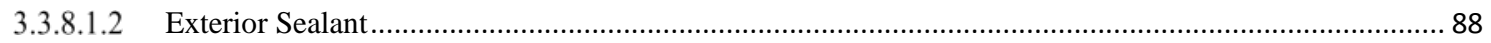

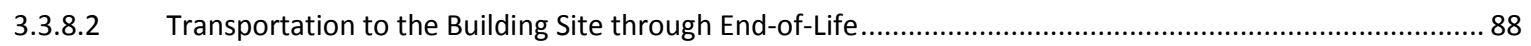

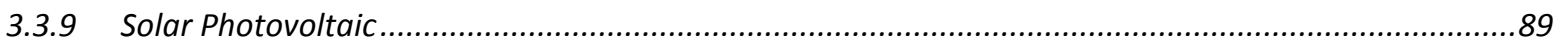

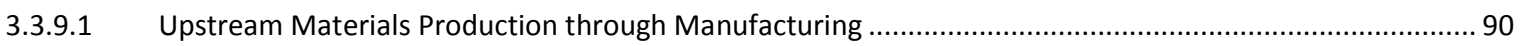

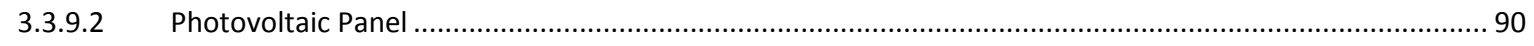

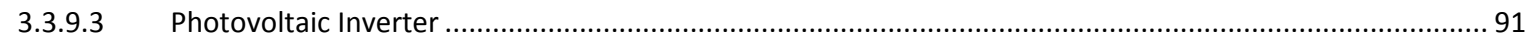

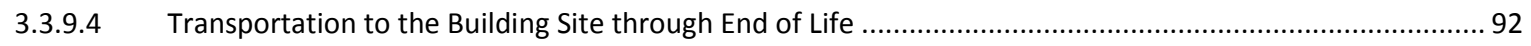

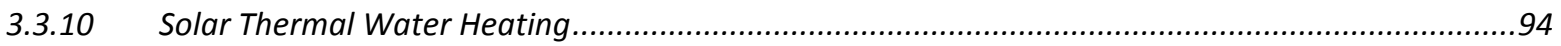

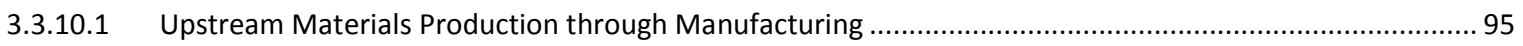

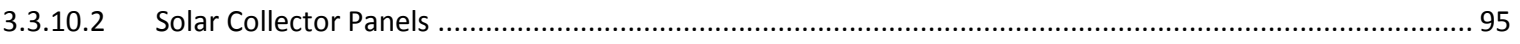

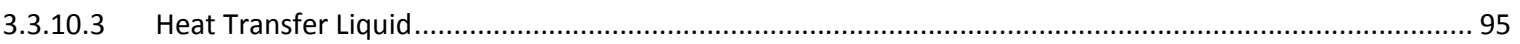

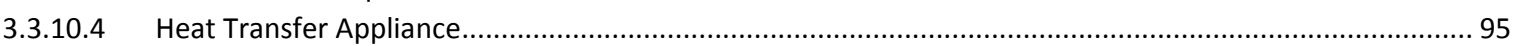

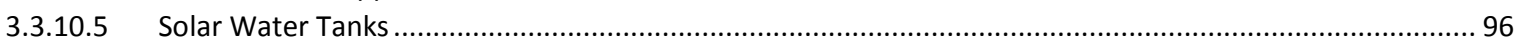

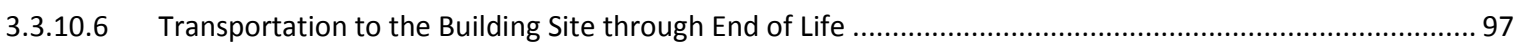

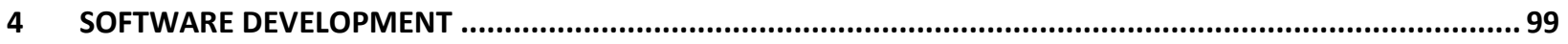

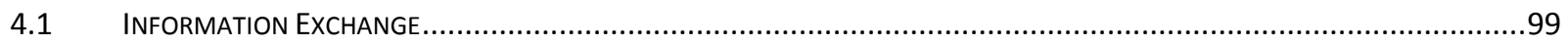

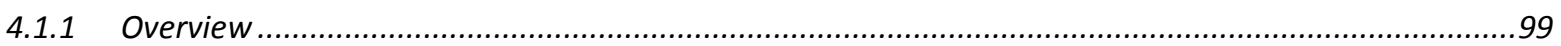

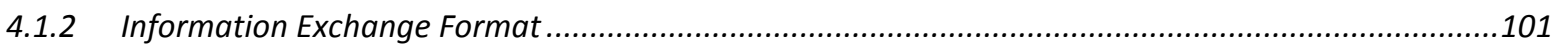

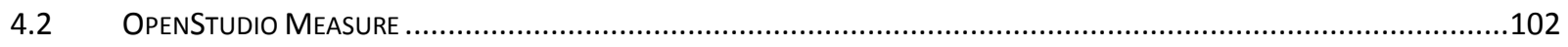

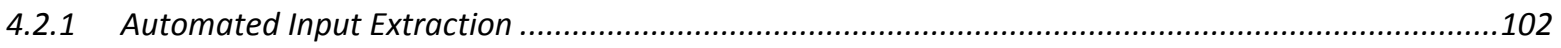

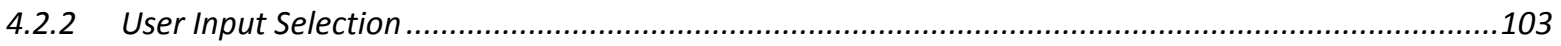

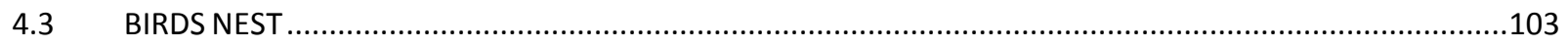

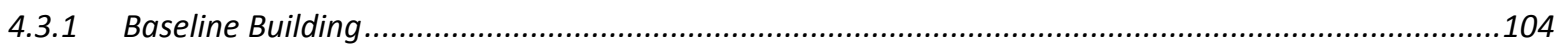

4.3.2 Building Envelope Component Options............................................................................ 104

4.3.3 Building System Component Options........................................................................................ 107

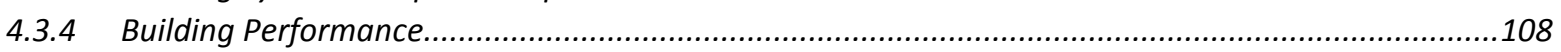

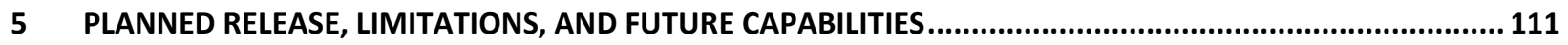

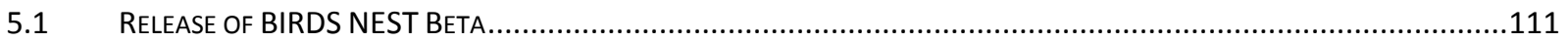

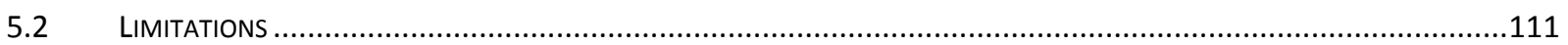

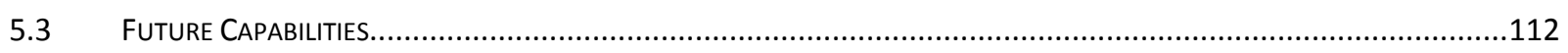

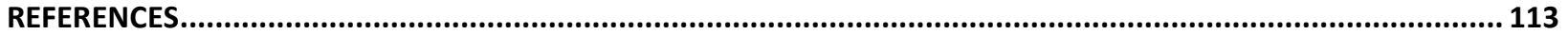




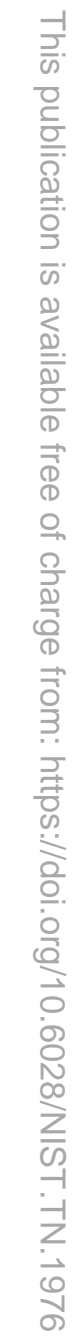




\section{List of Figures}

FIGURE 2-1 COMPILING LCA INVENTORIES OF ENVIRONMENTAL INPUTS AND OUTPUTS ..........................................9

FIGURE 2-2 ILLUSTRATION OF SUPPLY CHAIN CONTRIBUTIONS TO U.S. CONSTRUCTION INDUSTRY ..........................11

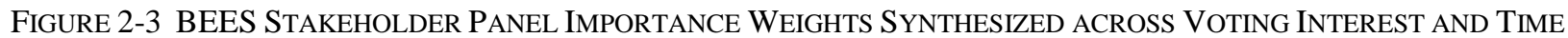

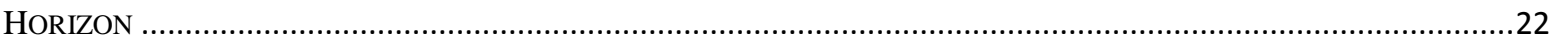

Figure 2-4 BEES STAKeHolder PANEL IMPORTANCE WeightS By STAKEHOLDER Voting INTEREST ....................22

FiguRE 2-5 BEES STAKEHOLDER PANEL IMPORTANCE WEIGHTS BY TIME HORIZON ...............................................23

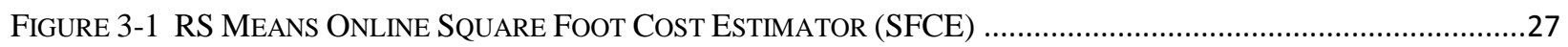

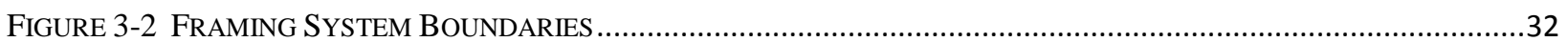

FigURE 3-3 INSULATION SYSTEM BOUNDARIES - FIBERGLASS BLANKET EXAMPLE …...........................................36

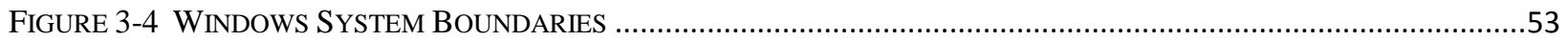

FIGURE 3-5 HVAC SYSTEM BOUNDARIES - ELECTRIC FURNACE EXAMPLE ……............................................59

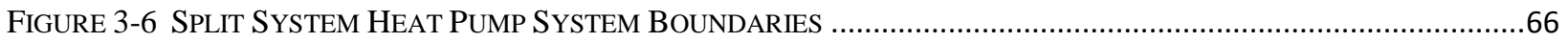

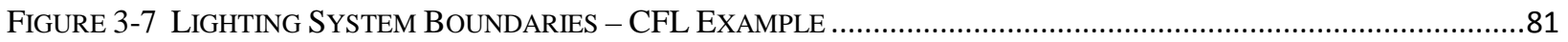

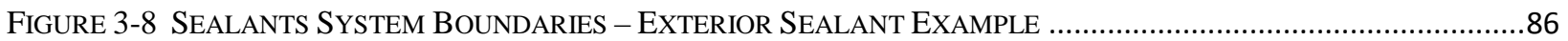

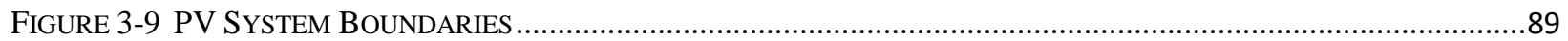

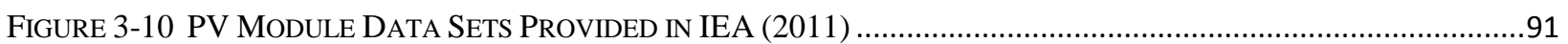

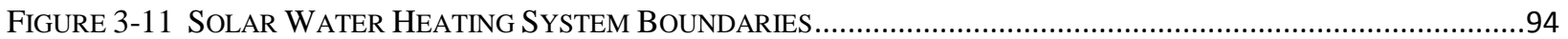

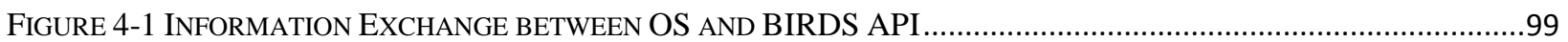

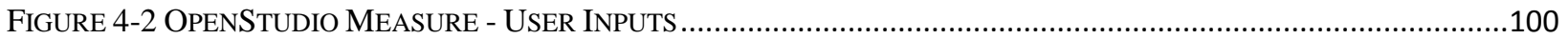

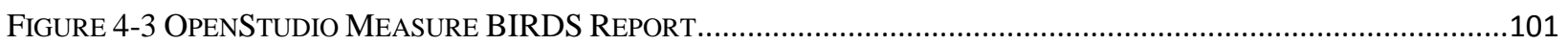




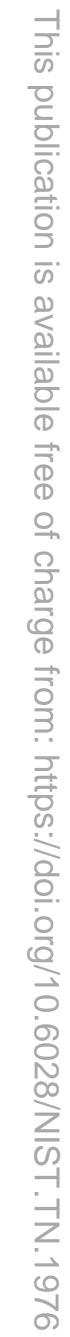

xiv 


\section{List of Tables}

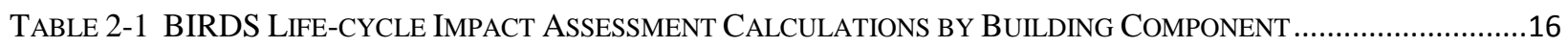

TABLE 2-2 BIRDS NORMALIZATION REFERENCES..........................................................................................17

TABLE 2-3 PAIRWISE COMPARISON VALUES FOR DERIVING IMPACT CATEGORY IMPORTANCE WEIGHTS ...................19

TABLE 2-4 RELATIVE IMPORTANCE WEIGHTS BASED ON SCIENCE ADVISORY BOARD STUDY ..................................19

TABLE 2-5 RELATIVE IMPORTANCE WEIGHTS BASED ON BEES STAKEHOLDER PANEL JUDGMENTS ...........................21

TABLE 3-1 CONSTRUCTION INDUSTRY OUTPUTS MAPPED TO BIRDS BUILDING TYPES .............................................26

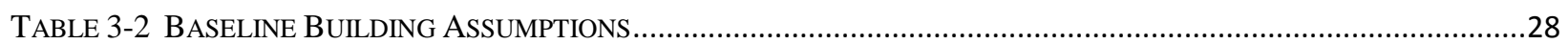

TABLE 3-3 Fuel CONSUMPTION FOR Forest ResourCE MANAgEMENT ProCESSES ..................................................33

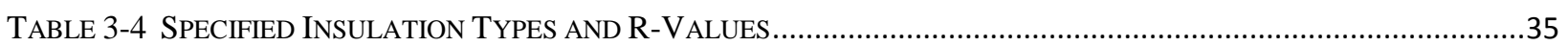

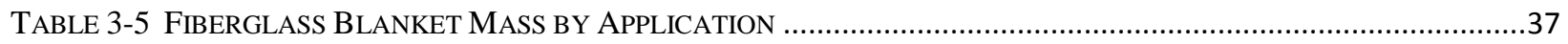

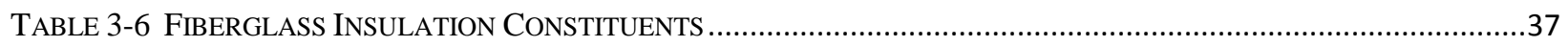

TABLE 3-7 ENERGY REQUIREMENTS FOR FIBERGLASS INSULATION MANUFACTURING ….......................................38

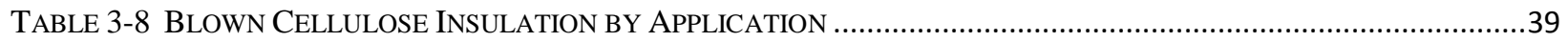

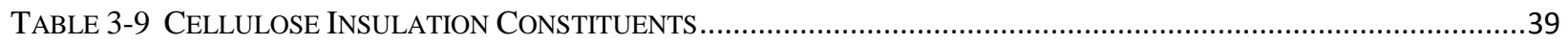

TABLE 3-10 B-Side FoRMULATION - MATERIAL CONSTITUENT PERCENTAGES ……..............................................41

TABLE 3-11 SPF INSULATION REFERENCE UNIT PARAMETERS FOR ORIGINAL AND BIRDS LCAS.............................42

TABLE 3-12 MATERIAL CONSTITUENTS FOR OPEN-CELL AND CLOSED-CELL SPF INSULATION .................................42

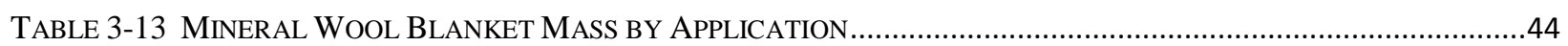

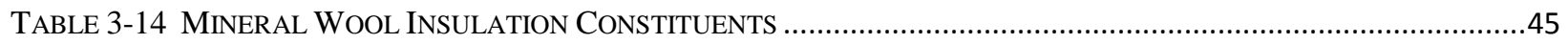

TABLE 3-15 ENERGY REQUIREMENTS FOR MinERAL WOOL INSULATION MANUFACTURING .....................................45

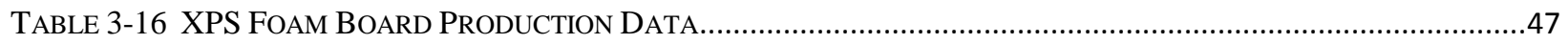

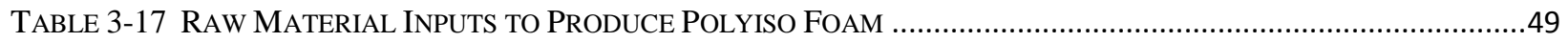

TABLE 3-18 ENERGY INPUTS AND PROCESS OUTPUTS FOR 1 BOARD-FOOT POLYISO FOAM ……..............................50

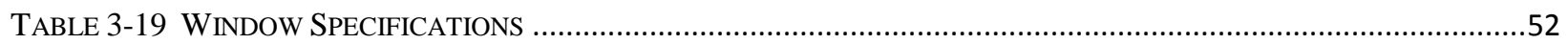

TABLE 3-20 DimENSIONS AND MAIN PARTS OF THE WOOD CLAD CASEMENT WindOW..........................................54

TABLE 3-21 DimENSIONS AND MAIN PARTS OF THE ALUMINUM CASEMENT WindOW …...........................................54

TABLE 3-22 DimENSIONS AND MAIN PARTS OF THE VINYL CASEMENT WindOW.......................................................54

TABLE 3-23 Dimensions ANd Main PaRTS Of THE WoOd Clad Double Hung Window …….............................55

TABLE 3-24 Dimensions AND Main PaRTS Of THE Aluminum Double Hung Window ………...........................55

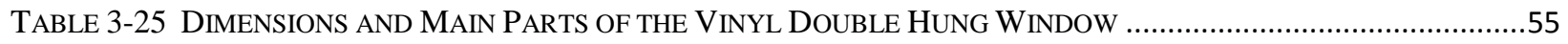

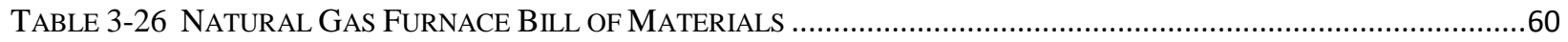

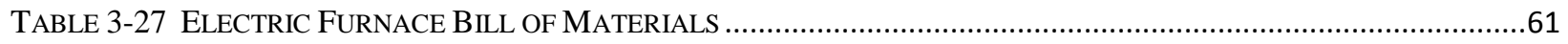

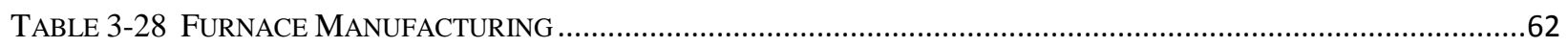

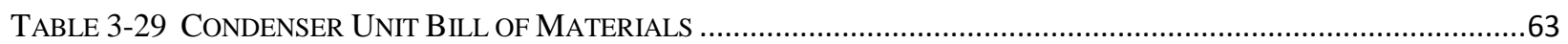

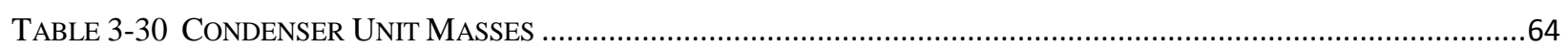

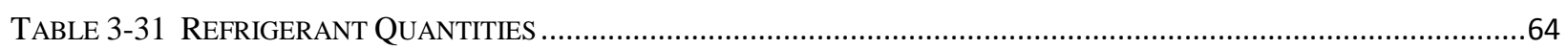

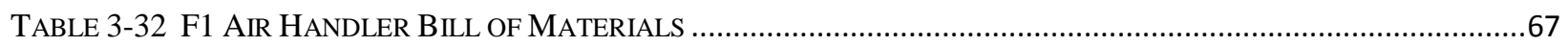

TABLE 3-33 VENMAR EKO 1.5 BILL OF MATERIALS...................................................................................69

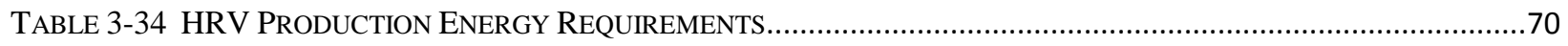

TABle 3-35 Ultra-Aire 70H Whole-House Ventilating Dehumidifier BiLl OF Materials .............................72

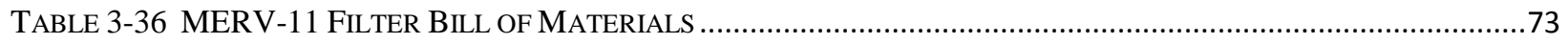

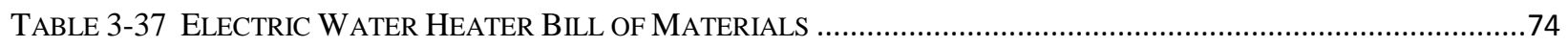

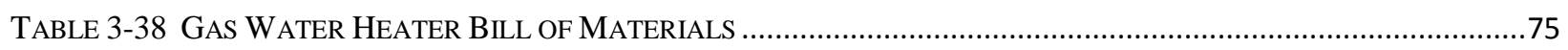

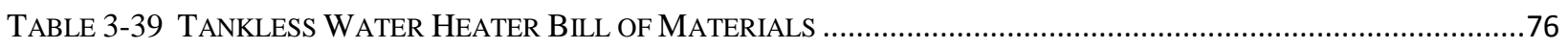

TABLE 3-40 Heat Pump Water Heater Weight Estimation .............................................................................78

TABLE 3-41 RheEM Hot WATER TANK PoRTION BILl OF MATERIALS …….......................................................78

TABLE 3-42 RheEM Heat Pump Portion Bill Of Materials ...............................................................................79 


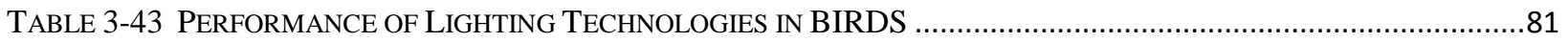

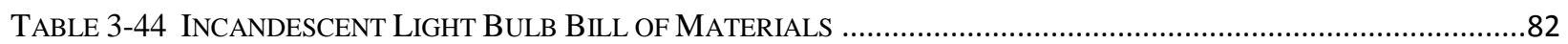

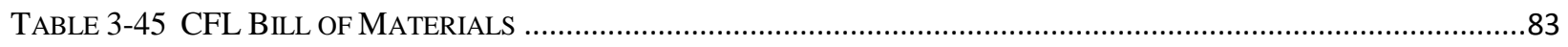

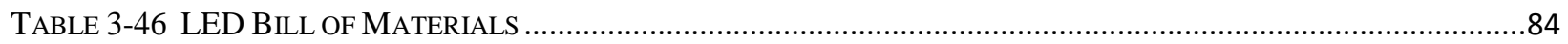

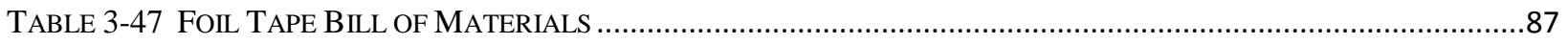

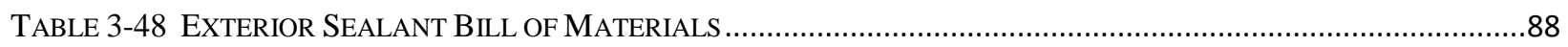

TABLE 3-49 SUNPOWER 5000M LUT PV INVERTER BILL OF MATERIALS …….................................................92

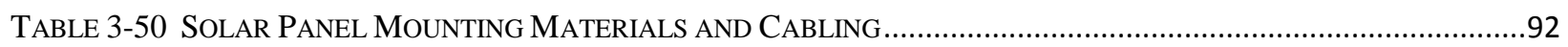

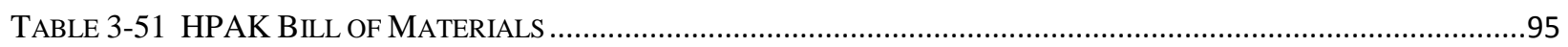

TABLE 3-52 HELIOdyne SOlaR WATER StORAGE TANKS BILL OF MATERIALS ……...........................................96

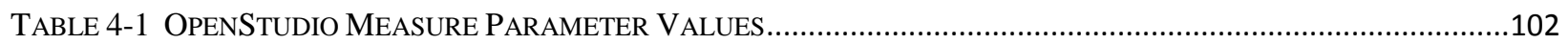

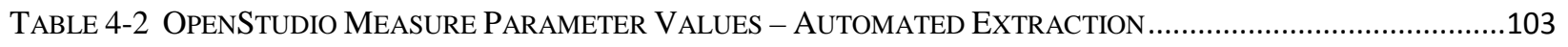

TABLE 4-3 OpenStUdio MEASURE PARAMETER VALUES - USER-SPECIFIED ........................................................103

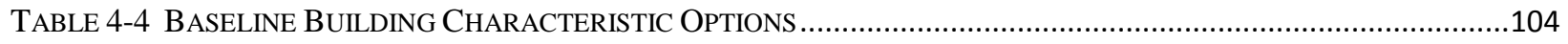

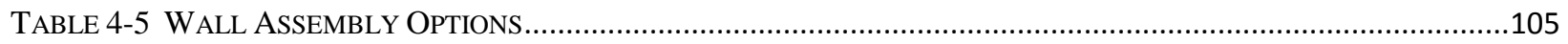

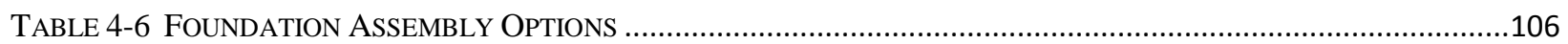

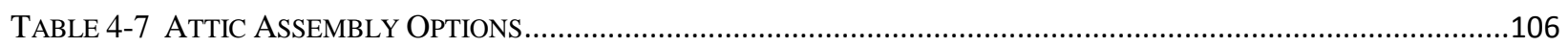

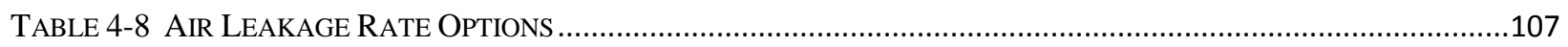

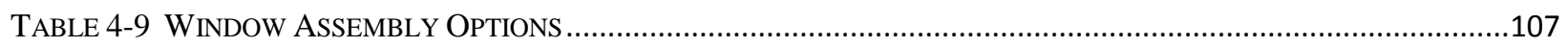

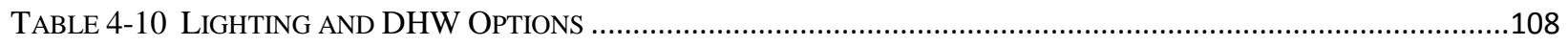

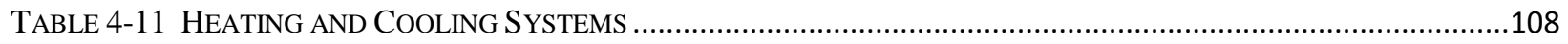




\section{List of Acronyms}

\section{Acronym Definition}

ABS acrylontrile-butadiene-styrene

$\mathrm{ACH} \quad$ air changes per hour

ACQ alkaline copper quaternary

AEO Applied Economics Office

AHP Analytical Hierarchy Process

AHRI Air Conditioning, Heating, and Refrigeration Institute

AHRTI Air-Conditioning, Heating, and Refrigeration Technology Institute

API application programming interface

BEA Bureau of Economic Analysis

BEES Building for Environmental and Economic Sustainability

BIM Building Information Model

BIRDS Building Industry Reporting and Design for Sustainability

C\&D construction and demolition

CAD computer-aided design

CFC-11 trichlorofluoromethane

CFL compact fluorescent lamp

CFM cubic feet per minute

$\mathrm{CO} 2 \quad$ carbon dioxide

CO2e carbon dioxide equivalent

CORRIM Consortium for Research on Renewable Industrial Materials

DHW domestic hot water

E+ EnergyPlus

EERE Office of Energy Efficiency \& Renewable Energy

eGDP environmental gross domestic product

EL Engineering Laboratory

ELDST Engineering Laboratory Data, Security, and Technology

EPA Environmental Protection Agency

EPD environmental product declaration

EPDM ethylene propylene diene monomer

EPS expanded polystyrene

FCRC Finished Cold Rolled Coil

GDP gross domestic product

HBCD hexabromocyclododecane

HCFC hydrochlorofluorocarbon

HDG hot-dip galvanized

HDPE high density polyethylene

HFC hydrochlorofluorocarbon

HRV heat recovery ventilator 


\begin{tabular}{|c|c|}
\hline Acronym & Definition \\
\hline HSPF & heating seasonal performance factor \\
\hline HVAC & heating, ventilation, and air-conditioning \\
\hline $\mathrm{I}-\mathrm{O}$ & input-output \\
\hline IAQ & indoor air quality \\
\hline IECC & International Energy Conservation Code \\
\hline IGU & insulated glass unit \\
\hline ISO & International Organization for Standardization \\
\hline LCA & life-cycle assessment \\
\hline LCC & life-cycle cost \\
\hline LCI & life-cycle inventory \\
\hline LCIA & life-cycle impact assessment \\
\hline LDPE & low-density polyethylene \\
\hline LED & light-emitting diode \\
\hline Low-E & low-emissivity \\
\hline M\&R & maintenance and repair \\
\hline MERV & Minimum Efficiency Reporting Value \\
\hline MDI & methylene diphenyl diisocyanate \\
\hline MSDS & material safety data sheet \\
\hline NERC & North American Electric Reliability Corporation \\
\hline NEST & Neutral Environment Sustainability Tool \\
\hline NIST & National Institute of Standards and Technology \\
\hline $\mathrm{NO}_{\mathrm{X}}$ & nitrous oxides \\
\hline NREL & National Renewable Energy Laboratory \\
\hline NZERTF & Net-Zero Energy Residential Test Facility \\
\hline $\mathrm{OC}$ & on center \\
\hline OS & OpenStudio \\
\hline PBDE & polybrominated diphenyl ethers \\
\hline PCR & product category rules \\
\hline PIB & polyisobutylene \\
\hline PIMA & Polyisocyanurate Insulation Manufacturers Association \\
\hline PM10 & particulate matter less than 10 micrometers in diameter \\
\hline pMDI & polymeric methylene diphenyl diisocyanate \\
\hline PMMA & polymethyl methacrylate \\
\hline PNNL & Pacific Northwest National Laboratory \\
\hline PNW & Pacific Northwest \\
\hline PP & propylene \\
\hline PUR & polyurethane \\
\hline PV & photovoltaic \\
\hline PVC & polyvinyl chloride \\
\hline SAB & Science Advisory Board \\
\hline
\end{tabular}




\section{Acronym Definition}

SE Southeastern U.S.

SEER seasonal energy efficiency ratio

SEIA Solar Energy Industries Association

SFCE Square Foot Cost Estimator

SHGC solar heat gain coefficient

SPF spray polyurethane foam

SPFA Spray Poluurethane Foam Association

TCPP Tris (2-chloroisopropyl) phosphate

TRACI Tool for the Reduction and Assessment of Chemical and other environmental Impacts

VOC volatile organic compound

WEEE waste electrical and electronic equipment

XPS extruded polystyrene

XPSA extruded polystyrene foam association 


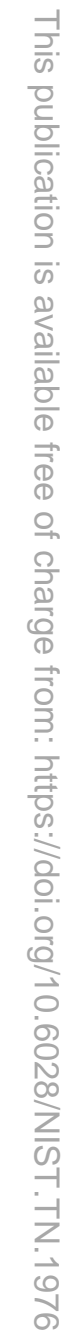




\section{Introduction to BIRDS and LCA}

\subsection{NIST's Existing Building Sustainability Tools}

Building stakeholders need practical metrics, data, and tools to support decisions related to sustainable building designs, technologies, standards, and codes. The Engineering Laboratory (EL) of the National Institute of Standards and Technology (NIST) has addressed this high priority national need by extending its metrics and tools for sustainable building products, known as Building for Environmental and Economic Sustainability (BEES), to whole-buildings. Whole-building sustainability metrics have been developed based on innovative extensions to environmental life-cycle assessment (LCA) and life-cycle costing (LCC) approaches involving whole-building energy simulations. The measurement system evaluates the sustainability of both the materials and energy used by a building over time. It assesses the "carbon footprint" of buildings as well as 11 other environmental performance metrics, and integrates economic performance metrics to yield science-based measures of the business case for investment choices in high-performance green buildings.

The approach previously developed for BEES has now been applied at the wholebuilding level to address building sustainability measurement in a holistic, integrated manner that considers complex interactions among building materials, energy technologies, and systems across dimensions of performance, scale, and time (NIST 2010). Building Industry Reporting and Design for Sustainability (BIRDS) applies the sustainability measurement system to an extensive whole-building performance database NIST has compiled for this purpose. The energy, environment, and cost data in BIRDS provide measures of building operating energy use based on detailed energy simulations, building materials use through innovative life-cycle material inventories, and building costs over time for constructing, operating, and maintaining, repairing, and replacing building components.

The most recent release of BIRDS (v3.1) includes 3 sustainability databases (NIST 2017). One that includes energy, environmental, and cost measurements for 12540 commercial and non-low rise residential buildings, covering 11 building prototypes in 228 cities across all U.S. states for 9 study period lengths. See Lippiatt et al. (2013) for additional details.

The second sustainability database includes residential data that incorporates the energy, environmental, and cost measurements for 9120 residential buildings, covering 10 single family dwellings ( 5 one-story and 5 two-story of various conditioned floor area) in 228 cities for study period lengths ranging from 1 year to 40-years. See Kneifel et al (2015) for additional details.

Instead of considering locations across the country with minimal building design options, the third database allows for detailed incremental energy efficiency measure analysis for a single location, 480000 variations in residential building designs based on the NIST 
Net-Zero Energy Residential Test Facility (NZERTF) specifications and varying requirements across International Energy Conservation Code (IECC) editions (ICC 2006, 2009, 2012, 2015). Again, study period lengths from 1 year to 40 years are included in the Low-Energy Residential Database. The sustainability performance of buildings designed to meet current energy codes can be compared to several alternative building designs to determine the impacts of improving building energy efficiency as well as varying the investor time horizon and other assumptions affecting overall sustainability performance. Along with the energy, environmental, and economic measurements, this database includes indoor environmental quality metrics based on occupant thermal comfort and indoor air quality (IAQ). See Kneifel et al (2017) for additional details.

BIRDS v4.0 is currently under development and will include several key additions and improvements. First, the standard/code-based commercial database is being redeveloped using the Pacific Northwest National Laboratory (PNNL) Commercial Prototype Building Models. Second, the standard/code-based residential database is being updated using new construction cost data. Third, natural gas-fired space and water heating equipment options are being added to the Low-Energy Residential Database. Fourth, the web interfaces for all three databases are being updated to incorporate the new data and features under a consistent interface layout and aesthetics.

\subsection{Introduction to LCA in BIRDS}

LCA is a "cradle-to-grave" systems approach for measuring environmental performance. The approach is based on two principles. First, the belief that all stages in the life of a product generate environmental impacts and must be analyzed, including raw materials acquisition, product manufacture, transportation, installation, operation and maintenance, and ultimately recycling and waste management. An analysis that excludes any of these stages is limited because it ignores the full range of upstream and downstream impacts of stage-specific processes. LCA broadens the environmental discussion by accounting for shifts of environmental problems from one life-cycle stage to another. The second principle is that multiple environmental impacts must be considered over these life-cycle stages to implement a trade-off analysis that achieves a genuine reduction in overall environmental impact, rather than a simple shift of impact. By considering a range of environmental impacts, LCA accounts for impact-shifting from one environmental medium (land, air, water) to another.

The LCA method is typically applied to products, or simple product assemblies, in a "bottom up" manner. The environmental inputs and outputs to all the production processes throughout a product's life-cycle are compiled. These product life-cycle "inventories" quantify hundreds, even thousands, of environmental inputs and outputs. This is a data-intensive, time-consuming, and expensive process that must be repeated for every product.

The bottom-up approach becomes unwieldy and cost prohibitive for complex systems, such as buildings, that involve potentially hundreds of products. Furthermore, a 
building's sustainability is not limited to the collective sustainability of its products. The way designers integrate these products and systems at the whole-building level has a large influence on another major dimension of its sustainability performance, operating energy use.

The BIRDS model applies a unifying LCA framework developed for the U.S. economy to the U.S. construction sector and its constituent building types. The U.S. Bureau of Economic Analysis (BEA) creates what are called Input-Output Accounts, or "I-O tables," for the U.S. economy that tracks economic value flowing across sectors in the economy. Academics have developed "environmentally-extended" I-O tables (Suh 2005, Hendrickson, Lave et al. 2006, Suh 2010) that associate environmental flows with these transactions to estimate flows across industries. Through this "top-down" LCA approach, a series of baseline sustainability measurements are made for prototypical buildings, yielding a common yardstick for measuring sustainability with roots in well-established national environmental and economic statistics.

Using detailed "bottom-up" data compiled through traditional LCA approaches, the baseline measurements for prototypical buildings are then "hybridized" to reflect a range of improvements in building energy efficiency, enabling assessment of their energy, environmental, and economic benefits and costs. The idea is to provide a cohesive database and measurement system based on sound science that can be used to prioritize green building issues and to track progress over time as design and policy solutions are implemented. "Bottom-up" and "top-down" data sources and approaches will be discussed in further detail in Chapter 4.

The BIRDS hybrid LCA approach combines the advantages of both the bottom-up and top-down approaches - namely the use of higher-resolution, bottom-up data and the use of regularly-updated, top-down statistical data without truncation (Suh, Lenzen et al. 2004, Suh and Huppes 2005). The hybrid approach generally reduces the uncertainty of existing pure bottom-up or pure top-down systems by reducing truncation error in the former and increasing the resolution of the latter (Suh, Lenzen et al. 2004). The hybrid approach will be discussed in further detail in Chapter 4 .

\subsection{BIRDS Neutral Environment Software Tool (NEST)}

One of the key shortcomings of BIRDS is that it is based on predefined building prototypes and does not allow for sustainability analysis of custom building designs. Architects and designers have interest in their own unique building designs, which will vary (likely significantly) from any prototype building that is selected to be a feasible representation of a building type, whether it's a two-story colonial house or a high-rise office building. A tool that implements the BIRDS framework, including access to the underlying source data, while offering greater flexibility for building designers would benefit the construction industry in meeting ever increasing sustainability goals.

An evaluation of the feasibility and high priority characteristics of such a tool led to the identification of several key requirements. First, the tool must give maximum flexibility 
in building characteristics and designs for evaluation. A user should be able to evaluate a building of any geometry and as many building assembly options as possible, including incremental or continuous options where feasible. Second, the tool must be interoperable in both directions with at least one existing whole building energy simulation modeling software package. It requires the ability to successfully exchange information between the tool and the software package about the building characteristics (e.g., geometry), performance (e.g., energy consumption), and sustainability results. The preference was to design the tool to be a building sustainability calculation engine in a "neutral environment" that can receive inputs and send outputs successfully regardless of how those building designs are submitted, whether it is whole building energy simulation software, Computer-aided Design (CAD) or Building Information Model (BIM) software, or web interface. Third, the tool must be able to be run from within the existing software package. Allowing a user to remain within a software package for which they are already familiar while still being able to generate and view sustainability results will increase the usability, and hopefully adoption, of the tool while lowering the costs of maintaining and expanding capabilities of the tool moving forward. Finally, all software should be highly supported, regularly updated, and freely available to the public to ensure maximum benefit to the industry.

To accelerate proof of concept and development of such a tool, the most simplistic and impactful capabilities were identified for the initial version. First, the calculations would focus solely on environmental performance using life cycle impact assessment (LCIA) while excluding LCC analysis. The two reasons for focusing on environmental impacts are: (1) it is unlikely that users will have access to LCIA data and/or technical knowledge of LCIA development, and (2) users are likely to have access to cost data that is more accurate for their specific building design than the cost databases that are available to NIST to develop LCC estimates. Second, the calculation engine will limit users to evaluating single-family dwellings. The two reasons for focusing on single-family dwellings are: (1) houses are relatively simple buildings for which to develop LCIA estimates, and (2) NIST already has detailed LCIA data for a wide range of building components in residential buildings. These two constraints will be relaxed in the future as the tool's capabilities can be expanded.

Based on these characteristics and limited scope, NIST has developed the BIRDS Neutral Environment Software Tool (NEST), which is an application programming interface (API) designed to exchange information with the National Renewable Energy Laboratory (NREL) OpenStudio (OS) software (NREL 2017) to complete LCIA estimates for singlefamily residential buildings. The OS suite of applications were determined to have all the desired characteristics described above. OS allows a user to design a custom building, run whole building energy simulations using EnergyPlus (E+) (DOE 2015), and using its "Measure" capabilities send and receive information on the building's design, operation, and performance as well as display results. OS is free to the public and typically updated on a 6-month cycle in conjunction with E+. 
By leveraging the significant capabilities of OS, BIRDS NEST could be designed as a calculation engine without a user interface, allowing for efficient future allocation of resources for maintenance and improvements to the API's capabilities. New capabilities could include more detailed LCIA calculations and results as well as interoperability with other software. Therefore, the development of the BIRDS NEST API has been generalized to allow for any software, whether it's a CAD or BIM application or a simple web interface, to submit an input file for which the API can calculate the LCIA results.

Chapter 2 and Chapter 3 will describe the LCA methodology, assumptions, and source data used in developing the hybrid LCIAs, both for the "top-down" and "bottom-up" data. Chapter 4 will describe the development of BIRDS NEST and the associated OS Measure. Chapter 5 will review the limitations of BIRDS NEST as well as discuss the plan for future development. 


\section{Life Cycle Assessment Methodology}

BIRDS NEST implements the BIRDS framework, which evaluates the environmental performance of whole-buildings using a life-cycle assessment (LCA) approach based on International Organization for Standardization (ISO) standards. The general LCA methodology involves four steps (International Organization for Standardization (ISO) 2006a, International Organization for Standardization (ISO) 2006b).

1. Goal and scope definition

2. Inventory analysis

3. Impact assessment

4. Interpretation

The goal and scope definition step spells out the purpose of the study and its breadth and depth. The inventory analysis step identifies and quantifies the environmental inputs and outputs associated with a building over its entire life-cycle. Environmental inputs include water, energy, land, and other resources. Outputs include releases to air, land, and water. However, it is not these inputs and outputs, or inventory flows, which are of primary interest. What is more interesting is their consequences, or impacts on the environment. Thus, the impact assessment step characterizes these inventory flows in relation to a set of environmental impacts. For example, the impact assessment step might relate carbon dioxide emissions, a flow, to climate change, an impact. Finally, the interpretation step examines the environmental impacts in accordance with the goals of the LCA study.

\subsection{Goal and Scope Definition}

The goal of BIRDS LCAs is to generate environmental performance scores for U.S. buildings based on a user's custom design to assist designers, investors, and policymakers in quantifying sustainability performance of buildings.

The scoping phase of any LCA involves defining the boundaries of the product system or, in the case of BIRDS, the building under study. In traditional bottom-up LCAs, the setting of the boundary conditions requires expert judgment by the analyst because consideration must be given to the various unit processes related to the construction of the building (e.g., asphalt production for input to the manufacturing of facing for fiberglass batt insulation). Each unit process involves many inventory flows, some of which themselves involve other, subsidiary unit processes. Because including an ever-expanding number of unit processes in LCAs is not feasible, the product system's supply chain links are truncated at some point to include only those judged to make non-negligible contributions to the product system. The analyst typically uses mass, energy, and/or cost contributions as decision criteria. Use of different boundary setting criteria is one of the main reasons LCA results from different studies are often incomparable. 
One important advantage of the BIRDS hybrid approach is that it addresses the bottom-up issue of truncation in supply chain links, thereby improving consistency in system boundary selections. Through the hybridization process, truncated supply chain links are connected to the background U.S. economic system represented by the top-down data. These linkages follow the metabolic structure of the U.S. economy, thereby benefitting from a more complete system definition including potentially thousands of supply chain interactions.

Due to their long service lives, buildings are unique when it comes to the end-of-life stage of the life-cycle. For most non-consumable product LCAs, end-of-life waste flows are included in the inventory analysis for full coverage of the life-cycle. If there is an active recycling market that diverts some of the product from the waste stream, that portion of the product's end-of-life flows can be ignored. In BIRDS, however, a residential building lifetime is 65 years, much longer than the 40-year maximum length for the study period considered in BIRDS. Therefore, $100 \%$ of each building is "recycled" at the end of the study period and there are no end-of-life waste flows allocated to the building at the end of the BIRDS study period. Rather, end-of-life waste flows should be allocated to a different "product," representing use of the building from the end of the study period to the end of the building service life. For example, a home that is sold to a new owner will be occupied and not torn down, which means the entire house is "recycled." Similarly, the environmental burdens from building construction are allocated only to its first use (equally distributed across each year of the selected study period); LCAs for all subsequent uses should be treated as free of these initial construction burdens. This effectively credits the use of existing buildings over new construction and ensures there will be no double counting if existing building LCAs are ever included in future versions of BIRDS NEST.

Defining the unit of comparison is an important task in the goal and scoping phase of LCA. The basis for all units of comparison is the functional unit, defined so that the systems compared are true substitutes for one another. In the BIRDS model, the functional unit is construction and use of one building prototype over a user-defined study period. The functional unit provides the critical reference point to which the LCA results are scaled.

Scoping also involves setting data requirements. With respect to geographic coverage, the BIRDS inventory data are generally U.S. average data. An exception is made for the electricity production inventory data applied to a building's use of electricity. These data are customized to each U.S. state. In terms of technology coverage, the top-down inventory data represent the mix of technologies in place as of 2002. ${ }^{1}$ For the bottom-up inventory data on building energy technologies, the most representative technology for which data are available is evaluated.

\footnotetext{
${ }^{1}$ More recent data is not available due to funding limitations of developing environmental inventory data for the most recent U.S. Economic Census.
} 


\subsection{Life-Cycle Inventory Analysis}

BIRDS applies a hybridized life-cycle assessment approach. The approach is hybridized in the sense that a mixture of top-down and bottom-up data are collected and systematically integrated in the inventory analysis LCA step. Traditional process-based LCAs gather data by modeling all the in-scope industrial processes involved in a product's production (raw materials acquisition, materials processing, manufacture, transportation), use, and waste management. For each industrial process, the analyst collects very detailed, bottom-up data on all its inputs from the environment (e.g., materials, fuel, water, land) and outputs to the environment (e.g., products, water effluents, air emissions, waste). This process is summarized in Figure 2-1.

To address the complexities of a whole building, BIRDS takes a multi-layered approach to inventory analysis. Since a building's operating energy efficiency has an important influence on its sustainability performance, and energy efficiency is largely driven by the building's energy technologies, BIRDS pays special attention to the materials used in them. Specifically, BIRDS uses detailed life-cycle inventory (LCI) data for a range of building component technologies that have been analyzed at the traditional, bottom-up LCA level. The bottom-up approach is also used to gather inventory data for a building's use of electricity and natural gas over the study period. These bottom-up data were developed under contract to NIST by Four Elements Consulting, LLC, of Seattle, Washington, and are documented in Section 3.2 and Section 3.3. For all other building constituents, industry average LCI data are gathered from the top-down approach and then systematically combined with bottom-up data into a comprehensive, hybrid LCI for a whole building.

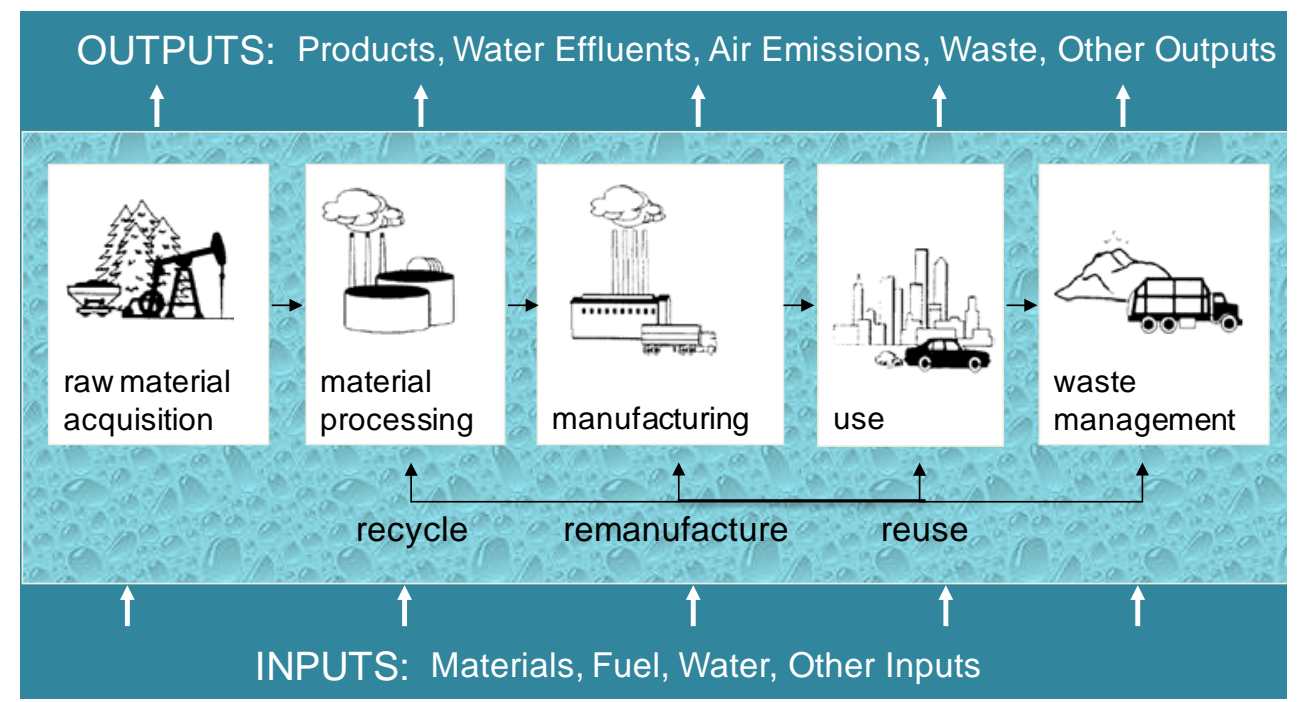

Figure 2-1 Compiling LCA Inventories of Environmental Inputs and Outputs

The inventory data items collected through the bottom-up and top-down approaches are identical - for example, kilogram (kg) carbon dioxide, kWh primary energy consumption - but some of the data sources are quite different. The systematic hybridization of the 
data sets bridges these differences to yield coherent and consistent BIRDS life-cycle inventories for a wide variety of new commercial and residential buildings. The LCAs for the buildings are then completed by applying conventional methods of life-cycle impact assessment (LCA) and interpretation to the hybrid inventory data.

An economy's accounting structure provides a cost-effective top-down approach to LCA inventory data collection. Many developed economies maintain economic input-output (I-O) accounts that trace the flow of goods and services throughout industries. Much the same way that a product's production can be traced upstream through its supply chain, an industry's production can be traced upstream through its supply chain. The U.S. Census Bureau conducts an Economic Census of U.S. industry every five years that establishes industry linkages. Covering $97 \%$ of business receipts, the census reaches nearly all U.S. business establishments. Based on the detailed data collected, the U.S. Bureau of Economic Analysis (BEA) creates what are called Input-Output Accounts, or "I-O tables,” for the U.S. economy.

The U.S. I-O tables show how around 500 industries provide input to, and use output from, each other to produce Gross Domestic Product (GDP) - the total value of the consumption of goods and services in a year. These tables, for example, can show how $\$ 100$ million of U.S. economic output in the residential building construction sector traces back through its direct monetary inputs - from the construction process itself - to its indirect inputs from contributing sectors such as the steel, concrete, lumber, and plastics industries. Economic output from the steel, concrete, lumber, and plastics industries, in turn, can be traced back through those supply chains such as mining, forestry, fuel extraction, and so on.

While BEA provides these I-O tables in purely monetary terms, academics have successfully developed “environmentally-extended” I-O tables (Suh 2005, Hendrickson, Lave et al. 2006, Suh 2010). These top-down tables tap into a wide range of national environmental statistics to associate environmental inputs and outputs with economic activity in industry sectors, including use of raw materials, fuel, water, and land and releases of water effluents, air emissions, and waste. BIRDS uses environmentallyextended I-O tables for the U.S. construction industry developed under contract to NIST by Industrial Ecology Research Services of Goleta, California, which are documented in Section 3.1.

To understand the contribution of building construction to the nation's environmental footprint (impact), it is useful to focus on the concept of “final demand.” The BEA's monetary I-O tables use GDP to measure final demand. This value consists of spending and investment by consumers, businesses, and government, as well as net exports. Since final demand is satisfied through annual production - goods and services need to be produced before they can be bought - each industry’s value-added, or “direct” contribution to GDP, reflects its share of final demand, and will be referred to as GDP for the remainder of this document. 
The environmentally-extended I-O tables translate economic activity into environmental terms, or monetary GDP into environmental GDP (eGDP). In LCA terms, the construction industry's contribution to eGDP is not limited to the direct impact from value-added construction processes and activities. Its contribution to eGDP also includes the indirect impacts stemming from contributions by upstream construction supply chains up to and including raw materials acquisition. The supply chain relationships built into the environmentally-extended I-O tables enable estimation of construction industry impacts on this cumulative, life-cycle basis. Figure 2-2 illustrates these supply chain relationships for some of the inputs to ready-mix concrete manufacturing, an indirect construction industry input.

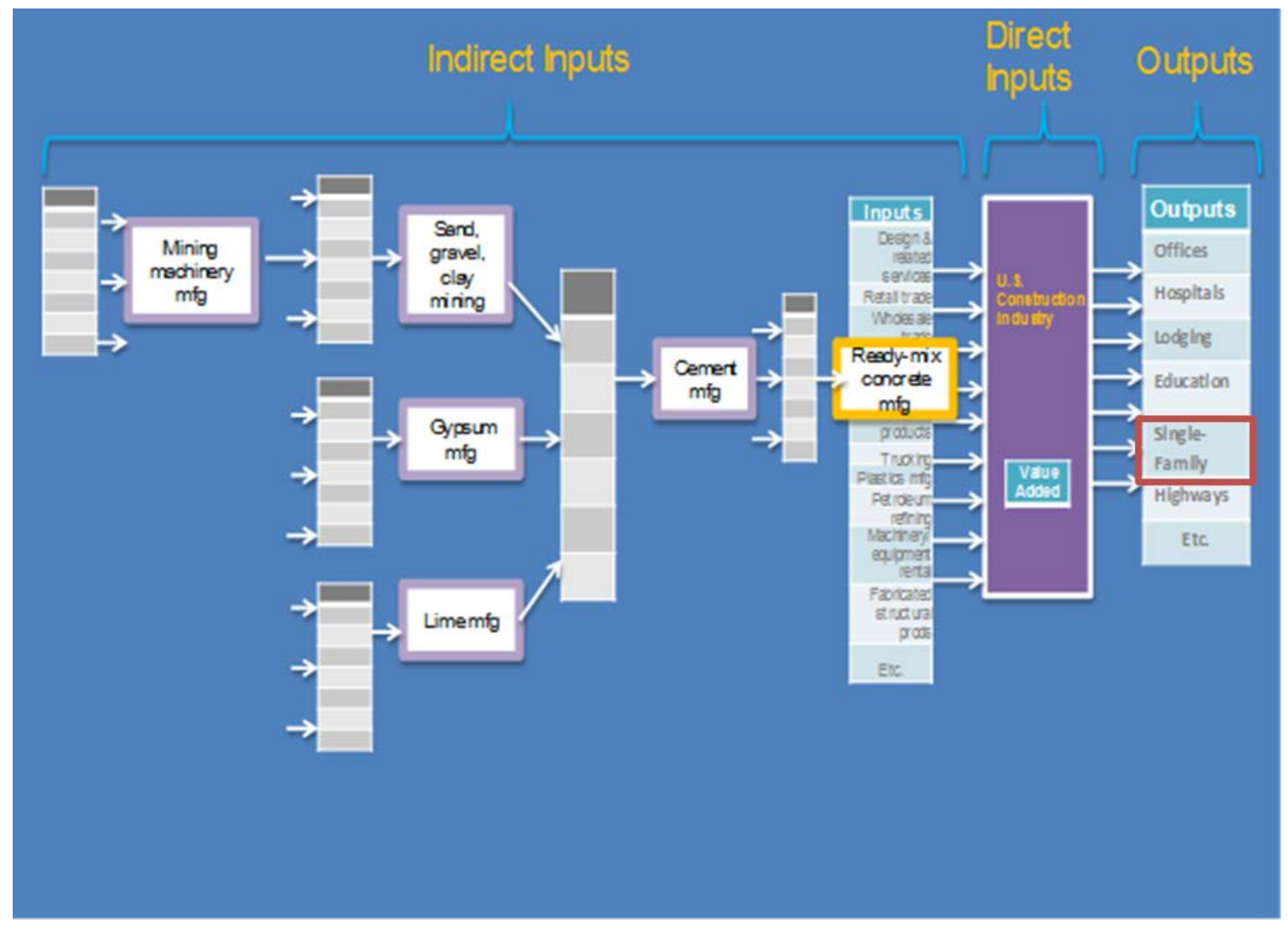

Figure 2-2 Illustration of Supply Chain Contributions to U.S. Construction Industry

\subsection{Life-Cycle Impact Assessment}

Environmental impacts from building construction and use derive from the 6204 inputs and outputs occurring throughout production supply chains, as quantified in the hybrid BIRDS LCI. The impact assessment step of LCA quantifies the potential contribution of these inventory items to a range of environmental impacts. The approach preferred by most LCA practitioners and scientists today involves a two-step process: 
- Classification of inventory flows that contribute to specific environmental impacts. For example, greenhouse gases such as carbon dioxide, methane, and nitrous oxide are classified as contributing to climate change.

- Characterization of the potential contribution of each classified inventory flow to the corresponding environmental impact. This results in a set of indices, one for each impact, which is obtained by weighting each classified inventory flow by its relative contribution to the impact. For instance, the Climate Change Potential index is derived by expressing each greenhouse gas in terms of its equivalent amount of carbon dioxide heat trapping potential.

There are two general applications of this life-cycle impact assessment (LCIA) approach: midpoint-level and endpoint-level analyses. An endpoint-level analysis attempts to measure the ultimate damage that each environmental input and output in the inventory will have along the cause-effect chain. Methods of this type include just a few impact categories, such as damage to human health, ecosystems, and resource availability that are easier to interpret in the final step of life-cycle assessment. This approach is criticized for the numerous assumptions, value judgments, and gaps in coverage of the underlying damage models. A midpoint-level analysis, on the other hand, selects points along the cause-effect chain at which more certain and comprehensive assessments may be carried out. While this approach generates many impact categories and makes life-cycle interpretation more difficult, it is more scientifically defensible. Even so, a midpoint-level analysis does not offer the same degree of relevance for all environmental impacts. For global and regional effects (e.g., climate change and acidification) the method provides an accurate description of the potential impact. For impacts dependent upon local conditions (e.g., smog), it may result in an oversimplification of the actual impacts because the indices are not tailored to localities. Note that some impact assessments apply a mix of midpoint and endpoint approaches.

\subsubsection{BIRDS Impact Assessment}

BIRDS uses a midpoint-level analysis to translate its 6204 environmental inputs and outputs into a manageable set of science-based measurements across 12 environmental impacts. BIRDS primarily uses the U.S. Environmental Protection Agency's (EPA) Tool for the Reduction and Assessment of Chemical and other environmental Impacts (TRACI) version 2.0 set of state-of-the-art, peer-reviewed U.S. life-cycle impact assessment methods (Bare 2011). Since TRACI 2.0 does not include land and water use, these two important resource depletion impacts are assessed using other characterization methods (Guinée 2002, Goedkoop, Heijungs et al. 2008). Together these methods are used to develop BIRDS performance metrics indicating the degree to which construction and use of a building contributes to each environmental impact. What follows are brief descriptions of the 12 BIRDS impact categories. 


\subsubsection{Impact Categories}

\subsection{Climate Change}

The Earth absorbs radiation from the Sun, mainly at the surface. This energy is then redistributed by the atmosphere and ocean and re-radiated to space at longer wavelengths. Greenhouse gases in the atmosphere, principally water vapor, but also carbon dioxide, methane, chlorofluorocarbons, and ozone, absorb some of the thermal radiation. The absorbed energy is re-radiated in all directions, downwards as well as upwards, such that the radiation that is eventually lost to space is from higher, colder levels in the atmosphere. The result is that the surface loses less heat to space than it would in the absence of the greenhouse gases and consequently stays warmer than it would be otherwise. This phenomenon, which acts like a 'blanket' around the Earth, is known as the greenhouse effect.

The greenhouse effect is a natural phenomenon. The environmental issue is the change in the greenhouse effect due to emissions (an increase in the effect) and absorptions (a decrease in the effect) attributable to humans. A general increase in temperature can alter atmospheric and oceanic temperatures, which can potentially lead to alteration of natural circulations and weather patterns. A rise in sea level is also predicted from an increase in temperature due to thermal expansion of the oceans and the melting of polar ice sheets.

\subsection{Primary Energy Consumption}

Primary energy consumption leads to fossil fuel depletion when fossil fuel resources are consumed at rates faster than nature renews them. Some experts believe fossil fuel depletion is fully accounted for in market prices. That is, market price mechanisms are believed to take care of the scarcity issue, with price being a measure of the level of depletion of a resource and the value society places on that depletion. However, price is influenced by many factors other than resource supply, such as resource demand and nonperfect markets (e.g., monopolies and subsidies). The primary energy consumption metric is used to account for the resource depletion aspect of fossil fuel extraction.

\subsection{Human Health - Criteria Air Pollutants}

These pollutants can arise from many activities including combustion, vehicle operation, power generation, materials handling, and crushing and grinding operations. They include coarse particles known to aggravate respiratory conditions such as asthma, and fine particles that can lead to more serious respiratory symptoms and disease.

\subsection{Human Health - Cancer Effects}

These effects can arise from exposure to industrial and natural substances, and can lead to illness, disability, and death. Its assessment is based on the global consensus model known as USEtox, which describes the fate, exposure and effects of thousands of chemicals (Rosenbaum, Huijbregts et al. 2011). 


\subsection{Water Consumption}

Water resource depletion has not been routinely assessed in LCAs to date, but researchers are beginning to address this issue to account for areas where water is scarce, such as the Western United States. While some studies use water withdrawals to evaluate this impact, a more refined analysis considers that a portion of water withdrawn may be returned through evapotranspiration (the sum of evaporation from surface water, soil, and plant leaves). BIRDS uses the latter approach to measure water consumption, or water withdrawn net of evapotranspiration. BIRDS evaluates water consumption from cradle to grave, including water consumption during building use.

\subsection{Ecological Toxicity}

Measures of ecological toxicity consider the potential of pollutants from industrial sources to harm land- and water-based ecosystems. Its assessment is based on the global consensus model known as USEtox, which describes the fate, exposure and effects of thousands of chemicals.

\subsection{Eutrophication Potential}

Eutrophication is the addition of mineral nutrients to the soil or water. In both media, the addition of large quantities of mineral nutrients, such as nitrogen and phosphorous, results in generally undesirable shifts in the number of species in ecosystems and a reduction in ecological diversity. In water, it tends to increase algae growth, which can lead to a lack of oxygen and subsequent death of species like fish.

\subsection{Land Use}

This impact category measures the use of land resources in hectares by humans which can lead to undesirable changes in habitats. Note that the BIRDS land use approach does not consider the original condition of the land, the extent to which human activity changes the land, or the length of time required to restore the land to its original condition. As impact assessment science continues to evolve, it is hoped that these potentially important factors will become part of BIRDS land use assessment.

\subsection{Human Health - Non-cancer Effects}

The effects can arise from exposure to industrial and natural substances, and range from transient irritation to permanent disability and even death. Its assessment is based on the global consensus model known as USEtox, which describes the fate, exposure and effects of thousands of chemicals.

\subsection{Smog Formation}

Smog forms under certain climatic conditions when air emissions (e.g., nitrous oxides $\left(\mathrm{NO}_{\mathrm{X}}\right)$, volatile organic compounds (VOCs)) from industry and transportation are trapped at ground level where they react with sunlight. Smog leads to harmful impacts on human health and vegetation.

\subsection{Acidification Potential}


Acidifying compounds may, in a gaseous state, either dissolve in water or fix on solid particles. These compounds reach ecosystems through dissolution in rain or wet deposition and can affect trees, soil, buildings, animals, and humans. The two compounds principally involved in acidification are sulfur and nitrogen compounds, with their principal human source being fossil fuel and biomass combustion. Other compounds released by human sources, such as hydrogen chloride and ammonia, also contribute to acidification.

\subsection{Ozone Depletion}

Ozone depletion is the thinning of the stratospheric ozone layer, allows more harmful shortwave radiation to reach the Earth's surface, potentially causing undesirable changes in ecosystems, agricultural productivity, skin cancer rates, and eye cataracts, among other issues.

\subsubsection{Computational Algorithms}

There are six building components represented in the BIRDS life-cycle impact assessment (LCIA) calculations for whole-buildings:

- Baseline building: new construction (Base_New)

- Baseline building: maintenance and repair over study period (Base_M\&R)

- Energy technology package: new construction (ETP_New)

- Energy technology package: annual maintenance and repair (ETP_M\&R)

- Annual operating energy use: electricity (ELEC)

- Annual operating energy use: natural gas (NG)

The hybridized LCI data for each component are expressed in different units. For example, the baseline building inventories are given on a per-dollar basis, the energy technology package inventories on a per-physical unit basis (usually area), and the operating energy use inventories on a per-unit of energy basis. Thus, each requires its own LCIA computational algorithm as shown in Table 2-1. These calculations ensure that after adjusting for study period length, all LCIA results are expressed in the consistent functional unit defined for BIRDS: construction and use of one building prototype over a user-defined study period. 
Table 2-1 BIRDS Life-cycle Impact Assessment Calculations by Building Component

\begin{tabular}{|c|c|c|c|}
\hline $\begin{array}{l}\text { Building } \\
\text { Component }\end{array}$ & LCIA Equation & & \multirow{4}{*}{$\begin{array}{l}\text { Notation } \\
\text { LCIA=classified and characterized } \\
\text { life-cycle inventories } \\
\text { c=construction type code, } 1=\text { new, } \\
2=M \& R \\
\text { E=electricity }\end{array}$} \\
\hline Base_New & $\operatorname{LCIA}_{\mathrm{i}, \mathrm{j}, \mathrm{c}=1}$ & $=\left(\operatorname{LCIA}_{\mathrm{i}, \mathrm{j}, \mathrm{c}=1} / \$\right) \cdot \$_{\mathrm{i}, \mathrm{c}=1}$ & \\
\hline Base_M\&R & $\operatorname{LCIA}_{\mathrm{i}, \mathrm{j}, \mathrm{c}=2, \mathrm{yr}}$ & $=\quad\left(\operatorname{LCIA}_{\mathrm{i}, \mathrm{j}, \mathrm{c}=2} / \$\right) \cdot \$_{\mathrm{i}, \mathrm{c}=2, \mathrm{yr}}$ & \\
\hline ETP_New & $\operatorname{LCIA}_{\mathrm{i}, \mathrm{j}, \mathrm{c}=1, \mathrm{x}, \mathrm{K}, \mathrm{T}}$ & $\begin{aligned}= & \sum\left(\mathrm{LCIA}_{\mathrm{j}, \mathrm{c}=1, \mathrm{ET}(\mathrm{i}, \mathrm{x}, \mathrm{K}, \mathrm{T})} / \mathrm{FU}\right) \cdot \mathrm{FU}_{\mathrm{i}, \mathrm{T}} \\
& \text { from } \mathrm{T}=1 \text { to } 6\end{aligned}$ & \\
\hline ETP_M\&R & LCIA $_{\mathrm{i}, \mathrm{j}, \mathrm{c}=2, \mathrm{x}, \mathrm{K}, \mathrm{T}} / \mathrm{yr}$ & $\begin{aligned} & \Sigma\left(\mathrm{LCIA}_{\mathrm{j}, \mathrm{c}=2, \mathrm{ET}(\mathrm{i}, \mathrm{x}, \mathrm{K}, \mathrm{T})} / \mathrm{FU} / \mathrm{yr}\right) \\
= & \cdot \mathrm{FU}_{\mathrm{i}, \mathrm{T}} \\
& \text { from } \mathrm{T}=1 \text { to } 6\end{aligned}$ & $\begin{array}{l}\text { ETP=energy technology product } \\
\text { FU=functional unit* } \\
\text { i = building type }\end{array}$ \\
\hline ELEC & $\mathrm{LCIA}_{\mathrm{i}, \mathrm{j}, \mathrm{x}, \mathrm{K}} / \mathrm{yr}$ & $=\left(\mathrm{LCIA}_{\mathrm{j}, \mathrm{s}} / \mathrm{BTU}_{\mathrm{E}}\right) \cdot\left(\mathrm{BTU} \mathrm{E}_{\mathrm{E}, \mathrm{i}, \mathrm{x}, \mathrm{K}} / \mathrm{yr}\right)$ & $\begin{array}{l}\mathrm{j}=\text { environmental impact, } \mathrm{j}=1 \text { to } 12 \\
\mathrm{~K}=\text { building design }\end{array}$ \\
\hline NG & $\operatorname{LCIA}_{\mathrm{i}, \mathrm{j}, \mathrm{x}, \mathrm{K}} / \mathrm{yr}$ & $=\begin{array}{l}\left(\mathrm{LCIA}_{\mathrm{j}} / \mathrm{BTU}_{\mathrm{NG}}\right) \\
\left(\mathrm{BTU}_{\mathrm{NG}, \mathrm{i}, \mathrm{x}, \mathrm{K}} / \mathrm{yr}\right)\end{array}$ & $\begin{array}{l}n=\text { study period length in years, } \\
n=1 \text { to } 40 \\
N G=\text { natural gas } \\
s=U . S \text {. state, } \\
T=\text { energy technology group, } T=1 \\
\text { to } 10 \\
x=\text { building location }\end{array}$ \\
\hline min & & & \\
\hline
\end{tabular}

\subsubsection{BIRDS Normalization}

Once impacts have been classified and characterized, the resulting LCIA metrics are expressed in incommensurate units. Climate change is expressed in carbon dioxide equivalents $\left(\mathrm{CO}_{2} \mathrm{e}\right)$, acidification in hydrogen ion equivalents, eutrophication in nitrogen equivalents, and so on. To assist in the next LCA step, interpretation, these metrics are often placed on the same scale through normalization.

The EPA has developed "normalization references" corresponding to its TRACI set of impact assessment methods (Bare, Gloria et al. 2006). These U.S. data are updated and expanded for use in BIRDS. Shown in Figure 2-3, these values quantify the U.S. economy's annual contributions to each impact category. As such, they represent a "U.S. impact yardstick" against which to evaluate the significance of building-specific impacts. Normalization is accomplished by dividing BEES building-specific impact assessment results by the fixed U.S.-scale normalization references, expressed in the same units, yielding an impact category score for a building that has been placed in the context of annual U.S. contributions to that impact. By placing each building-specific impact result in the context of its associated U.S. impact result, the measures are all reduced to the same scale, allowing comparison across impacts.

The environmental impact of a single building is small relative to the total U.S. emissions in an impact category, leading to normalized values that are small fractions of a percent. 
To improve the user experience, the Low-Energy Residential Database adjusted these normalized values by multiplying by the U.S. population ( 309 million), creating a normalized value that represents the fraction of emissions per capita for each impact category.

\section{Table 2-2 BIRDS Normalization References}

\begin{tabular}{lrl}
\hline Impact Category & $\begin{array}{c}\text { Normalization } \\
\text { reference } \\
\text { (U.S. total/yr) }\end{array}$ & Units \\
\hline Climate Change & $7.16 \mathrm{E}+12$ & $\mathrm{~kg}(\mathrm{lb}) \mathrm{CO}_{2} \mathrm{e}$ \\
Primary Energy & $(1.6 \mathrm{E}+13)$ & \\
Consumption & $3.52 \mathrm{E}+13$ & $\mathrm{kWh}$ \\
& $(1.20 \mathrm{E}+14)$ & $(\mathrm{kBTU})$ \\
\hline HH Criteria Air & $2.24 \mathrm{E}+10$ & $\mathrm{~kg}(\mathrm{lb})$ particulate matter 10 equivalents \\
& $(4.94 \mathrm{E}+10)$ & (PM10 = particulate matter $<10$ microns in diameter) \\
\hline HH Cancer & $1.05 \mathrm{E}+04$ & comparative human toxicity units \\
\hline Water Consumption & $1.69 \mathrm{E}+14$ & $\mathrm{~L}$ \\
& $(4.5 \mathrm{E}+13)$ & (Gal) \\
\hline Ecological Toxicity & $3.82 \mathrm{E}+13$ & comparative ecotoxicity units \\
\hline Eutrophication & $1.01 \mathrm{E}+10$ & $\mathrm{~kg}(\mathrm{lb})$ nitrogen equivalents \\
& $(2.23 \mathrm{E}+10)$ & \\
\hline Land Use & $7.32 \mathrm{E}+08$ & hectare \\
& $(1.81 \mathrm{E}+09)$ & (acre) \\
HH Non-cancer & $5.03 \mathrm{E}+05$ & comparative human toxicity units \\
\hline Smog Formation & $4.64 \mathrm{E}+11$ & $\mathrm{~kg}(\mathrm{lb})$ ozone equivalents \\
& $(1.0 \mathrm{E}+12)$ & \\
\hline Acidification & $1.66 \mathrm{E}+12$ & moles hydrogen ion equivalents \\
\hline Ozone Depletion & $5.10 \mathrm{E}+07$ & $\mathrm{~kg}(\mathrm{lb})$ CFC-11 equivalents \\
& $(1.1 \mathrm{E}+08)$ & \\
\hline
\end{tabular}

\subsection{Life-Cycle Interpretation}

At the BIRDS LCA interpretation step, a building's normalized impact scores are evaluated. The midpoint-level impact assessments yield scores for twelve impact categories, making interpretation at this level difficult. To enable comparisons across buildings, the scores across impact categories may be synthesized. Note that in BIRDS, the synthesis of impact scores is optional.

Impact scores may be synthesized by weighting each impact category by its relative importance to overall environmental performance, then computing the weighted average impact score. In the BIRDS software, the set of importance weights is selected by the user. Several alternative weight sets are provided as guidance, and may be either used directly or as a starting point for developing user-defined weights. The alternative weight sets are based on an EPA Science Advisory Board study, a BEES Stakeholder Panel's structured judgments, a set of equal weights, and a set exclusively focusing on the climate change impact, representing a spectrum of ways in which people value diverse aspects of the environment. 


\subsubsection{EPA Science Advisory Board Study}

In 1990 and again in 2000, EPA's Science Advisory Board (SAB) developed lists of the relative importance of various environmental impacts to help EPA best allocate its resources (U.S. EPA Science Advisory Board 1990, U.S. EPA Science Advisory Board 2000). The following criteria were used to develop the lists:

- The spatial scale of the impact

- The severity of the hazard

- The degree of exposure

- The penalty for being wrong

Ten of the twelve BIRDS impact categories were covered by the SAB lists of relative importance:

- Highest-Risk Problems: climate change, land use

- High-Risk Problems: ecological toxicity, human health (cancer and non-cancer effects)

- Medium-Risk Problems: ozone depletion, smog, acidification, eutrophication, and human health - criteria air pollutants

The SAB did not explicitly consider primary energy consumption or water consumption. For BIRDS, these impacts are assumed to be relatively medium-risk and low-risk problems, respectively, based on other relative importance lists (Levin 1996).

Verbal importance rankings, such as "highest risk," may be translated into numerical importance weights by following ASTM International standard guidance for applying a Multi-attribute Decision Analysis method known as the Analytic Hierarchy Process (AHP) (ASTM 2011). The AHP methodology suggests the following numerical comparison scale:

1 Two impacts contribute equally to the objective (in this case environmental performance)

3 Experience and judgment slightly favor one impact over another

5 Experience and judgment strongly favor one impact over another

7 One impact is favored very strongly over another, its dominance demonstrated in practice

9 The evidence favoring one impact over another is of the highest possible order of affirmation

$* 2,4,6$, and 8 can be selected when compromise between values of $1,3,5,7$, and 9 , is needed.

Through an AHP known as pairwise comparison, numerical comparison values are assigned to each possible pair of environmental impacts. Relative importance weights can then be derived by computing the normalized eigenvector of the largest eigenvalue of the matrix of pairwise comparison values. Table 2-3 and Table 2-4 list the pairwise 
comparison values assigned to the verbal importance rankings, and the resulting SAB importance weights computed for the BIRDS impacts, respectively. Note that the pairwise comparison values were assigned through an iterative process based on NIST's background and experience in applying the AHP technique. Furthermore, while the SAB evaluated cancer and non-cancer effects as a group, the resulting $13 \%$ weight was apportioned between the two based on the relative judgments of the BEES Stakeholder Panel discussed in the next section.

\section{Table 2-3 Pairwise Comparison Values for Deriving Impact Category Importance Weights}

\begin{tabular}{lc}
\hline $\begin{array}{c}\text { Verbal Importance } \\
\text { Comparison }\end{array}$ & $\begin{array}{c}\text { Pairwise } \\
\text { Comparison Value }\end{array}$ \\
\hline Highest vs. Low & 6 \\
Highest vs. Medium & 3 \\
Highest vs. High & 1.5 \\
High vs. Low & 4 \\
High vs. Medium & 2 \\
Medium vs. Low & 2 \\
\hline
\end{tabular}

Table 2-4 Relative Importance Weights based on Science Advisory Board Study

\begin{tabular}{lc}
\hline Impact Category & $\begin{array}{c}\text { Relative Importance } \\
\text { Weight } \mathbf{( \% )}\end{array}$ \\
\hline Climate Change & 18 \\
Primary Energy Consumption & 7 \\
HH Criteria Air & 7 \\
HH Cancer & 8 \\
Water Consumption & 3 \\
Ecological Toxicity & 12 \\
Eutrophication & 5 \\
\hline Land Use & 18 \\
HH Non-cancer & 5 \\
\hline Smog Formation & 7 \\
\hline Acidification & 5 \\
\hline Ozone Depletion & 5 \\
\hline
\end{tabular}

\subsubsection{BEES Stakeholder Panel Judgments}

While the derived EPA SAB-based weight set is helpful and offers expert guidance, several interpretations and assumptions were required in order to translate $\mathrm{SAB}$ findings into numerical weights for interpreting LCA-based analyses. A more direct approach to weight development would consider a closer match to the context of the application; that is, environmentally preferable purchasing in the United States based on life-cycle impact assessment results, as reported by BIRDS.

To develop such a weight set, NIST assembled a volunteer stakeholder panel that met at its facilities in Gaithersburg, Maryland, for a full day in May 2006. To convene the panel, 
invitations were sent to individuals representing one of three "voting interests:" producers (e.g., building product manufacturers), users (e.g., green building designers), and LCA experts. Nineteen individuals participated in the panel: seven producers, seven users, and five LCA experts. These "voting interests" were adapted from the groupings ASTM International employs for developing voluntary standards, to promote balance and support a consensus process.

The BEES Stakeholder Panel was led by Dr. Ernest Forman, founder of the AHP firm Expert Choice Inc. Dr. Forman facilitated panelists in weighting the BEES impact categories using the AHP pairwise comparison process. The panel weighted all impacts in the Short Term (0 years to 10 years), Medium Term (10 years to 100 years), and Long Term ( $>100$ years). One year's worth of U.S. flows for each pair of impacts was compared, with respect to their contributions to environmental performance. For example, for an impact comparison over the Long Term, the panel evaluated the effect that the current year's U.S. emissions would have more than 100 years hence.

Once the panel pairwise-compared impacts for the three time horizons, its judgments were synthesized across the selected time horizons. Note that when synthesizing judgments across voting interests and time horizons, all panelists were assigned equal importance, while the short, medium, and long-term time horizons were assigned by the panel to carry $24 \%, 31 \%$, and $45 \%$ of the weight, respectively.

The environmental impact importance weights developed through application of the AHP technique at the facilitated BEES Stakeholder Panel event are shown in Table 2-5. These weights reflect a synthesis of panelists' perspectives across all combinations of stakeholder voting interest and time horizon. The weight set draws on each panelist's personal and professional understanding of, and value attributed to, each impact category. While the synthesized weight set may not equally satisfy each panelist's view of impact importance, it does reflect contemporary values in applying LCA to real world decisions. This synthesized BEES Stakeholder Panel weight set is offered as an option in BIRDS online.

The panel's application of the AHP process to derive environmental impact importance weights is documented in an appendix to Gloria, Lippiatt et al. (2007) and ASTM (2011). 
Table 2-5 Relative Importance Weights based on BEES Stakeholder Panel Judgments

\begin{tabular}{lc}
\hline Impact Category & $\begin{array}{c}\text { Relative Importance Weight } \\
(\%)\end{array}$ \\
\hline Climate Change & 29.9 \\
Primary Energy Consumption & 10.3 \\
HH Criteria Air & 9.3 \\
HH Cancer & 8.2 \\
Water Consumption & 8.2 \\
Ecological Toxicity & 7.2 \\
Eutrophication & 6.2 \\
Land Use & 6.2 \\
HH Non-cancer & 5.2 \\
Smog Formation & 4.1 \\
Acidification & 3.1 \\
Ozone Depletion & 2.1 \\
Note: Since BIRDS does not currently include an Indoor Air Quality \\
impact category, its 3 \% BEES Stakeholder Panel weight has been \\
redistributed by proportion among the remaining 12 impacts.
\end{tabular}

The three figures below display in graphical form the BEES Stakeholder Panel weights used in BIRDS. Figure 2-3 displays the synthesized weight set. Figure 2-4 displays the weights specific to panelist voting interest, and Figure 2-5 displays the weights specific to time horizon. The BIRDS user is free to interpret results using either of the weight sets displayed in Figure 2-4 and Figure 2-5 by entering them as a user-defined weight set.

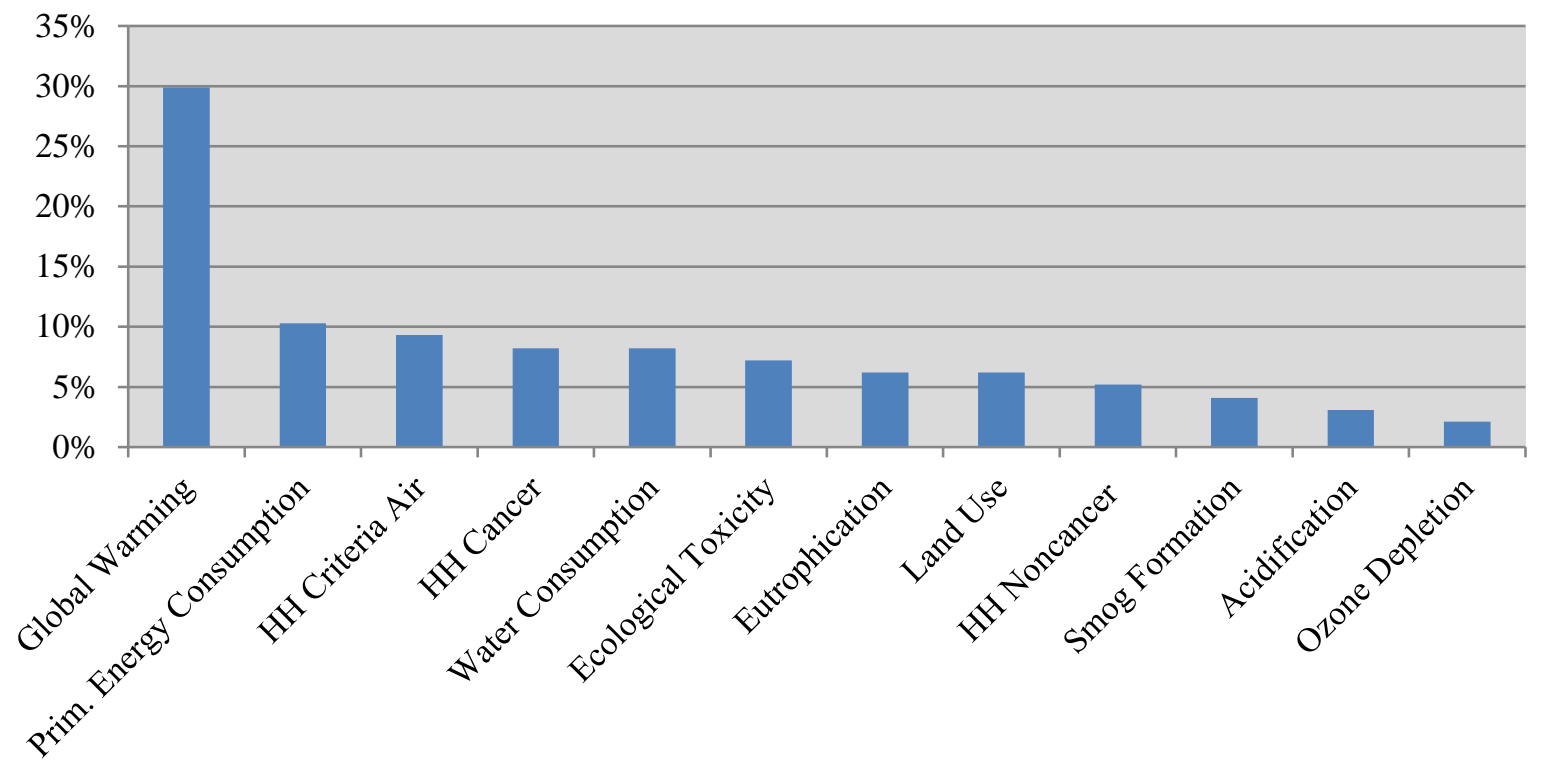

Impact Category 
Figure 2-3 BEES Stakeholder Panel Importance Weights Synthesized across Voting Interest and Time Horizon

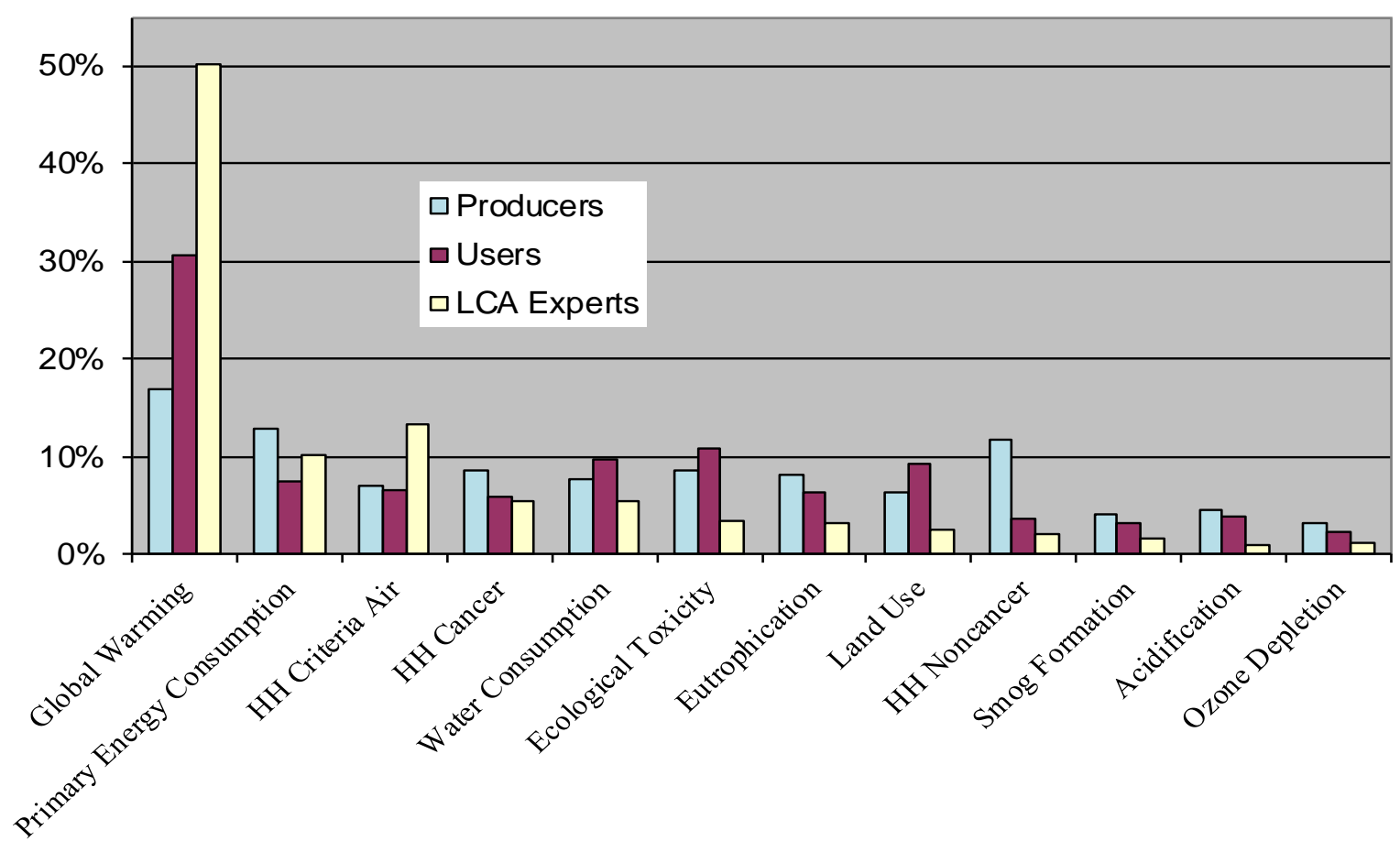

Figure 2-4 BEES Stakeholder Panel Importance Weights by Stakeholder Voting Interest 


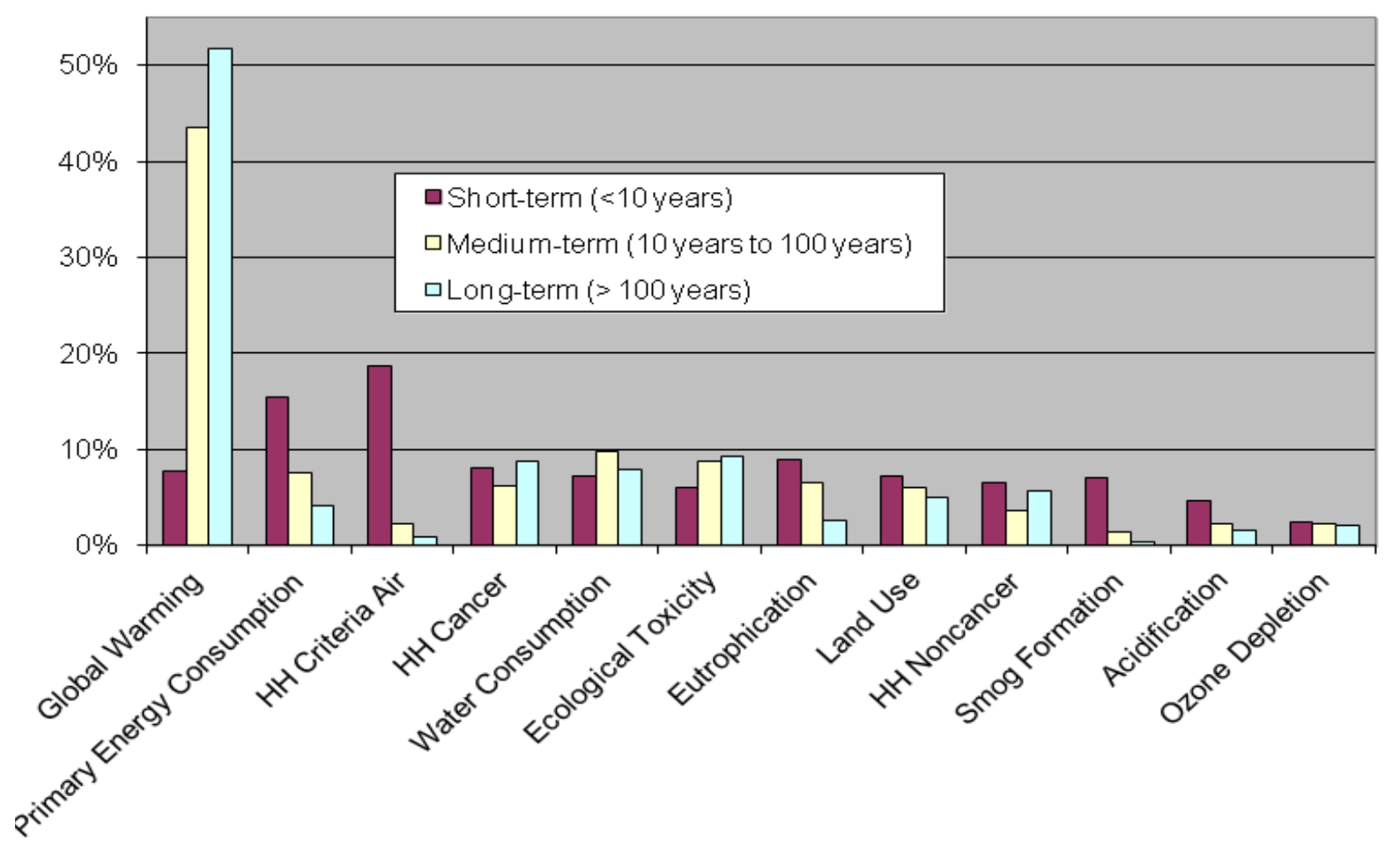

Figure 2-5 BEES Stakeholder Panel Importance Weights by Time Horizon 


\section{BIRDS Hybrid Life-Cycle Impact Assessment Data}

As discussed in Section 2.2, the hybrid LCIA estimates for whole buildings requires LCIA data from both environmentally extended I-O tables and process-based LCAs. The expenditure-based, "top-down” I-O data is developed for specific building types and construction activities, which is used to estimate the LCIAs for "typical" building construction using common practices and building components that will be referred to as the "baseline building design" for the remainder of this document. The baseline building design LCIA is estimated using the cost of initially constructing the building and any constant maintenance and repair of the building over time, and excludes the LCIA for any building component that may be changed to increase energy efficiency (e.g., insulation, windows, heating, ventilation, and air conditioning (HVAC) system, lighting system). The "bottom-up,” process-based LCIA data is developed for individual building components that lead to greater energy efficiency than those in the baseline building design, such as increased insulation levels or more efficient HVAC equipment. For a given building design, the LCIA for each energy efficiency-related building component is added to the baseline building design LCIA, including initial construction and any maintenance, repair, or replacement of those building components. The operational energy LCIA calculations combine the consumption estimates using the whole building energy simulation results and location-specific source LCIAs for each fuel type. The total LCIAs for a building are the summation of the baseline, building component, and operational energy-related LCIAs over the study period. This chapter discusses the development of the LCIA data used in BIRDS.

\subsection{Baseline Building LCIA data}

BIRDS uses environmentally-extended I-O tables for the U.S. construction industry developed under contract to NIST by Industrial Ecology Research Services of Goleta, California. The "top-down" inventory data is based on the 2007 release of the 2002 BEA I-O data (newest available at the time of development) quantifying 6204 environmental inputs and outputs occurring throughout production supply chains for the construction sector, which was disaggregated into building type-specific flows per dollar of expenditure for construction, maintenance, and repair (Lippiatt, Kneifel et al. 2013). The environmentally extended I-O tables classify U.S. construction into 42 distinct industry outputs. Given that the initial version of BIRDS NEST only allows for single-family dwelling LCIA estimates, the two residential construction industry outputs shown in Table 3-1 are the only two currently used. The first output corresponds to new residential construction. The second corresponds to maintenance and repair (M\&R) activities in residential buildings. For both construction industry outputs, the baseline top-down inventory data are expressed in terms of life-cycle environmental flows per dollar of construction. For more information on the mathematics, accounting structure, and stepby-step process under which the BIRDS hybrid environmental database is built, see Suh and Lippiatt (2012). 
Table 3-1 Construction Industry Outputs Mapped to BIRDS Building Types

\begin{tabular}{|l|l|}
\hline Construction Type & \multicolumn{1}{|c|}{ Industry Output } \\
\hline New Construction & New Residential Construction \\
\hline M\&R Construction & Residential maintenance and repair construction \\
\hline
\end{tabular}

One advantage of the BIRDS approach is the economic dimension built into the top-down inventory data. These data are directly associated with U.S. economic data, permitting seamless integration of the economic dimension in the BIRDS sustainability measurement system. The top-down inventory values on a per-dollar basis are multiplied by the corresponding BIRDS construction, maintenance, and repair costs to translate them into the LCA functional unit representing the whole-building over a user-defined study period.

The baseline construction costs are calculated based on national average cost of construction per unit of finished floor area for the assumed number of stories, construction quality, and wall/framing type for residential new construction using RSMeans Square Foot Cost Estimator (SFCE) (RS Means 2017). National average cost data is used because the LCIA data is based on national average environmental I-O data. A screenshot of the SFCE is shown in Figure 3-1. Two levels of construction quality (average and luxury) - based on architectural design and interior finishes - are considered in this initial version of the BIRDS NEST. 


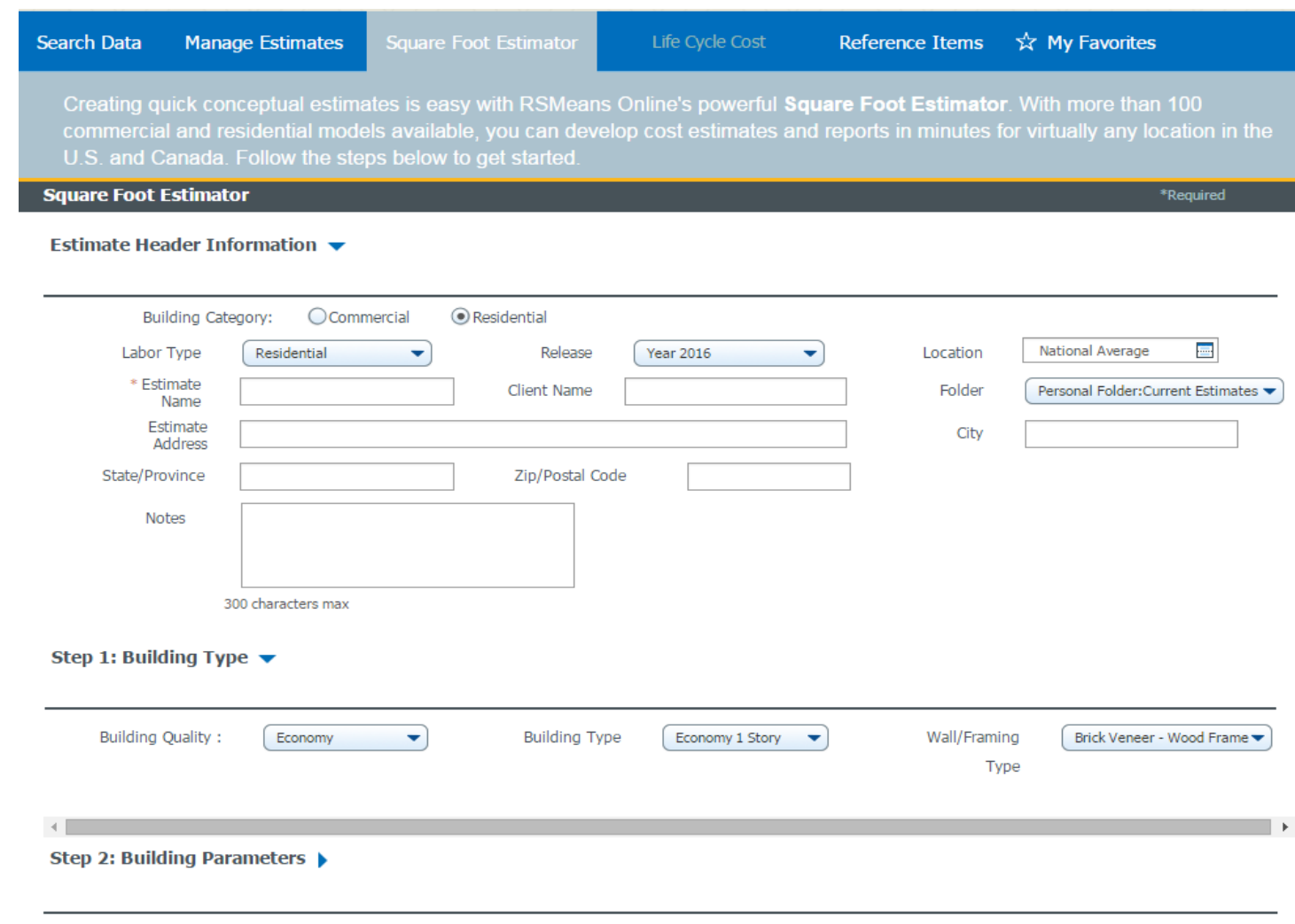

Step 3: Building Additives (optional) •

Calculate Building cost

Figure 3-1 RS Means Online Square Foot Cost Estimator (SFCE)

Incremental national average cost data from Faithful+Gould (2012) for each building component related to energy efficiency subtracted from the baseline building costs to estimate the baseline construction costs for which to use in estimating the baseline building LCIAs. ${ }^{2}$ The costs of up to 8 building components are necessary to subtract from the construction costs: attic insulation, exterior wall framing and insulation, foundation insulation, air leakage sealant, windows, lighting, domestic hot water heater (DHWH), and HVAC equipment.

$$
\begin{aligned}
& C_{B}=\left(C_{F F A}\right) * F F A_{B}-\left[\left(C_{\text {Wall }}\right)+\left(C_{\text {Attic }}\right)+\left(C_{\text {Foundation }}\right)+\left(C_{\text {Sealant }}\right)+\right. \\
& \left.\left(C_{\text {Window }}\right)+\left(C_{\text {Lighting }}\right)+\left(C_{D H W H}\right)+\left(C_{H V A C}\right)\right] \\
& \text { Where } C_{B}=\text { Baseline construction costs } \\
& C_{F F A}=\text { Building construction costs per unit of floor area } \\
& F_{F} \quad=\text { Finish Floor Area } \\
& C_{\text {Wall }} \quad=\text { Wall framing and insulation costs } \\
& C_{\text {Attic }}=\text { Attic insulation costs }
\end{aligned}
$$

\footnotetext{
${ }^{2}$ National average cost data is used because the LCIA data is based on national average environmental I O data.
} 


$\begin{array}{ll}C_{\text {Foundation }} & =\text { Foundation costs } \\ C_{\text {Sealant }} & =\text { Air sealing costs } \\ C_{\text {Window }} & =\text { Window costs } \\ C_{\text {Lighting }} & =\text { Lighting costs } \\ C_{D H W H} & =\text { DHWH costs } \\ C_{H V A C} & =H V A C \text { system costs }\end{array}$

To estimate the costs of each building component that need to be subtracted from the total initial construction costs to calculate the baseline costs for the baseline LCIA estimates, it is necessary to identify the characteristics of the building components included in the baseline building costs. Table 3-2 shows the baseline building components that are considered "typical" in states with no state building energy code. Once $C_{B}$ is calculated, it can be multiplied by the flow per dollar of expenditure for each environmental impact category (i) to get the baseline building LCIAs for a given building “B” $\left(L C I A_{B, i}=C_{B} * F_{B, i}\right)$.

\section{Table 3-2 Baseline Building Assumptions}

\begin{tabular}{|c|c|c|}
\hline \multicolumn{2}{|r|}{ Building Component } & Baseline \\
\hline \multirow[t]{2}{*}{ Exterior Wall } & Framing & $\begin{array}{c}5 \mathrm{~cm} \times 10 \mathrm{~cm}-41 \mathrm{~cm} \text { on center (OC) } \\
(2 \text { in } \mathrm{x} 4 \text { in }-16 \text { in OC) }\end{array}$ \\
\hline & Insulation & $\mathrm{R}_{\mathrm{SI}}-2.3$ (R-13) in Cavity \\
\hline \multirow[t]{2}{*}{ Basement Wall } & Wall & $\mathrm{R}_{\mathrm{SI}}-0(\mathrm{R}-0)$ \\
\hline & Slab & $\mathrm{R}_{\mathrm{SI}}-0(\mathrm{R}-0)$ \\
\hline \multirow[t]{2}{*}{ Attic } & Roof & $\mathrm{R}_{\mathrm{SI}-}-0$ (R-0) \\
\hline & Ceiling & $\mathrm{R}_{\mathrm{SI}}-5.3(\mathrm{R}-30)$ \\
\hline \multirow{2}{*}{ Windows } & U-factor* & $6.84(1.2)$ \\
\hline & Solar Heat Gain Coefficient (SHGC) & No Requirement \\
\hline Air Exchange Rate & Air Changes per Hour at $50 \mathrm{~Pa}\left(\mathrm{ACH}_{50}\right)$ & 7.0 \\
\hline Lighting & Fraction Efficient & Typical \\
\hline \multirow[t]{2}{*}{ Heating and Cooling } & System & 3 Ton Heat Pump \\
\hline & Efficiency & SEER 13 / HSPF 7.7** \\
\hline \multicolumn{2}{|l|}{ Mechanical Ventilation } & No Requirement \\
\hline Water Heater & Efficiency & 0.90 \\
\hline
\end{tabular}

\subsection{Energy LCIA data}

Energy LCIA data is developed using a process-based approach. The electricity production inventory data is applied to a building's consumption and production of electricity to convert site flows to source flows, which are customized to each U.S. state using 2008 eGRID average source emissions data from North American Electric Reliability Corporation (NERC) subregions while data for specific fuel use/combustion in a utility originates from the U.S. LCI database. Natural gas LCIA $\left(L C I A_{G a s}\right)$ are based on 
national average source production inventory data because the impacts associated with the burning of a unit of natural gas is relatively constant regardless of the location at which it is consumed.

Total operating energy-related LCIA ( $L C I A_{\text {Energy, }}$ ) for each environmental impact category ( $i$ ) over study period " $T$ ” for a building are estimated using the following formula where $E C_{t}$ is electricity consumption in year $t, E P_{t}$ is electricity production in year $t$, and $G C_{t}$ is natural gas consumption in year $t, L C I A_{G a s, i}$ is the natural gas LCIA for impact category $i$, and $L C I A_{E l e c t, i}$ is the electricity LCIA for impact category $i$ :

$$
L C I A_{\text {Energy }, i}=\sum_{1}^{T}\left(\left(E C_{t}-E P_{t}\right) * L C I A_{E l e c t, i}+G C_{t} * L C I A_{G a s, i}\right)
$$

On-site electricity production from solar photovoltaics is assumed to offset the equivalent consumption-related emissions. Solar photovoltaic production is assumed to degrade at an annual rate of $0.5 \%\left(E P_{t-1}=E P_{t} *(1-0.05)\right)$ while electricity and natural gas consumption is assumed constant $\left(E C_{1}=E C_{2}=\cdots=E C_{T}\right.$ and $\left.G C_{1}=G C_{2}=\cdots=G C_{T}\right)$.

\subsection{Residential Energy Technology LCIA Data}

Since buildings have very long lives, operating energy efficiency has an important influence on their sustainability performance. Energy efficiency is largely driven by a building's energy technologies, but top-down inventory data are not readily available at this level of resolution. Therefore, BIRDS NEST includes detailed LCI data for a range of energy technology packages that have been compiled at the traditional, bottom-up LCA level. Energy technologies include wall framing and insulation, attic (ceiling and roof) insulation, windows, heating, ventilation, and air-conditioning (HVAC) equipment, water heaters, lighting, and interior and exterior sealants, solar thermal systems, and solar photovoltaics.

\subsubsection{General Information Regarding the Energy Technology LCIs}

\subsubsection{Standards Used}

The LCAs in BIRDS NEST have been built based on the principles and framework in the International Organization for Standardization (ISO) (2006a) and the guidelines specified in International Organization for Standardization (ISO) (2006b).

\subsubsection{Primary and Secondary Data Sources}

Both primary data (collected directly from a manufacturing facility) and secondary data (publicly-available literature sources) can be used to build LCAs, and it is common to see a combination of both data types based on the level of disclosure organizations or companies prefer related to the information pertaining to their products. Sources of data on the energy technologies in BIRDS NEST vary from one category to the next, and 
within categories themselves for the different products. Data were based on one or more of the following:

- Primary data from a group of companies and/or an industry association, compiled into an industry average product;

- Primary data on a product provided by one company;

- Secondary data that represent an average or typical product; and/or

- Secondary data that represent one product in a category.

For optimal data quality, the preference is to have the most representative data temporally, technologically, and geographically - on a product or system, so that the model produced most closely represents the product. But this is often not possible to achieve due to data constraints. It is also not always possible to have a data set that represents an entire category of products. For example, high quality, current, companyspecific data might be collected and used to build the LCA for a given product. Likewise, data for another product might be compiled from literature sources due to lack of other available data. In both cases, the LCI profiles may be used to represent the full product category, even though they may not be representative of all products within the category, based on market share, technology, geographical location, etc. The user should be aware of this limitation.

\subsubsection{Data Sources Used for the Background Data}

Secondary data have been applied to production of material inputs, production and combustion of fuels used for process energy, and transportation processes. The U.S. LCI Database (National Renewable Energy Laboratory (NREL) 2012) and the ecoinvent v.2.2 database (Ecoinvent 2007) are the main sources of background data throughout the various life-cycle stages. Other sources of data were used where data were not available from the U.S. LCI Database or ecoinvent, and/or where they were deemed to be of better quality than these sources.

The following subsections describe modeling, assumptions, and data sources of the product life-cycle data. Data to produce material inputs for each product are described in the subchapters since these may vary for different industries. The following data aspects are consistent for all products except where noted differently in the subchapters:

- All energy production, including production of fuels and conversion into energy and electricity production come from the U.S. LCI Database.

- All transportation data come from the U.S. LCI Database.

- Whenever possible, where ecoinvent or other non-North American data sets were used, they were customized into North American processes by switching out foreign energy, electricity, transportation, and other processes for comparable North American based data sets from the U.S. LCI databases. Exceptions to this are noted. 
- Data for parts forming (e.g., forming of metal parts and pieces, injection molding of plastic parts, etc.), are modeled with raw materials production. Most of these data come from ecoinvent.

\subsubsection{Framing}

BIRDS includes two types of wood framing: the typical $5.1 \mathrm{~cm} \mathrm{x} 10.2 \mathrm{~cm}$ (2 in x 4 in) $40.6 \mathrm{~cm}$ (16 in) on center (OC) used in residential construction and "advanced framing" technique with $5.1 \mathrm{~cm} \mathrm{x} 15.2 \mathrm{~cm}$ (2 in x 6 in) $61.0 \mathrm{~cm}$ (24 in) OC. Wood framing is the most common structural system used for non-load-bearing and load-bearing interior and exterior walls, and consists of lumber and specific applications of treated lumber. The load-bearing walls support floors, ceilings, roof and lateral loads, and nonbearing walls carry only their own weight. Interior walls can be either non-load bearing or load bearing, whereas all exterior walls should be considered load bearing. Exterior walls are comprised of one or two top and bottom plates and vertical studs. Sheathing or diagonal bracing ensures lateral stability. When the wall is on a concrete foundation or slab, building codes require that the sill or sole plate (also called bottom plate) that is in contact with the concrete must be treated wood.

In general, dimensions for framing lumber are given in nominal inches, but the actual dimensions are $3.8 \mathrm{~cm}$ x $8.9 \mathrm{~cm}$ (1.5 in x 3.5 in) and 3.8 x $14 \mathrm{~cm}$ ( 1.5 x 5.5 in), respectively. The reference flow for the framing is $0.09 \mathrm{~m}^{2}\left(1 \mathrm{ft}^{2}\right)$ of framing on a load-bearing exterior wall. The wood-framed walls consist of wood studs placed $41 \mathrm{~cm}$ (16 in) on center and $61 \mathrm{~cm}$ (24 in) on center for the $5.1 \mathrm{~cm} \mathrm{x} 10.2 \mathrm{~cm}$ (2 in x 4 in) and $5.1 \mathrm{~cm} \times 15.2 \mathrm{~cm}$ (2 in x 6 in), respectively. While an exterior wall is constructed as an assembly with sheathing components and insulation, only the framing material is described here; the remaining exterior wall parts of the assembly are included in the homes' full life cycles within BIRDS.

Wood studs are produced in a sawmill, where harvested wood is debarked and sawn into specific dimensions. The lumber is dried in a controlled environment until the desired moisture content (between $12 \%$ and $19 \%$ ) is reached. Framing lumber may be treated with preservatives to guard against insect attack or fungal decay. Treated lumber is used for any application where wood is in contact with concrete or the ground. All wood, including framing, used in places with serious termite problems, such as in Hawaii, must be treated (AF \& PA 2001). For BIRDS, an assumed 25\% of framing lumber has been treated.

Figure 3-2 presents the general system boundaries for wood framing as it is modeled for BIRDS. 


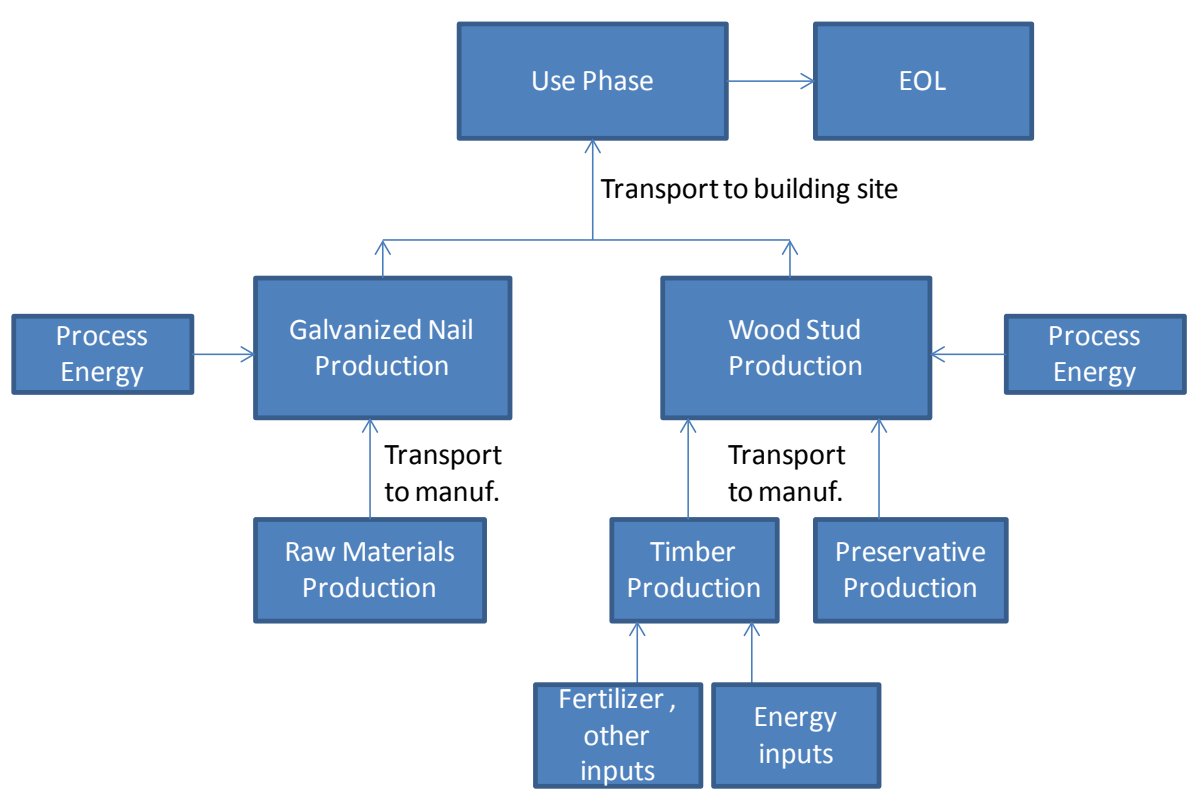

Figure 3-2 Framing System Boundaries

\subsubsection{Upstream Materials Production through Manufacturing}

\subsection{Forest Processes}

Harvested trees are used to produce the dimension lumber necessary for framing loadbearing walls. The lumber is assumed to be produced primarily in the Pacific Northwest (PNW) and the Southeastern United States (SE). For PNW the species of wood used are Douglas Fir (22 \%) and Western Hemlock (78 \%) (CORRIM, 2013a). In the SE, the wood species is Southern Yellow Pine, which is a group of six different softwood species.

The data to grow and harvest softwood logs for a composite forest management scenario for PNW and SE are found in CORRIM (2013a, 2013b). The growing and harvesting of wood includes a mix of low-, medium-, and high-intensity managed timber. In the PNW, $42 \%$ of the lands were classified in the lowest site productivity/ management intensity class, $46 \%$ in the middle class, and $12 \%$ in the highest management intensity class (CORRIM, 2013a). In the SE, $37 \%$ of the lands were classified in the lowest site productivity/ management intensity class, $58 \%$ in the middle class, and $5 \%$ in the highest management intensity class CORRIM (2013a, 2013b). Section 3.3.1 provides detailed data on forestry operations, including growing seedlings, planting, thinning, fertilization (where applicable) and final harvest. Energy use for wood production includes electricity for greenhouses to grow seedlings, gasoline for chain saws, diesel fuel for harvesting mechanical equipment, and fertilizer (when applicable). Table 3-3 summarizes the fuel consumption modeled for the PNW and SE forest resource management processes. (CORRIM, 2013a, Table 4; CORRIM 2013b, Table 4) 
Table 3-3 Fuel Consumption for Forest Resource Management Processes

\begin{tabular}{|c|c|c|c|}
\hline Description & Unit & $\begin{array}{l}\text { Per m3 } \\
\text { (PNW) }\end{array}$ & $\begin{array}{c}\text { Per m3 } \\
\text { (SE) }\end{array}$ \\
\hline \multicolumn{4}{|c|}{ Seedling, site prep, plant, pre-commercial thinning } \\
\hline Diesel and gasoline & $\mathrm{L}$ & 0.088 & 0.515 \\
\hline Lubricants & $\mathrm{L}$ & 0.002 & 0.009 \\
\hline Electricity & $\mathrm{kWh}$ & 0.107 & 0.455 \\
\hline \multicolumn{4}{|c|}{ Commercial thinning and final harvest } \\
\hline Diesel & $\mathrm{L}$ & 2.85 & 2.93 \\
\hline Lubricants & $\mathrm{L}$ & 0.051 & 0.05 \\
\hline \multicolumn{4}{|c|}{ Total forest extraction process } \\
\hline Diesel and gasoline & $\mathrm{L}$ & 2.94 & 3.44 \\
\hline Lubricants & $\mathrm{L}$ & 0.053 & 0.054 \\
\hline Electricity & $\mathrm{kWh}$ & 0.107 & 0.455 \\
\hline
\end{tabular}

Emissions associated with production and combustion of gasoline and diesel fuel, and those for the production and delivery of electricity, are based on the U.S. LCI Database. Fertilizer production data comes from the U.S. LCI Database (for nitrogen- and phosphorus-based) and ecoinvent (for potassium-based fertilizer). Electricity use for greenhouse operation is based on the grids for the regions where the seedlings are grown, while the U.S. average electricity grid is used for fertilizer production. The weight of wood harvested for lumber is based on an average oven-dry density of $450 \mathrm{~kg} / \mathrm{m}^{3}(28.1$ $\mathrm{lb} / \mathrm{ft}^{3}$ ) for the PNW and $510 \mathrm{~kg} / \mathrm{m}^{3}$ (31.8 lb/ft ${ }^{3}$ ) for the SE (CORRIM 2013a, 2013b).

The framing model in BIRDS accounts for the absorption of carbon dioxide by trees as they grow since the product is long-life; the carbon becomes part of the wood, and the oxygen is released to the atmosphere. The "uptake" of carbon dioxide from the atmosphere during the growth of timber comes to $829 \mathrm{~kg}$ (8 $126 \mathrm{lb}$ ) of carbon dioxide per $1 \mathrm{~m}^{3}$ (35.3 ft3) lumber. (CORRIM, 2013a, Table 18)

\subsection{Treating Wood}

Wood is put into a vacuum chamber where air is removed from the wood cells. Preservative is pumped into the chamber, and with the pressure in the chamber raised, the preservative is forced into the wood. At the end of the treatment, a vacuum removes excess preservative from wood cells. The retention rate is the amount of preservative left in the wood. No data were readily available to model this process, except for the upstream production data for alkaline copper (ACQ).

The treated wood has been modeled as treated with ACQ quaternary (quat), a dissolved copper-based preservative that is $66.7 \%$ copper oxide and $33.3 \%$ quat as didecyldimethylammonium chloride (DDAChloride) (AWPA P5-09, 2010, Sec.14). The treated wood is assumed to have an ACQ retention of $2.40 \mathrm{~kg} / \mathrm{m}^{3}\left(0.15 \mathrm{lb} / \mathrm{ft}^{3}\right)$ (SFPA, 2014, Table 3-2). The copper component is dissolved in ethanolamine at 2.75 parts ethanolamine, by weight, for each part copper oxide, and the DDAC is shipped separately 
and mixed during the treating process. For one $\mathrm{kg}$ (one lb) ACQ, the formulation uses $0.67 \mathrm{~kg}(0.67 \mathrm{lb})$ copper oxide, $0.33 \mathrm{~kg}(0.33 \mathrm{lb})$ quat, and $1.83 \mathrm{~kg}(1.83 \mathrm{lb})$ ethanolamine (TWC, 2011, Sec. 4.2.3). Based on their research and sources within the industry, much of the copper used in the ACQ is recycled or reclaimed scrap or off-specification copper; TWC (2011, Sec. 4.2.3) makes the assumption that one-third of the copper is virgin and two-thirds are recycled or reclaimed, and the same assumption was made for BIRDS. The data used for copper oxide comes from ecoinvent. The data for ethanolamine come from ecoinvent, as monoethanolamine. For lack of better available data, proxy data was used to represent didecyldimethyl ammonium chloride; ecoinvent's ammonium chloride was used.

\subsection{Transportation and Manufacturing}

Sawmills are often located close to tree harvesting areas. For transportation of logs to the sawmill in the PNW, Consortium for Research on Renewable Industrial Materials (CORRIM) surveys reported an average truck transportation distance of $113 \mathrm{~km}$ (70 mi) for harvested wood, and for the SE this distance is $92 \mathrm{~km}$ (57 mi) (CORRIM, 2011a, 2011b). The delivery distances are one-way with an empty backhaul. For preservativetreated lumber, truck transportation of $322 \mathrm{~km}(200 \mathrm{mi})$ is assumed for transport of the preservative.

The weight of wood shipped includes its moisture content. For the shipping weight of the SE lumber, for example, the oven-dry density of $510 \mathrm{~kg} / \mathrm{m}^{3}\left(31.8 \mathrm{lb} / \mathrm{ft}^{3}\right)$, plus a moisture content of $19 \%$ (an additional $97 \mathrm{~kg}$ of water), yields a shipping weight of $607 \mathrm{~kg} / \mathrm{m}^{3}$ $\left(37.9 \mathrm{lb} / \mathrm{ft}^{3}\right)$. The ACQ-treated lumber is usually shipped green, so $40 \%$ to $60 \%$ moisture content is assumed.

CORRIM (2013a, 2013b) Section 3.3.2 provides the detailed data on wood product manufacturing that were included in the BIRDS model, including: sawing logs into rough-green lumber; kiln drying rough-green lumber to produce rough dry softwood lumber; planing rough, dry lumber to produce planed dry softwood lumber, and packaging the final lumber product. Allocations of the main products and coproducts were made on a mass allocation basis. The interested reader is encouraged to go to CORRIM (2013a, 2013b) for the detailed unit process data and a description of woodburning energy use, emissions, and modeling methodology.

\subsubsection{Transportation to the Building Site through End of Life}

Transportation of wood framing by heavy-duty truck to the building site is modeled using $1207 \mathrm{~km}$ (750 mi). Data come from the U.S. LCI Database.

Installation of wood framing is assumed to be done primarily by manual labor, so there are no assumed installation emissions. ${ }^{3}$ Wood studs are placed $41 \mathrm{~cm}$ (16 in) on center for the 2x4 boards or $61 \mathrm{~cm}$ (24 in) on center for the $5.1 \mathrm{~cm} \mathrm{x} 15.2 \mathrm{~cm}$ (2 in x 6 in) boards and are fastened with approximately $0.04 \mathrm{~kg}(0.09 \mathrm{lb})$ of galvanized steel nails.

\footnotetext{
${ }^{3}$ Emissions from construction power tools (e.g. nail guns) are considered negligible.
} 
Production data for galvanized steel come from World Steel Association (2011). At installation, $5 \%$ of the product is lost to waste, and it is disposed of in a landfill.

CORRIM (2004) assumes a lifetime of 75 years for the residential shell, including wood framing, but acknowledges that the life “probably exceeds 85 years” (CORRIM, 2004 and Lippke, 2004). To be conservative, 75 years is assumed. No routine maintenance for the framing is modeled for BIRDS; the building envelope (roof and siding) should be maintained to ensure water tightness and prevent water damage to the shell.

All the wood framing is assumed to be disposed of in landfill at the end of life. End-of-life modeling includes transportation by diesel-fuel powered truck approximately $80 \mathrm{~km}$ (50 mi) to a construction \& demolition landfill. The landfill model is based on ecoinvent end of life waste management process data.

\subsubsection{Wall and Ceiling Insulation}

The insulation categories considered for the residential walls and ceilings are presented in Table 3-4. BIRDS performance data for the insulation types were provided based on 2.54 $\mathrm{cm}$ ( 1 in) or $0.09 \mathrm{~m}^{2}\left(1 \mathrm{ft}^{2}\right)$, which was then multiplied by the area and required thickness to meet the requirements of the home's design and energy code edition. Table 3-4 presents the thermal resistance in $\mathrm{R}_{\mathrm{SI}}$-value per-cm (R-value per in) for each.

\section{Table 3-4 Specified Insulation Types and R-Values}

\begin{tabular}{|c|c|c|}
\hline Insulation Type & 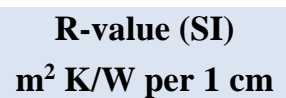 & $\begin{array}{c}\text { R-value (IP) } \\
\mathrm{ft}^{2}{ }^{\circ} \mathbf{F} \mathbf{h r} / \text { Btu per } 1 \text { in }\end{array}$ \\
\hline Kraft faced fiberglass blanket $-\mathrm{R}_{\mathrm{SI}}-2.3$ (R-13) & 0.26 & $\mathrm{R}-3.7$ \\
\hline Kraft faced fiberglass blanket - $\mathrm{R}_{\mathrm{SI}}-3.4$ (R-19) & 0.21 & $\mathrm{R}-3.0$ \\
\hline Blow-in cellulose - $\mathrm{R}_{\mathrm{SI}}-2.3$ (R-13) & 0.26 & R-3.7 \\
\hline Blow-in cellulose - RsI-6.7 (R-38) & 0.25 & R-3.5 \\
\hline Spray polyurethane foam (open cell) & 0.25 & R-3.6 \\
\hline Spray polyurethane foam (closed cell) & 0.42 & R-6.2 \\
\hline Mineral wool blanket - $\mathrm{R}_{\mathrm{SI}}-2.6(\mathrm{R}-15)^{\text {Note }} 1$ & 0.30 & $\mathrm{R}-4.3$ \\
\hline Mineral wool blanket - $\mathrm{R}_{\mathrm{SI}}-4.1$ (R-23) ${ }^{\text {Note }} 1$ & 0.30 & $\mathrm{R}-4.2$ \\
\hline Extruded polystyrene (XPS) foam board & 0.35 & $\mathrm{R}-5.0^{\text {Note } 2}$ \\
\hline Polyisocyanurate foam board & 0.46 & R-6.5 \\
\hline \multicolumn{3}{|c|}{$\begin{array}{l}\text { Note 1: Thermal resistance values } \mathrm{R}_{\mathrm{SI}}-2.3(\mathrm{R}-13) \text { and } \mathrm{R}_{\mathrm{SI}}-3.4 \text { (R-19) are used for BIRDS wall insulation; } \\
\text { mineral wool blankets have been modeled per R-values more commonly offered for this insulation } \\
\text { material (i.e., } \mathrm{R}_{\mathrm{SI}}-2.6(\mathrm{R}-15) \text { and } \mathrm{R}_{\mathrm{SI}}-4.1 \text { (R-23)). For BIRDS, the data have been normalized to } \mathrm{R}_{\mathrm{SI}}-2.3 \\
\text { (R-13) and } \mathrm{R}_{\mathrm{SI}}-3.4 \text { (R-19). } \\
\text { Note 2: See the XPS foam documentation (Section 3.3.3.5) regarding the increase of thermal resistance } \\
\text { with increasing foam thickness. }\end{array}$} \\
\hline
\end{tabular}

Figure 3-3 presents the general system boundaries for the insulation category as it is modeled for BIRDS. 


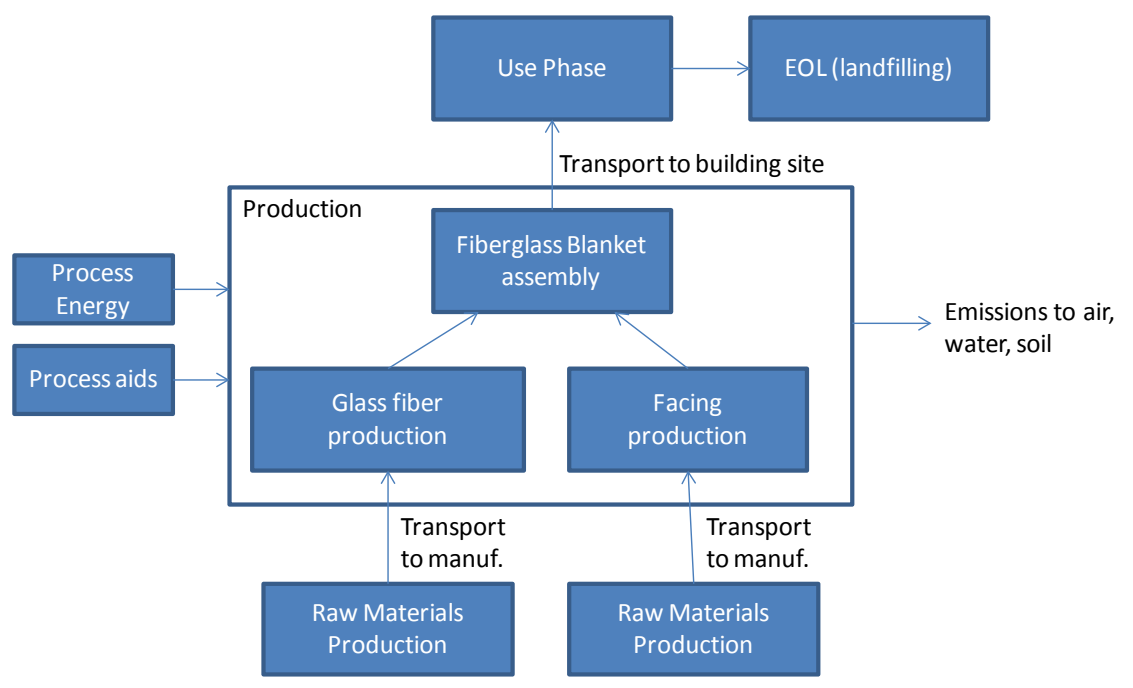

Figure 3-3 Insulation System Boundaries - Fiberglass Blanket Example

The modeling and assumptions for each type of insulation are presented in the following sections.

\subsubsection{Fiberglass Blanket}

Fiberglass blanket, or batt, insulation is made by forming spun-glass fibers into batts. At an insulation plant, the product feedstock is weighed and sent to a melting furnace. The raw materials are melted in a furnace at very high temperatures. Streams of the resulting vitreous melt are either spun into fibers after falling onto rapidly rotating flywheels or drawn through tiny holes in rapidly rotating spinners. This process shapes the melt into fibers. Glass coatings are added to the fibers that are then collected on conveyers. The structure and density of the product is continually controlled by the conveyer speed and height as it passes through a curing oven. The cured product is then sawn or cut to the required size. Off-cuts and other scrap material are recycled back into the production process.

Thermal resistance values of $\mathrm{R}_{\mathrm{SI}}-2.3(\mathrm{R}-13)$ and $\mathrm{R}_{\mathrm{SI}}-3.4$ (R-19) are used for wall insulation, and Table 3-5 specifies fiberglass insulation by type and R-value. Most of the fiberglass insulation data is based on the model presented in the online documentation of the BEES software (NIST 2010). 
Table 3-5 Fiberglass Blanket Mass by Application

\begin{tabular}{|c|c|c|c|c|c|}
\hline Application & $\begin{array}{l}\text { Thickness } \\
\text { cm (in) }\end{array}$ & $\begin{array}{c}\text { Density } \mathbf{k g} / \mathrm{m}^{3} \\
\left(\mathbf{l b} / \mathbf{f t}^{3}\right)\end{array}$ & $\begin{array}{l}\text { Mass per } 1 \text { in } \\
\text { Functional Unit } \\
\text { kg/m } \mathbf{m}^{2}\left(\mathrm{oz} / \mathrm{ft}^{2}\right)\end{array}$ & $\begin{array}{c}\text { R-Value per } \\
\text { Reference Flow } \\
\left(\mathbf{m}^{2} \mathrm{~K} / \mathrm{W} \text { per } 1 \mathrm{~cm}\right)\end{array}$ & $\begin{array}{c}\text { R-Value per } \\
\text { Reference Flow } \\
\left(\mathrm{ft}^{2}{ }^{\circ} \mathrm{F} \text { hr/Btu per } 1 \text { in }\right)\end{array}$ \\
\hline $\begin{array}{l}\text { Wall - R RI-2.3 } \\
\text { (R-13) }\end{array}$ & $8.9(3.5)$ & $12.1(0.76)$ & $0.31(1.01)$ & R-0.26 & R-3.7 \\
\hline $\begin{array}{l}\text { Wall - R } \mathrm{R}_{\mathrm{SI}}-3.4 \\
\text { (R-19) }\end{array}$ & $15.9(6.25)$ & $7.0(0.44)$ & $0.18(0.58)$ & R-0.21 & R-3.0 \\
\hline
\end{tabular}

\subsection{Upstream Materials Production through Manufacturing}

Fiberglass insulation is made with a blend of sand, limestone, soda ash, and recycled glass cullet. Recycled window, automotive, or bottle glass is used in the manufacture of glass fiber; it accounts for $30 \%$ to $50 \%$ of the raw material input. The recycled content is limited by the amount of usable recycled material available in the market - not all glass cullet is of sufficient quality to be used in the glass fiber manufacturing process. The use of recycled material has helped to steadily reduce the energy required to produce insulation products. The raw materials used to produce fiberglass insulation are broken down by the glass and facing contents, shown in Table 3-6.

\section{Table 3-6 Fiberglass Insulation Constituents}

\begin{tabular}{lc} 
Glass Constituent & Mass Fraction (\%) \\
\hline Soda Ash & 9.0 \\
Borax & 12.0 \\
Glass Cullet & 34.0 \\
Limestone & 9.0 \\
Phenolic resin (binder coating) & 5.0 \\
Sand & 31.0 \\
Total & $\mathbf{1 0 0}$ \\
Facing & Mass Fraction (\%) \\
Kraft paper & 25.0 \\
Asphalt & 75.0 \\
Total & $\mathbf{1 0 0}$ \\
\hline
\end{tabular}

The production data for the soda ash, limestone, and phenol formaldehyde resin come from the U.S. LCI Database. The borax, glass cullet, and silica sand data come from ecoinvent. For the facing, Kraft paper data come from ecoinvent and the asphalt data come from U.S. LCI Database.

The raw materials are transported to the manufacturing plant via diesel truck. Materials are sourced domestically, and transportation distances range on average from $161 \mathrm{~km}$ (100 mi) to $805 \mathrm{~km}$ (500 mi). 
The energy requirements for melting the glass constituents into fibers and drying off the completed blanket involve use of natural gas and electricity, shown in Table 3-7.

\section{Table 3-7 Energy Requirements for Fiberglass Insulation Manufacturing

$\begin{array}{lc}\text { Energy Carrier } & \text { MJ/kg (Btu/lb) } \\ \text { Natural Gas } & 1.99(857) \\ \text { Electricity } & 1.37(591) \\ \text { Total } & \mathbf{3 . 3 6}(\mathbf{1 4 4 8})\end{array}$

Besides combustion emissions from fuel usage at manufacturing, particulates are emitted at a rate of $2.38 \mathrm{~g} / \mathrm{kg}$ (4.76 lb/ton) of bonded blankets and volatile organic compounds (VOCs) are emitted at a rate of $0.76 \mathrm{~g} / \mathrm{kg}(1.52 \mathrm{lb} / \mathrm{ton})$ of bonded blankets.

All waste produced during the cutting and blending process is either recycled into other insulation materials or added back into the glass mix. Thus, no solid waste is assumed to be generated during the production process.

\subsection{Transportation to the Building through End-of-Life}

Transportation of the insulation from the manufacturer to the building site is assumed to be an average of $805 \mathrm{~km}$ (500 mi) by heavy-duty diesel-fueled truck.

Installing fiberglass blanket insulation is primarily a manual process, with no energy or emissions included in the model. During installation, any waste material is added into the building shell where the insulation is installed - there is effectively no installation waste.

Fiberglass insulation has a functional lifetime of over 50 years so no replacement is needed during the 40-year study period. How this product affects operating energy during the home's use phase is addressed in other sections of this report.

While fiberglass insulation is recyclable, it is assumed that it is disposed of in a landfill at end-of-life. End-of-life modeling includes transportation by heavy-duty diesel-fuel powered truck approximately $80 \mathrm{~km}$ (50 mi) to a construction and demolition (C\&D) landfill. Landfilled insulation is modeled based on ecoinvent end-of-life waste management process data.

\subsubsection{Blown Cellulose Insulation}

Thermal resistance values of $\mathrm{R}_{\mathrm{SI}}-3.4$ (R-13) for a wall application and $\mathrm{R}_{\mathrm{SI}}-6.7$ (R-38) for a ceiling application of blown cellulose have been used in BIRDS. The models for BIRDS are largely based on the blown cellulose in NIST (2010). Table 3-8 specifies blown cellulose insulation by type and R-value. 
Table 3-8 Blown Cellulose Insulation by Application

\begin{tabular}{|c|c|c|c|c|c|}
\hline Application & $\begin{array}{c}\text { Thickness } \\
\text { cm (in) }\end{array}$ & $\begin{array}{l}\text { Density } \\
\mathbf{k g} / \mathbf{m}^{3} \\
\left(\mathbf{l b} / \mathbf{f t}^{3}\right)\end{array}$ & $\begin{array}{l}\text { Mass per } 1 \text { in } \\
\text { Functional Unit } \\
\mathbf{k g} / \mathbf{m}^{2}\left(\mathbf{l b} / \mathbf{f t}^{2}\right)\end{array}$ & $\begin{array}{c}\text { R-Value per } \\
\text { Reference Flow } \\
\left(\mathrm{m}^{2} \mathrm{~K} / \mathrm{W} \text { per } 1\right. \\
\mathrm{cm})\end{array}$ & $\begin{array}{c}\text { R-Value per } \\
\text { Reference Flow } \\
\left(\mathrm{ft}^{2}{ }^{\circ} \mathrm{F} \text { hr/Btu per } 1 \text { in) }\right.\end{array}$ \\
\hline $\begin{array}{l}\text { Wall - RSI-2.3 } \\
\text { (R-13) }\end{array}$ & 8.9 (3.5) & $35.3(2.20)$ & $0.89(0.18)$ & $\mathrm{R}_{\mathrm{SI}-}-0.26$ & R-3.7 \\
\hline $\begin{array}{l}\text { Ceiling - } \mathrm{R}_{\mathrm{SI}^{-}}-6.7 \\
\text { (R-38) }\end{array}$ & $\begin{array}{c}27.6 \\
(10.9)\end{array}$ & $27.2(1.70)$ & $0.69(0.14)$ & $\mathrm{R}_{\mathrm{SI}}-0.24$ & R-3.5 \\
\hline
\end{tabular}

\subsection{Upstream Materials Production through Manufacturing}

Cellulose insulation is essentially shredded, recovered wastepaper that is coated with fire retardants. Blown cellulose insulation is produced primarily from post-consumer wood pulp (newspapers), typically accounting for roughly $85 \%$ of the insulation by weight. Ammonium sulfate, borates, and boric acid are the fire retardants used most commonly and account for the other $15 \%$ of the cellulose insulation by weight. The mix of these materials is provided in Table 3-9; while the relative proportions of the fire retardants vary among manufacturers, it is assumed that they are mixed in equal proportions for BIRDS.

\section{Table 3-9 Cellulose Insulation Constituents}

\begin{tabular}{lc} 
Constituent & Mass Fraction (\%) \\
Recovered Newspaper & 85 \\
Ammonium Sulfate & 7.5 \\
Boric Acid & 7.5 \\
Total & $\mathbf{1 0 0}$ \\
\hline
\end{tabular}

BIRDS recovered newspaper data includes impacts from wastepaper collection, sorting, and subsequent transportation to the insulation manufacturer. Since it is a recovered product, the impacts from upstream production of the pulp are not included in the system boundaries. Data for ammonium sulfate and boric acid come from ecoinvent. It is assumed that the raw materials are shipped $161 \mathrm{~km}(100 \mathrm{mi})$ to the manufacturing plant via diesel truck.

The manufacturing process includes shredding the wastepaper and blending it with the different fire retardants. It is assumed that the manufacturing energy is purchased electricity in the amount of $0.35 \mathrm{MJ} / \mathrm{kg}(150 \mathrm{Btu} / \mathrm{lb})$. Any waste produced during the production process is recycled back into other insulation materials. Therefore, no solid waste is generated during the production process.

\subsection{Transportation to the Building Site through End-of-Life}

Transportation of the insulation to the building site is modeled using an assumed average of $805 \mathrm{~km}$ (500 mi) by heavy-duty diesel-fueled truck. 
At installation, a diesel generator is used to blow the insulation material into the space. For one hour of operation, a typical $18 \mathrm{~kW}$ (25 hp) diesel engine can blow $818 \mathrm{~kg}$ (1800 lb) of insulation. The emissions and energy use for this generator are included in the system boundaries for this product. No other installation energy is required. Any waste material during installation is added into the building shell where the insulation is installed, so there is effectively no installation waste.

Cellulose insulation has a functional lifetime of over 50 years so no replacement is needed during the 40-year study period. How this product affects operating energy during the home's use phase is addressed in other sections of this report.

While cellulose insulation is mostly recyclable, it is assumed that all of the insulation is disposed of in a landfill at end-of-life. End-of-life modeling includes transportation approximately $80 \mathrm{~km}(50 \mathrm{mi})$ to a C\&D landfill. Landfilled insulation is modeled based on ecoinvent end-of-life waste management process data.

\subsubsection{Spray Polyurethane Foam Insulation}

Spray polyurethane foam (SPF) is an insulation and roofing material that is formulated at the building installation site using a combination of an isocyanate, or "A-side," with an equal volume of a polyol blend, or "B-side." For SPF, the A-side is a blend of monomeric and polymeric methylene diphenyl diisocyanate (pMDI). The B-side formulation varies based on formulator and desired properties, and includes at least five different types of chemical ingredients: polyols, blowing agents, flame retardants, catalysts, and surfactants. When the A and B side are mixed, it expands in place providing both insulation and an air barrier; some SPF types deliver other performance properties including a vapor retarder, water resistance and structural enhancement.

Two classifications for SPF insulation used in the U.S. construction industry are opencell (low-density) and closed-cell (medium-density) SPF. Open-cell has a nominal density ranging from $6.4 \mathrm{~kg} / \mathrm{m}^{3}$ to $11.1 \mathrm{~kg} / \mathrm{m}^{3}\left(0.4 \mathrm{lb} / \mathrm{ft}^{3}\right.$ to $\left.0.7 \mathrm{lb} / \mathrm{ft}^{3}\right) ; 7.9 \mathrm{~kg} / \mathrm{m}^{3}$ $\left(0.5 \mathrm{lb} / \mathrm{ft}^{3}\right)$ has been assumed for the LCA. Open-cell foam is formed using water as a reactive blowing agent. Water reacts with the A-side methylene diphenyl diisocyanate (MDI) to create carbon dioxide $\left(\mathrm{CO}_{2}\right)$ gas that expands the curing liquid into a cellular foam material. Thermal resistance per inch is in the range of $\mathrm{R}_{\mathrm{SI}}-0.25$ to $\mathrm{R}_{\mathrm{SI}}-0.28$ per cm (R-3.6 to R-4.0 per inch); RsI-0.25 (R-3.6) has been assumed.

Closed-cell foam has a nominal density ranging from 27.0 to $36.5 \mathrm{~kg} / \mathrm{m}^{3}$ (1.7 to 2.3 $\left.\mathrm{lb} / \mathrm{ft}^{3}\right) ; 31.8 \mathrm{~kg} / \mathrm{m}^{3}\left(2.0 \mathrm{lb} / \mathrm{ft}^{3}\right.$ ) has been assumed. Fluorocarbon (physical) blowing agents are used to expand closed-cell foams: the fluorocarbon liquid in the B-side converts to a gas from the heat of the reaction to expand the cells. The low thermal conductivity fluorocarbon gas yields an $\mathrm{R}$-value ranging from $\mathrm{R}_{\mathrm{SI}}-0.07$ to $\mathrm{R}_{\mathrm{SI}}-0.08$ per $\mathrm{cm}(\mathrm{R}-5.8$ to R-6.8 per in); RsI-0.43 (R-6.2) has been assumed. Emissions from the Pentafluoropropane (HFC-245fa) were included in the LCA, and the assumptions around its release are stated later in this documentation. 
The information provided in this summary is based on a comprehensive LCA study on SPF (PE International 2012). The quantitative data come mainly from a Spray Polyurethane Foam Alliance (SPFA) summary report (SPFA 2012) and SPFA's Environmental Product Declaration (EPD), both based on PE International (2012).

\subsection{Upstream Materials Production through Manufacturing}

SPF's A-side is MDI. The B-side is made up of several combinations and types of chemicals. Primary data for the year 2010 were collected from six formulation plants to attain an industry average. Table 3-10 provides the material constituent percentages of the B-side formulations (SPFA 2012). These data are assumed to be representative of SPF in the U.S., based on input and consensus by SPFA members. Nonetheless, these formulations are generic and thus do not represent one specific producer's formulation.

\section{Table 3-10 B-Side Formulation - Material Constituent Percentages}

\begin{tabular}{lcc} 
Constituent & $\begin{array}{c}\text { Low density (open } \\
\text { cell foam) } \%\end{array}$ & $\begin{array}{c}\text { Medium density } \\
\text { (closed cell foam) \% }\end{array}$ \\
\hline Polyol - polyester & $\mathrm{n} / \mathrm{a}$ & 45.0 \\
Polyol - Mannich & $\mathrm{n} / \mathrm{a}$ & 30.0 \\
Polyol - compatibilizer & 10.0 & $\mathrm{n} / \mathrm{a}$ \\
Polyol - polyether & 35.0 & $\mathrm{n} / \mathrm{a}$ \\
Fire retardent - TCPP & 25.0 & 4.0 \\
Fire retardent - brominated & $\mathrm{n} / \mathrm{a}$ & 6.0 \\
Blowing agent - reactive (de-ionized H2O) & 23.5 & 2.0 \\
Blowing agent - physical (HFC-245fa) & $\mathrm{n} / \mathrm{a}$ & 8.5 \\
Catalyst - amine & 6.0 & 3.0 \\
Catalyst - metal & $\mathrm{n} / \mathrm{a}$ & 0.5 \\
Surfactant - silicone & 0.5 & 1.0 \\
Total & $\mathbf{1 0 0}$ & $\mathbf{1 0 0}$ \\
\hline
\end{tabular}

The reference flows used for the original LCA were based on the functional unit defined by UL Environment (2011) Product Category Rules (PCR) on U.S. insulation: one square meter of foam provides an R-value of $1.00 \mathrm{~m}^{2} \mathrm{~K} / \mathrm{W}\left(5.68 \mathrm{~h} \cdot \mathrm{ft}^{2} \cdot{ }^{\circ} \mathrm{F} / \mathrm{Btu}\right)$. The specifications for the original LCA and the BIRDS LCA are shown together in Table 3-11. 
Table 3-11 SPF Insulation Reference Unit Parameters for Original and BIRDS LCAs

\begin{tabular}{|c|c|c|c|c|}
\hline & & Unit & $\begin{array}{c}\text { Low-density } \\
\text { Open-Cell }\end{array}$ & $\begin{array}{l}\text { Medium-density } \\
\text { Closed-Cell }\end{array}$ \\
\hline Foam R-Value & & $\begin{array}{c}\mathrm{m}^{2} \mathrm{~K} / \mathrm{W}\left(\mathrm{h} \cdot \mathrm{ft}^{2} \cdot{ }^{\circ} \mathrm{F} / \mathrm{Btu}\right) \text { per } \\
\mathrm{cm}(\text { per in) }\end{array}$ & $0.25(3.6)$ & $0.43(6.2)$ \\
\hline \multirow[t]{4}{*}{ Original LCA } & Foam area & $\mathrm{m}^{2}\left(\mathrm{ft}^{2}\right)$ & $1.0(10.76)$ & $1.0(10.76)$ \\
\hline & Target R-value & $\mathrm{m}^{2} \mathrm{~K} / \mathrm{W}\left(\mathrm{h} \cdot \mathrm{ft}^{2} \cdot{ }^{\circ} \mathrm{F} / \mathrm{Btu}\right)$ & $1.00(5.68)$ & $1.00(5.68)$ \\
\hline & $\begin{array}{l}\text { Thickness per } \\
\text { reference unit }\end{array}$ & cm (in) & $4.0(1.58)$ & $2.3(0.92)$ \\
\hline & $\begin{array}{l}\text { Mass per } \\
\text { reference unit }\end{array}$ & kg (lb) & $0.59(1.31)$ & $1.16(2.55)$ \\
\hline \multirow[t]{4}{*}{ BIRDS LCA } & Foam area & $\mathrm{m}^{2}\left(\mathrm{ft}^{2}\right)$ & $0.09(1.0)$ & $0.09(1.0)$ \\
\hline & $\begin{array}{l}\text { R-value per cm } \\
\text { (per in) }\end{array}$ & $\mathrm{m}^{2} \mathrm{~K} / \mathrm{W}\left(\mathrm{h} \cdot \mathrm{ft}^{2} \cdot{ }^{\circ} \mathrm{F} / \mathrm{Btu}\right)$ & $0.25(3.6)$ & $0.43(6.2)$ \\
\hline & $\begin{array}{l}\text { Thickness per } \\
\text { reference unit }\end{array}$ & cm (in) & $2.54(1.0)$ & $2.54(1.0)$ \\
\hline & $\begin{array}{l}\text { Mass per } \\
\text { reference unit }\end{array}$ & kg (lb) & $0.035(0.077)$ & $0.117(0.26)$ \\
\hline
\end{tabular}

Based on the percentages of the B-side material constituents (presented in Table 3-10) and the mass per reference unit for the BIRDS LCA, the masses of materials in the foam shown in Table 3-12 were modeled for BIRDS. The quantities of the pMDI were calculated based on SPFA (2012), which provided the masses of A-side and B-side from a drum set at installation.

\section{Table 3-12 Material Constituents for Open-Cell and Closed-Cell SPF Insulation}

\begin{tabular}{|c|c|c|c|c|}
\hline \multirow{2}{*}{ Constituent } & \multicolumn{2}{|c|}{$\begin{array}{c}\text { Low Density } \\
\text { (Open-Cell) Foam }\end{array}$} & \multicolumn{2}{|c|}{$\begin{array}{l}\text { Medium Density } \\
\text { (Closed-Cell) Foam }\end{array}$} \\
\hline & kg & lb & kg & lb \\
\hline Polyol - polyester & $\mathrm{n} / \mathrm{a}$ & $\mathrm{n} / \mathrm{a}$ & 0.026 & 0.057 \\
\hline Polyol - Mannich & $\mathrm{n} / \mathrm{a}$ & $\mathrm{n} / \mathrm{a}$ & 0.017 & 0.038 \\
\hline Polyol - compatibilizer & 0.002 & 0.004 & $\mathrm{n} / \mathrm{a}$ & $\mathrm{n} / \mathrm{a}$ \\
\hline Polyol - polyether & 0.006 & 0.013 & $\mathrm{n} / \mathrm{a}$ & $\mathrm{n} / \mathrm{a}$ \\
\hline Fire retardent - Tris(2-chloroisopropyl) & & & & \\
\hline $\begin{array}{l}\text { phosphate (TCPP) } \\
\text { Fire retardent - Brominated }\end{array}$ & $\begin{array}{c}0.004 \\
\mathrm{n} / \mathrm{a}\end{array}$ & $\begin{array}{c}0.009 \\
\mathrm{n} / \mathrm{a}\end{array}$ & $\begin{array}{l}0.002 \\
0.003\end{array}$ & $\begin{array}{l}0.005 \\
0.008\end{array}$ \\
\hline Blowing agent - reactive (deionized H2O) & 0.004 & 0.009 & 0.001 & 0.003 \\
\hline Blowing agent - physical (HFC-245fa) & $\mathrm{n} / \mathrm{a}$ & $\mathrm{n} / \mathrm{a}$ & 0.005 & 0.011 \\
\hline Catalyst - amine & 0.001 & 0.002 & 0.002 & 0.004 \\
\hline Catalyst - metal & $\mathrm{n} / \mathrm{a}$ & $\mathrm{n} / \mathrm{a}$ & 0.0003 & 0.001 \\
\hline Surfactant - silicone & $\mathrm{n} / \mathrm{a}$ & $\mathrm{n} / \mathrm{a}$ & 0.001 & 0.001 \\
\hline pMDI - A-Side & 0.018 & 0.040 & 0.060 & 0.131 \\
\hline Total & 0.035 & 0.077 & 0.117 & 0.258 \\
\hline
\end{tabular}


Data for the MDI comes from the U.S. LCI Database. Data for the polyester polyol comes from PE International (2010). Due to lack of other available data, proxies were used for the other polyols: polyether polyol was used for the Mannich polyol and ethylene glycol was used for compatibilizer polyol. Both come from the U.S. LCI Database.

Data for Tris(2-chloroisopropyl) phosphate (TCPP) are U.S. compiled from PE International (2012). Due to lack of specific data on the brominated fire retardant, ecoinvent's data set on diphenyl ether compounds was used as a proxy, since brominated fire retardants may be part of a group called polybrominated diphenyl ethers (PBDEs).

Deionized water-blowing agent data come from ecoinvent. Data for the HFC-245fa are based on stoichiometry and information from McCulloch (2009). Dimethylamine from ecoinvent was used for the amine catalyst, and the silicone surfactant was modeled using tetrachlorosilane as a proxy. Both these data sets come from ecoinvent. No data were available to include the metal catalyst.

Transport distances and modes of transportation of raw materials to the formulation plants were provided in the original LCA; these distances were used in the BIRDS LCA but are not included in this text due to non-disclosure requests.

Weighted average process energy data from the six formulation sites were provided in Table 3.1 of PE International (2012). Data included electric and other fuel energy sources, waste quantities and their fates, packaging in steel drums, plastic drums and totes, plastic wrap, and pallets, plus direct process emissions from foam reactions. These data were included in the BIRDS LCA but are not provided in this summary to protect confidentiality.

\subsection{Transportation to the Building Site through End-of-Life}

Per PE International (2012), transportation to the building site of the A- and B-side drums is modeled as a weighted industry average of $1287 \mathrm{~km}$ (800 mi) by heavy-duty dieselfueled truck.

On-site application is nearly identical for all high-pressure SPF materials. The A- and Bside chemicals are delivered to the SPF contractor in pairs (sets) of 208-liter (55-gal) drums from the formulator. These unpressurized drum sets are stored at the contractor's facility at room temperature conditions until taken to the jobsite in a spray rig.

At the jobsite, the chemicals are heated and pressurized by specialized equipment. The chemicals are aerosolized by a spray gun and combined by impingement mixing during application. Weighted average data from six installation contractors from across North America were provided in Table 3.3 of PE International (2012). Data included electricity, diesel fuel, and waste materials. These data were included in BIRDS but are not provided in this summary to protect confidentiality. Per the UL Environment (2013) EPD, it is assumed that $50 \%$ of the original HFC-245fa blowing agent in the closed-cell foam will 
stay with the product. The remaining original amount of the blowing agent is released per the EPD as follows:

- $10 \%$ emitted at installation;

- $24 \%$ emitted over its lifetime in the building;

- $16 \%$ emitted at end-of-life.

SPF insulation has a functional lifetime of 60 years so no replacement is needed during the BIRDS' 40-year study period. Installed SPF insulation normally requires no maintenance and has no impacts associated with it besides the release of blowing agent as mentioned above. How insulation in the building affects operating energy during the use phase is addressed in other sections of this report.

It is assumed that SPF insulation is disposed of in a landfill at end-of-life. The foam is inert in the landfill, except for the release of the HFC-245fa, as stated above. End-of-life modeling includes transportation by heavy-duty diesel-fuel powered truck approximately $80 \mathrm{~km}$ (50 mi) to a C\&D landfill. Insulation in a landfill is modeled based on ecoinvent end-of-life waste management process data.

\subsubsection{Mineral Wool Blanket Insulation}

Mineral wool insulation is made by spinning fibers from natural rock like diabase or basalt (rock wool) or iron ore blast furnace slag (slag wool). Rock wool and slag wool are manufactured by melting the constituent raw materials in a cupola. A molten stream is created and poured onto a rapidly spinning wheel or wheels. The viscous molten material adheres to the wheels and the centrifugal force throws droplets of melt away from the wheels, forming fibers. A binder, used to stabilize the fibers, and a de-dusting agent to reduce free, airborne wool during use, are applied during this process. The material is heated to cure the binder and stabilize the material, and is then cooled. The blankets are then cut to size and packaged. A portion of the data on mineral wool insulation come from NIST (2010).

Thermal resistance values of $\mathrm{R}_{\mathrm{SI}}-2.3(\mathrm{R}-13)$ and $\mathrm{R}_{\mathrm{SI}}-3.4$ (R-19) are used in BIRDS for wall insulation but data used for this LCA have been modeled per thermal resistances more commonly offered for mineral wool blankets (i.e., R $\mathrm{R}_{\mathrm{SI}}-2.6$ (R-15) and $\mathrm{R}_{\mathrm{SI}}-4.1$ (R23)) for each of comparison. Table 3-13 specifies mineral wool blanket insulation by type and R-value (ROXUL 2013).

Table 3-13 Mineral Wool Blanket Mass by Application

\begin{tabular}{|c|c|c|c|c|}
\hline Application & $\begin{array}{c}\text { Thickness } \\
\text { cm (in) }\end{array}$ & $\begin{array}{c}\text { Density } \\
\mathrm{kg} / \mathrm{m}^{3}\left(\mathbf{l b} / \mathrm{ft}^{3}\right)\end{array}$ & $\begin{array}{c}\text { Mass per } 1 \text { in } \\
\text { Functional Unit } \\
\text { kg/m² }\left(\mathbf{l b} / \mathbf{f t}^{2}\right)\end{array}$ & $\begin{array}{c}\text { R-Value per } \\
\text { Reference Flow } \\
\text { m² K} / W \text { per cm }^{2} \mathbf{f t}^{2} \cdot{ }^{\circ} \text { F/Btu per in) }\end{array}$ \\
\hline Wall - R $\mathrm{RI}_{\mathrm{SI}}-2.6$ (R-15) & $8.9(3.5)$ & $31.5(2.0)$ & $0.074(0.16)$ & $0.30(4.3)$ \\
\hline Wall - $\mathrm{R}_{\mathrm{SI}}-4.1$ (R-23) & $14.0(5.5)$ & $34.3(2.1)$ & $0.081(0.18)$ & $0.30(4.2)$ \\
\hline
\end{tabular}




\subsection{Upstream Materials Production through Manufacturing}

Mineral wool can be manufactured using slag wool or rock wool. Some products contain both materials; about $80 \%$ of North American mineral wool is manufactured using iron ore slag. The binder is modeled as phenol formaldehyde resin. Quantities of resin vary for different manufacturers and performance characteristics; eight percent was modeled for BIRDS. Additionally, a small amount of mineral oil was modeled as added to seal the surface against dust production (U.K. Department for Environment 2008). Table 3-14 presents the weighted mix of the different types of mineral wool feedstock representing production in North America, plus the additional materials used in blankets.

\section{Table 3-14 Mineral Wool Insulation Constituents}

$\begin{array}{lc}\text { Constituent } & \text { Mass Fraction (\%) } \\ \text { Diabase Rock/Basalt } & 20.2 \\ \text { Iron Ore Slag } & 71.5 \\ \text { Phenol formaldehyde resin } & 8.0 \\ \text { Mineral oil } & 0.3 \\ \text { Total } & \mathbf{1 0 0}\end{array}$

Data for rock mining and grinding come from ecoinvent. Slag is produced during steel production, when molten iron and slag are produced together in the blast furnace. The slag is recovered and can be used to produce mineral wool, as an additive to cement, etc. For mineral wool, the production of slag is considered environmentally "free" of upstream impacts. However, the LCA accounts for the transportation to fiber production and the processing into fiber. The data for phenol formaldehyde resin and mineral oil come from the U.S. LCI database.

The raw materials are transported to the manufacturing plant via diesel truck. Materials are sourced domestically, and transportation distances range on average from $161 \mathrm{~km}$ (100 mi) to $805 \mathrm{~km}$ (500 mi).

The energy requirements for melting the product constituents into fibers and drying of the fibers involve a mixture of coke and electricity. The energy demands are outlined in Table 3-15 (NIST 2010).

Table 3-15 Energy Requirements for Mineral Wool Insulation Manufacturing

\begin{tabular}{lc} 
Energy Source & MJ/kg (Btu/lb) \\
Coke & $6.38(2740)$ \\
Electricity & $1.0(430)$ \\
Total & $\mathbf{7 . 3 8 ( 3 1 7 0 )}$ \\
\hline
\end{tabular}


The manufacturing process generates air emissions from energy use, particulates and fluorides during melting and spinning of the mineral feedstocks, and phenol and formaldehyde during melting and binding. These emissions are included in the model. All waste produced during the production process is either recycled into other insulation materials or added back into the melt. Therefore, no solid waste is generated during production.

\subsection{Transportation to the Building Site through End-of-Life}

Transportation of the insulation to the building site is modeled using an assumed average of $805 \mathrm{~km}$ (500 mi) by heavy-duty diesel-fueled truck. Installation is primarily a manual process; no energy or emissions are included in the model. During installation, any waste material is added into the building shell where the insulation is installed - there is effectively no installation waste.

Mineral wool insulation has a functional lifetime of over 50 years so no replacement is needed during the 40-year study period. How this product affects operating energy during the home's use phase is addressed in other sections of this report.

While mineral wool insulation may be recyclable, it is assumed that it is disposed of in a landfill at end-of-life. End-of-life modeling includes transportation by heavy-duty dieselfuel powered truck approximately $80 \mathrm{~km}(50 \mathrm{mi})$ to a C\&D landfill. Landfilled insulation is modeled based on ecoinvent end-of-life waste management process data.

\subsubsection{XPS Foam Insulation}

Extruded Polystyrene (XPS) foam insulation has been modeled for the residential exterior wall. Type IV and Type XPS may be used for residential applications; the data in this document is representative of Type IV XPS, which has a typical average density of $26.2 \mathrm{~kg} / \mathrm{m}^{3}\left(1.63 \mathrm{lb} / \mathrm{ft}^{3}\right)$. The foam has the following R-values, depending on thickness: ${ }^{4}$

- $2.5 \mathrm{~cm}(1 \mathrm{in}): \mathrm{R}_{\mathrm{SI}}=0.9(\mathrm{R}=5.0)$

- $5.1 \mathrm{~cm}(2 \mathrm{in}): \mathrm{R}_{\mathrm{SI}}=1.9(\mathrm{R}=10.6)$

- $7.6 \mathrm{~cm}(3 \mathrm{in}): \mathrm{R}_{\mathrm{SI}}=2.9(\mathrm{R}=16.2)$

- $10.2 \mathrm{~cm}(4 \mathrm{in}): \mathrm{R}_{\mathrm{SI}}=3.9(\mathrm{R}=22.0)$

\subsection{Upstream Materials Production through Manufacturing}

Extruded Polystyrene Foam Association (XPSA) member companies provided representative industry average production data on XPS foam boards. XPSA represents the three largest producers in North America and accounts for over $95 \%$ of XPS products produced and sold. Table 3-16 provides a 2010 representative average of the raw material and processing energy inputs and process outputs to produce one kg of XPS foam board.

\footnotetext{
${ }^{4}$ Extruded Polystyrene Foam Association (XPSA) website, found at http://www.xpsa.com. Values are based on a round-robin study in 2003 using the CAN/ULC S770-00 LTTR standard.
} 
The table presents the current representative blowing agent assumptions for XPS. It should be noted that HFCs began to replace 1-Chloro-1, 1-difluoroethane (HCFC-142b) as the principal blowing agent in 2009, as the industry complied with U.S. EPA and Environment Canada ODS phase-out regulations requiring the XPS sector to discontinue HCFC use by the end of 2009. By 2010, all XPSA members had converted to non-HCFC blowing agents and have been using only HFC materials ever since.

\section{Table 3-16 XPS Foam Board Production Data}

\begin{tabular}{llcc} 
Inputs & & Quantity per kg & Quantity per lb \\
Blowing agents & HFC-134a & $0.060 \mathrm{~kg}$ & $0.060 \mathrm{lb}$ \\
& HFC-152a & $0.017 \mathrm{~kg}$ & $0.017 \mathrm{lb}$ \\
\multirow{2}{*}{ Solid additives } & CO $_{2}$ & $0.012 \mathrm{~kg}$ & $0.012 \mathrm{lb}$ \\
& PS resin & $0.907 \mathrm{~kg}$ & $0.907 \mathrm{lb}$ \\
Energy & Additives & $0.018 \mathrm{~kg}$ & $0.018 \mathrm{lb}$ \\
Outputs & Electricity & $1.00 \mathrm{kWh}$ & $0.454 \mathrm{kWh}$ \\
Air & & & \\
& HFC-134a & $0.0105 \mathrm{~kg}$ & $0.0105 \mathrm{lb}$ \\
Waste & HFC-152a & $0.0029 \mathrm{~kg}$ & $0.0029 \mathrm{lb}$ \\
& Waste & $1.0 \mathrm{E}-4 \mathrm{~kg}$ & $1.0 \mathrm{E}-4 \mathrm{lb}$ \\
\hline
\end{tabular}

The additives in the table include the flame retardant widely used in all polystyrene foams (hexabromocyclododecane (HBCD)) and colorants or dyes/pigments used to produce the characteristic color of each XPSA member's foam. Additives may also include a nucleation control agent, process lubricant, acid scavenger, or others.

The blowing agent conversion/trim losses during manufacturing are assumed to be on average $17.5 \%$ for North American XPS foam production (Intergovernmental Panel on Climate Change (IPCC) 2005). All of the polystyrene trim waste at the manufacturing plant is reused internally in the process. Only a very small amount of foam and other materials are occasionally sent off-site for disposal in a landfill.

Data for polystyrene come from the U.S. LCI Database. Data for all three blowing agents and some of the additives come from ecoinvent. Data were not available for all the additives; where data were not available proxy data were implemented.

All the raw materials are produced in the U.S., and most of the raw materials are centrally located, as are the XPS manufacturer's largest plants. The estimated weighted average distance from the main suppliers to most XPS manufacturing plants is $805 \mathrm{~km}$ (500 mi) for polystyrene, Tetrafluoroethane (HFC-134a), flame retardant, and $\mathrm{CO}_{2}$. 1,1Difluoroethane (HFC-152a) and other additives are transported an average distance of $1609 \mathrm{~km}(1000 \mathrm{mi})$ to manufacturing plants. All but the blowing agents and polystyrene 
are transported by diesel truck; the blowing agents and polystyrene are transported by rail.

\subsection{Transportation to the Building Site through End-of-Life}

Transportation of the insulation to the building site is modeled using $563 \mathrm{~km}$ (350 mi), an average factoring in the various plants around the United States. Transportation is by heavy-duty diesel truck.

Foam boards are installed with installation tape, but tape is excluded since it is considered negligible. Scrap XPS foam board generated at installation is assumed to be $2 \%$ of the total, consistent with other foam products in this category. While the product may be recyclable, it is modeled as being sent to a landfill $32 \mathrm{~km}$ (20 mi) from the building site. Data for the landfill come from waste management datasets in ecoinvent. Blowing agent escape during installation is insignificant. Minimal cutting to size on the jobsite is done and, even then, a sharp tool is typically used so that very few cells are opened.

XPS insulation has a functional lifetime of over 40-years so no replacement is needed during the 40-year study period. How insulation in the buildings affects operating energy during the prototype buildings' use phase is addressed in other sections of this report.

The diffusion of HFC-134a from XPS during use is $0.75 \%+/-0.25 \%$ per (Intergovernmental Panel on Climate Change (IPCC) 2005). The blowing agent emission loss during the use phase is complex and non-linear but can be represented for simplicity as a linear function after the first year. The rate is a function of the product thickness, properties (density, cell size, skins), blowing agent type(s) and transport properties (solubility, diffusion coefficient), and the installed application details (mean temperature, permeability of applied facings). The diffusion rate of HFC-152a is $15 \%$ per year (Intergovernmental Panel on Climate Change (IPCC) 2005).

Reuse of the foam is possible after building decommissioning, but the model assumes that at end-of-life the foam is disposed of in a landfill. End-of-life modeling includes transportation by heavy-duty diesel-fuel powered truck approximately $80 \mathrm{~km}$ (50 mi) to a C\&D landfill. Landfilled insulation is modeled based on ecoinvent end-of-life waste management process data. For a typical North America building demolition followed by disposal in a landfill, it is reasonable to assume an initial blowing agent end-of-life loss of $20 \%$ followed by annual losses of $1 \%$ (United Nations Environment Programme (UNEP) 2005).

\subsubsection{Polyisocyanurate Foam Insulation}

Polyisocyanurate (polyiso) foam insulation has been modeled for the exterior wall application. The thermal resistance value for wall polyiso board is 6.5 which includes its impermeable board facer. This R-value is based on a 6-month accelerated aging test and 
was provided by representatives at Bayer MaterialScience ${ }^{5}$. The foam has a wet, or preyield, density of $29.2 \mathrm{~kg} / \mathrm{m}^{3}\left(1.82 \mathrm{lb} / \mathrm{ft}^{3}\right)$. The final product, which includes the weight of the facers, has a nominal density of $32.0 \mathrm{~kg} / \mathrm{m}^{3}\left(2.0 \mathrm{lb} / \mathrm{ft}^{3}\right)$.

\subsection{Upstream Materials Production through Manufacturing Upstream Materials Production}

Cradle-to-gate data on production through manufacturing is based on a 2010 study performed for the Polyisocyanurate Insulation Manufacturers Association (PIMA) (Bayer MaterialScience 2008). The scope of this study included collecting and compiling mostly 2007 production data from the six PIMA member companies and compiling it into an industry average polyiso insulation board. Process energy data came from 29 out of 31 polyiso plants in the U.S. and Canada, representing approximately $94 \%$ of production in those geographies.

The chemicals to produce polyiso foam make up an "A" side (MDI) and a "B" side (polyester polyol with various additives such as catalysts, surfactants and flame retardants) plus a blowing agent (pentane). Table 3-17 presents the raw material inputs associated with polyiso foam production (Bayer MaterialScience 2011), provided on the basis of $2.54 \mathrm{~cm}$ (1 in) in thickness.

\section{Table 3-17 Raw Material Inputs to Produce Polyiso Foam}

$\begin{array}{lccc}\text { Inputs } & \text { \% in foam } & \begin{array}{c}\text { kg per } \mathbf{0 . 0 9} \mathbf{~ m}^{\mathbf{2}}, \\ \mathbf{2 . 5 4} \mathbf{~ c m ~ t h i c k}\end{array} & \begin{array}{c}\mathbf{l b} \text { per } \mathbf{~ f t} \mathbf{~}^{2} \\ \mathbf{1} \text { in thick }\end{array} \\ \text { MDI } & 55.5 & 0.0382 & 0.0842 \\ \text { Polyester Polyol } & 31 & 0.0213 & 0.0470 \\ \text { TCPP } & 3.4 & 0.0023 & 0.0051 \\ \text { Catalyst K15 } & 1.4 & 0.0010 & 0.0022 \\ \text { Catalyst PC46 } & 0.16 & 1.38 \mathrm{E}-04 & 0.0003 \\ \text { Catalyst PV } & 0.08 & 6.90 \mathrm{E}-05 & 0.0002 \\ \text { Surfactant } & 0.63 & 5.51 \mathrm{E}-04 & 0.0012 \\ \text { Pentane (blowing agent) } & 7.5 & 0.0052 & 0.0115 \\ \text { Process water } & 0.1 & 0.0001 & 0.0002\end{array}$

The MDI data come from the U.S. LCI Database. Data for the polyester polyol comes from an eco-profile study of aromatic polyester polyols (PE International 2010). Data for TCPP are U.S. data compiled from literature sources (PE International 2011). Pentane data come from ecoinvent. No data were available to include the three catalysts or silicone surfactant; they total $2.3 \%$ of the total input, so a total of $97.7 \%$ of the inputs were included in the model.

Polyiso wall applications normally use aluminum Kraft paper (foil) for the facer. The foil facer raw materials include paper, aluminum foil, adhesives and coatings, and has a mass

\footnotetext{
${ }^{5}$ Verbal communication with Bayer MaterialScience representatives, July 2013.
} 
of $0.098 \mathrm{~kg} / \mathrm{m}^{2}\left(0.02 \mathrm{lb} / \mathrm{ft}^{2}\right)$ (Bayer MaterialScience 2008). Data on material composition come from a material safety data sheet (MSDS). Based on this limited data source, the facer is modeled as 77 \% foil and 23 \% Kraft (Atlas Roofing Corporation 2012). Data for foil is modeled as 50/50 primary and secondary aluminum from the U.S. LCI Database, plus sheet rolling (ecoinvent). Data for Kraft paper come from ecoinvent.

Raw materials are transported to the manufacturing plant via diesel truck or rail. The following distances and modes of transport were modeled:

- MDI: 2414 km (1500 mi) by rail;

- Polyester polyol: $1384 \mathrm{~km}$ (860 mi) by rail (90 \%), $1384 \mathrm{~km}$ (860 mi) by truck (10\%);

- Pentane: 2414 km (1500 mi) by truck;

- Remaining materials: 1609 km (1000 mi) by truck.

Manufacturing

Per (Bayer MaterialScience 2011), polyiso plants consume primarily electricity and natural gas used to operate the laminator and associated operations support equipment, such as thermal oxidizers, storage areas, packaging machines, raw material pumps, offices, etc. A small amount of propane is used for fork lift trucks. Table 3-18 presents energy inputs and process outputs to produce 1 board-foot of foam, or $0.09 \mathrm{~m}^{2}\left(1 \mathrm{ft}^{2}\right)$ of $2.54 \mathrm{~cm}$ (1 in) thick polyiso foam.

\section{Table 3-18 Energy Inputs and Process Outputs for 1 Board-Foot Polyiso Foam}

\begin{tabular}{lcc} 
Energy inputs & Unit & Quantity \\
Electricity & $\mathrm{MJ}(\mathrm{kWh})$ & $0.0497(0.0138)$ \\
Nat gas & $\mathrm{MJ}(\mathrm{Btu})$ & $0.0913(86.55)$ \\
Propane & $\mathrm{kg} \mathrm{(lb)}$ & $0.00015(0.00031)$ \\
Outputs & Unit & Quantity \\
Pentane to air & $\mathrm{kg}(\mathrm{lb})$ & $0.00013(0.00030)$ \\
Waste scrap & board-foot & 0.01 \\
\hline
\end{tabular}

Based on review with polyiso plant manufacturers, approximately $2.5 \%$ of the pentane added to the foam is lost to air during manufacturing. Depending on the plant and local regulatory requirements, pentane is emitted directly to the atmosphere or to a thermal oxidizer for combustion. Only 13 plants out of 31 use thermal oxidizers to combust the pentane emissions. Since the majority of polyiso plants in North America do not use thermal oxidizers, the pentane is modeled as going directly to atmosphere (Bayer MaterialScience 2011).

Transportation and disposal of manufacturing waste scrap was modeled as going to an industrial landfill. It is assumed that a landfill for such non-hazardous waste is within 32 $\mathrm{km}$ (20 mi) of the polyiso plant. 


\subsection{Transportation to the Building Site through End-of-Life}

Transportation to the building site is modeled using $400 \mathrm{~km}$ (250 mi) by heavy-duty diesel truck (Bayer MaterialScience 2011).

Installation tape is used but is excluded since it is considered negligible. Scrap polyiso generated at installation is assumed to be $2 \%$ of the total, consistent with other foam products in this category. While the product may be recyclable, it is modeled as being sent to a landfill $32 \mathrm{~km}$ (20 mi) from the building site. Data for the landfill come from waste management datasets in ecoinvent. Pentane release at installation is negligible.

Polyiso insulation has a functional lifetime of over 40 -years so no replacement is needed during the 40-year study period. How insulation in the buildings affects operating energy during the prototype buildings' use phase is addressed in other sections of this report.

Polyiso insulation is modeled as disposed of in a landfill at end-of-life. End-of-life modeling includes transportation by heavy-duty diesel truck approximately $80 \mathrm{~km}$ (50 mi) to a C\&D landfill. Landfilled insulation is modeled based on ecoinvent end-of-life waste management process data. Per Bayer MaterialScience (2011), $50 \%$ of the total pentane in the product will have been released by end-of-life and $50 \%$ remains in the product.

\subsubsection{Windows}

\subsubsection{Introduction}

The BIRDS residential tool evaluates double hung and casement windows with specifications complying with different energy code editions. Table 3-19 provides the Ufactor and solar heat gain coefficients (SHGCs) used to address different climate zone and code edition requirements, plus the window characteristics and frame type modeled for each. The window that is the closest match to the thermal performance of the window options in BIRDS is used as a basis for calculating the window LCIA data. 
Table 3-19 Window Specifications

\begin{tabular}{cccc}
$\begin{array}{c}\text { U-Factor } \\
\mathbf{W} / \mathbf{m}^{2} \cdot \mathbf{K} \\
\left.\mathbf{( B t u} / \mathbf{f t}^{\mathbf{2}} \cdot \mathbf{F} \cdot \mathbf{h}\right)\end{array}$ & SHGC & Window characteristics & $\begin{array}{c}\text { Frame Type for } \\
\text { Double Hung and } \\
\text { Casement Windows }\end{array}$ \\
\hline $1.99(0.35)$ & No Req. & 2 window panes, low-e coating, argon gas & $\begin{array}{c}\text { Wood-clad frame } \\
\text { Vinyl frame }\end{array}$ \\
$2.27(0.4)$ & No Req. & 2 window panes, low-e coating, argon gas & Wood-clad frame \\
$2.56(0.45)$ & No Req. & 2 window panes, tint & Wood-clad frame \\
$2.84(0.5)$ & 0.3 & 2 window panes, tint & Wood-clad frame \\
$2.84(0.5)$ & No Req. & 2 window panes, tint & Wood-clad frame \\
$3.12(0.55)$ & No Req. & 2 window panes, tint & Aluminum frame \\
$3.41(0.6)$ & No Req. & 2 window panes, low-e coating, argon gas & Aluminum frame \\
$3.69(0.65)$ & 0.3 & 2 window panes, low-e coating, argon gas & Aluminum frame, \\
$3.69(0.65)$ & 0.4 & 2 window panes, tint & $\begin{array}{c}\text { thermal break } \\
\text { Aluminum frame }\end{array}$ \\
$3.69(0.65)$ & No Req. & 2 window panes, low-e coating, argon gas & Wood-clad frame \\
$4.26(0.75)$ & 0.4 & 1 window pane, tint & Wood-clad frame \\
$4.26(0.75)$ & No Req. & 1 window pane, no coating & Wood-clad frame \\
$5.11(0.9)$ & No Req. & 1 window pane, tint & Aluminum frame \\
$6.81(1.2)$ & 0.3 & 1 window pane, low-e coating, tint & Aluminum frame \\
$6.81(1.2)$ & 0.4 & 2 window panes, low-e coating, tint & Aluminum frame \\
$6.81(1.2)$ & No Req. & 1 window pane, no coating & \\
\hline
\end{tabular}

The compilation of window characteristics and frame types come from a variety of sources, including an online residential window selection tool ${ }^{6}$ and individuals in industry. There are many possible window assembly possibilities (combination of frame material, glass in-fill, and operability) for residential structures in any climate zone. Multiple window assembly options can be nearly identical in performance. The window assembly types presented in Table 3-19 represent some of the many options available to meet each U-SHGC combination. As such, the window assemblies presented here are not endorsed or preferred over any other type of window assembly for a residential home.

BIRDS environmental performance data for the windows category was provided per 0.09 $\mathrm{m}^{2}\left(1 \mathrm{ft}^{2}\right)$ of a typical or common size of residential window. Since data were collected on a full window basis, windows were modeled as full windows and then normalized to $0.09 \mathrm{~m}^{2}\left(1 \mathrm{ft}^{2}\right)$. Figure 3-4 presents the general system boundaries for the window category as it is modeled for BIRDS.

\footnotetext{
${ }^{6}$ Efficient Windows Collaborative tool, found at http://www.efficientwindows.org/selection.cfm.
} 


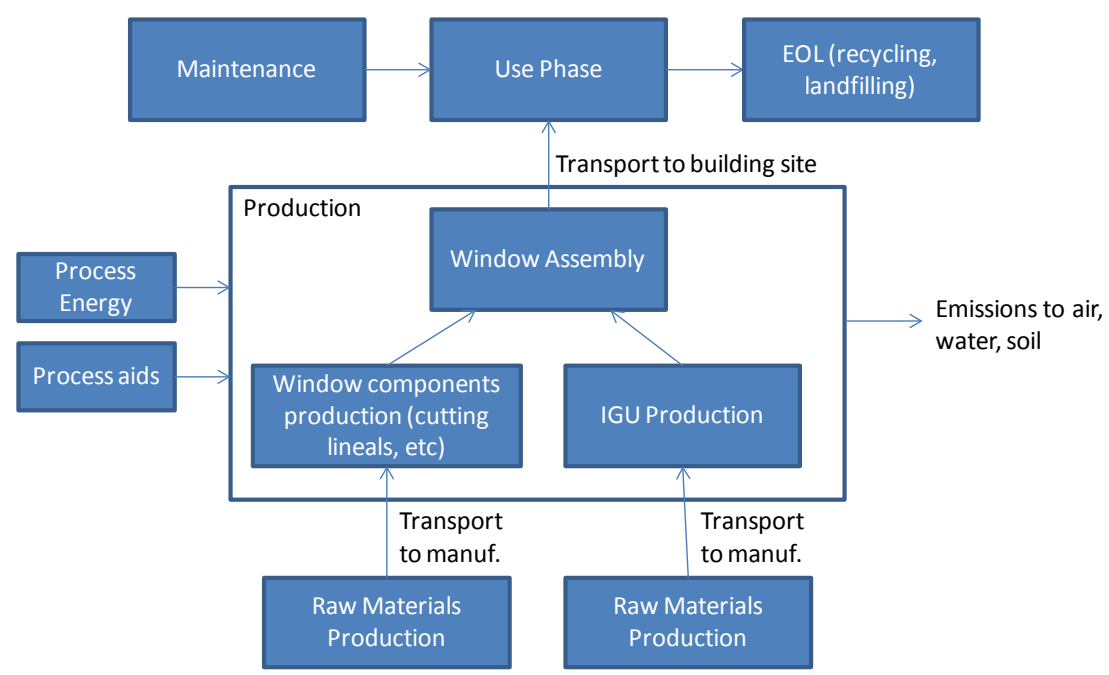

Figure 3-4 Windows System Boundaries

The next sections present the modeling and assumptions for the assemblies of wood clad, vinyl, aluminum, and aluminum with thermal break frames, for casement and double hung windows.

\subsubsection{Casement Windows Bill of Materials}

One North American manufacturer of residential windows provided primary data on wood clad, aluminum, and vinyl casement windows. Data were based on 2012 production, and material data were based on averaged information for all final assembly facilities located in North America. A generic casement window was modeled for each frame type, and the weight of each component was averaged between the plants. The data for the casement windows include:

- Frame and sash - quantities of each material;

- Insulated glass unit (IGU), including quantities and type(s) of glass, spacer, sealants, and gas if applicable;

- Hardware, weatherstrip, fasteners, and other components - quantities and types of each material.

Table 3-20, Table 3-21, and Table 3-22 provide dimensions and masses of the main parts of the casement windows. Due to the proprietary nature of the data, the details of the specific windows have been removed. Note that a thermal break is a material that separates the interior and exterior of a metal frame. The low thermal conductivity of the thermal break material reduces temperature transfer, making the metal window more energy efficient. 


\section{Table 3-20 Dimensions and Main Parts of the Wood Clad Casement Window}

\begin{tabular}{lccc} 
Description & Units & Single pane & Double pane \\
Dimension of the window & $\mathrm{m}^{2}\left(\mathrm{ft}^{2}\right)$ & $1.0(10.76)$ & $1.0(10.76)$ \\
Weight of the finished sealed unit & $\mathrm{kg}(\mathrm{lb})$ & $17.9(39.4)$ & $23.4(51.6)$ \\
Wood and extruded aluminum (frame) & $\mathrm{kg}(\mathrm{lb})$ & $10.4(22.9)$ & $10.4(22.9)$ \\
IGU & $\mathrm{kg}(\mathrm{lb})$ & $5.0(11)^{*}$ & $10.5(23.2)$ \\
Other components & $\mathrm{kg}(\mathrm{lb})$ & $2.5(5.5)$ & $2.5(5.5)$ \\
\hline * only glass & & &
\end{tabular}

Table 3-21 Dimensions and Main Parts of the Aluminum Casement Window

$\begin{array}{lcccc}\text { Description } & \text { Units } & \text { Single pane } & \text { Double pane } & \begin{array}{c}\text { Double pane w/ } \\ \text { thermal break }\end{array} \\ \text { Dimension of the window } & \mathrm{m}^{2}\left(\mathrm{ft}^{2}\right) & 1.0(10.76) & 1.0(10.76) & 1.0(10.76) \\ \text { Weight of the finished sealed unit } & \mathrm{kg}(\mathrm{lb}) & 16.4(36.2) & 20.9(46.1) & 21.6(47.6) \\ \text { Extruded aluminum (frame) } & \mathrm{kg}(\mathrm{lb}) & 9.7(21.4) & 9.7(21.4) & 9.7(21.4) \\ \text { IGU } & \mathrm{kg}(\mathrm{lb}) & 3.9(8.6)^{*} & 8.4(18.5) & 8.4(18.5) \\ \text { Other components } & \mathrm{kg}(\mathrm{lb}) & 2.8(6.2) & 2.8(6.2) & 3.6(7.9)\end{array}$

* only glass

Table 3-22 Dimensions and Main Parts of the Vinyl Casement Window

\begin{tabular}{lcc} 
Description & Units & Double pane \\
Dimension of the window & $\mathrm{m}^{2}\left(\mathrm{ft}^{2}\right)$ & $1.0(10.76)$ \\
Weight of the finished sealed unit & $\mathrm{kg}(\mathrm{lb})$ & $20.1(44.4)$ \\
Vinyl (frame) & $\mathrm{kg}(\mathrm{lb})$ & $8.0(17.6)$ \\
IGU & $\mathrm{kg}(\mathrm{lb})$ & $10.0(22.1)$ \\
Other components & $\mathrm{kg}(\mathrm{lb})$ & $2.1(4.6)$ \\
\hline
\end{tabular}

\subsubsection{Double Hung Window Bill of Materials}

One North American manufacturer of residential windows provided primary data on wood clad double hung windows. Data were based on 2011 North American production, and material data were based on a typical construction of an average sized window. The data for double hung windows include:

- Frame and sash - quantities of each material;

- Insulated glass unit (IGU), including quantities and type(s) of glass, spacer, sealants, and gas if applicable;

- Weatherstrip, fasteners, coatings, and other components - quantities and types of each material, where applicable. 
Table 3-23, Table 3-24, and Table 3-25 provide dimensions and masses of the main parts of the double hung windows modeled for BIRDS. Due to the proprietary nature of the data, the details of the specific windows have been removed. Note that data for the aluminum frame windows are based on extrapolation from casement windows data. The mass of framing material per linear foot of the casement's frame was used to calculate the estimated mass of that material in a double-hung window frame, using the perimeters of the double hung window. The same was done for the IGU sealants and spacer, using the perimeters of the IGUs. To estimate other IGU materials and glass, the glass area was used. Most of the casement hardware was removed from the data set. The resulting double hung window is therefore comprised of estimated data. Data for the vinyl windows are based on extrapolations as described above.

\section{Table 3-23 Dimensions and Main Parts of the Wood Clad Double Hung Window}

\begin{tabular}{lccc} 
Description & Units & Single pane & Double pane \\
Dimension of the window & $\mathrm{m}^{2}\left(\mathrm{ft}^{2}\right)$ & $1.3(14.0)$ & $1.3(14.0)$ \\
Weight of the finished sealed unit & $\mathrm{kg}(\mathrm{lb})$ & $35.0(77.2)$ & $43.8(96.5)$ \\
Wood and extruded aluminum (frame) & $\mathrm{kg}(\mathrm{lb})$ & $24.7(54.4)$ & $24.7(54.4)$ \\
IGU & $\mathrm{kg}(\mathrm{lb})$ & $6.2(13.7)^{*}$ & $15.0(33.0)$ \\
Other components & $\mathrm{kg}(\mathrm{lb})$ & $4.1(9.1)$ & $4.1(9.1)$ \\
\hline * only glass & & & \\
\hline
\end{tabular}

Table 3-24 Dimensions and Main Parts of the Aluminum Double Hung Window

\begin{tabular}{lcccc} 
Description & Units & Single pane & Double pane & $\begin{array}{c}\text { Double pane } \\
\text { w/ thermo-br }\end{array}$ \\
Dimension of the window & $\mathrm{m}^{2}\left(\mathrm{ft}^{2}\right)$ & $1.3(14.0)$ & $1.3(14.0)$ & $1.3(14.0)$ \\
Weight of the finished sealed unit & $\mathrm{kg}(\mathrm{lb})$ & $20.8(45.9)$ & $25.4(56.0)$ & $26.7(58.9)$ \\
Extruded aluminum (frame) & $\mathrm{kg}(\mathrm{lb})$ & $15.6(34.4)$ & $15.6(34.4)$ & $15.6(34.4)$ \\
IGU & $\mathrm{kg}(\mathrm{lb})$ & $4.0(8.8)^{*}$ & $8.6(19.0)$ & $8.6(19.0)$ \\
Other components & $\mathrm{kg}(\mathrm{lb})$ & $1.2(2.7)$ & $1.2(2.7)$ & $2.5(5.5)$ \\
\hline * only glass & & & &
\end{tabular}

\section{Table 3-25 Dimensions and Main Parts of the Vinyl Double Hung Window}

$\begin{array}{lcc}\text { Description } & \text { Units } & \text { Double pane } \\ \text { Dimension of the window } & \mathrm{m}^{2}\left(\mathrm{ft}^{2}\right) & 1.3(14.0) \\ \text { Weight of the finished sealed unit } & \mathrm{kg}(\mathrm{lb}) & 23.6(52.0) \\ \text { Vinyl (frame) } & \mathrm{kg}(\mathrm{lb}) & 12.9(28.4) \\ \text { IGU } & \mathrm{kg}(\mathrm{lb}) & 10.2(22.5) \\ \text { Other components } & \mathrm{kg}(\mathrm{lb}) & 0.5(1.1)\end{array}$




\subsubsection{Production Data for the Materials}

Greater than $99 \%$ of the mass of materials in each window were included and modeled for these window systems. While data in the tables represent masses of materials in the finished windows, manufacturers quantified amounts of unusable (i.e., waste) materials and materials recovered, recycled, or reused, including wood and extruded aluminum. Manufacturers noted which materials were reused, recycled, landfilled, or disposed of in another way. Where materials were reused or recycled, the production of that overage was not included in the model. Where material was landfilled or incinerated, the overage was included with the window model and the appropriate waste disposal treatment method was modeled. Some of the information used for the windows modeling was supplemented by Salazar (2007).

Supplier distances to the manufacturing or assembly plant were provided by the manufacturers. Modes of transportation included heavy-duty diesel-fueled truck, ocean freighter and rail. The appropriate distances and modes were modeled as such, using data from the U.S. LCI Database. Where transport distances were not given for smaller contributing materials, an average of $965 \mathrm{~km}$ (600 mi) was modeled as transported by diesel truck.

Window frame raw materials. The wood clad frame consists of planed, kiln-dried lumber and extruded aluminum profile. The wood part of the frame is modeled as having equal amounts of planed, kiln-dried wood from the Southeast and Pacific Northwest using data from the U.S. LCI Database. The aluminum profile is modeled as $50 \%$ primary and $50 \%$ secondary aluminum, and uses data from the U.S. LCI Database. Data for extrusion come from an average of primary data from one window manufacturer and ecoinvent. The thermal break (used in the aluminum windows only) is made up of glassreinforced polyamide, using data from ecoinvent, and polyurethane (PUR) resin, using data from U.S. LCI Database and ecoinvent. Where applicable, stains and external coatings were modeled. The paint and primer are modeled as alkyd oil based, and stain is assumed to be latex-based; these data are built using ecoinvent data sets.

IGU raw materials. The data for float glass come from ecoinvent and is based on early 2000's European processes and technologies. Due to the lack of available data on U.S. float glass production, older European data were implemented. Processes in the data set include melting, cullet addition, forming (on a float bath), annealing by cooling in an oven (know as a lehr), cutting of the glass, and storage. While this data set may not be representative of current U.S. production, it has been customized using U.S. energy and transportation data sets. Also, some transportation impacts have been removed, including transport between manufacturing plants and coating facilities, which, per U.S. windows industry representatives, exists for European operations but not for U.S. operations. The next version of BIRDS hopes to have more representative data on glass production.

The spacer, which separates the two panes of glass, can be made of an array of materials, including aluminum, stainless steel, and tin-plated steel. A hypothetical mix of equal 
parts of these three materials was used. Salazar (2007) reported a loss of approximately $10 \%$ of the spacer; this has been factored in to the model. However, the loss is recycled and is, therefore, not waste. The inner primary sealant, commonly polyisobutylene (PIB), is used to prevent leakage of the argon gas as well as penetration of water vapor into the space between the panes. An assumption of 50/50 polysulphide polymer and polyurethane as secondary sealants were implemented. The desiccant in the spacer, a silicone based product, is used to absorb moisture. Salazar (2007) reported a loss of approximately $0.7 \%$ of the desiccant and this has been factored into the model. Salazar (2007) reported an escape of argon when the cavity is flushed prior to being sealed approximately $95 \%$ more than the quantity in the finished unit. The manufacturers did not provide data on material losses. Since it is unknown if the reported quantity of escaped argon is high or low, a $50 \%$ escape is assumed for this model.

Aluminum and PUR data come from the U.S. LCI Database. Data for all other IGU materials come from ecoinvent. Synthetic rubber is used as a general proxy for PIB.

Other components raw materials. The jambliner, or the lining between the window sash and frame, is modeled as polyvinyl chloride (PVC). Data for PVC resin comes from the U.S. LCI Database and extrusion data come from ecoinvent. Other components may include a combination of clips, gaskets, hardware, weatherstrip, and sealant. Clips, and gaskets are modeled as PVC and rubber parts. The sealant is assumed to be siliconebased. U.S. LCI Database provided the production data for PVC while the ecoinvent database provided the data for the remaining materials. Weatherstrip is described in 3.3.4.6.

Hardware is custom ordered and may vary with the window. For BIRDS, a hypothetical mix of equal parts of stainless steel, cold rolled steel, and bronze has been modeled. The steel in screws and other steel parts are based on data from the World Steel Association (2011), with steel profiles customized to the U.S. using the U.S. electricity grid; steel product manufacturing, i.e., parts forming, data come from ecoinvent. Stainless steel is modeled from a chromium steel (18/8 grade) stainless steel data set from ecoinvent with a steel product manufacturing data set to account for part forming. Bronze data come from ecoinvent.

Coatings. Low-emissivity (low-E) coatings and tinted windows have been included in the windows modeling to meet different performance characteristics of the windows. Coatings are used to improve the insulation properties of the glass by reflecting visible light and infrared radiation. The BIRDS Low-Emissivity coating is modeled using the coating details of ecoinvent's "flat glass, coated" data set as a starting point. The technology used at the plant is based on a cathodic sputtering technology which involves depositing thin silver and other layer(s) on the glass. Per the ecoinvent documentation, the raw materials used for sputtering are bismuth, silver and nickel-chrome. The quantity of $1.19 \mathrm{E}-4 \mathrm{~kg}(2.62 \mathrm{E}-4 \mathrm{lb})$ metals per kg was divided into three to account for $1 / 3$ nickel, $1 / 3$ chromium, and 1/3 silver. These data are approximate. 
Tint is obtained by adding small amounts of metal oxides during glass manufacturing, coloring the glass uniformly. For BIRDS, iron oxide has been assumed to be the mineral additive for the tint, and it is modeled as applied at an assumed proportion of $0.1 \%$ of the glass weight.

\subsubsection{Manufacturing}

Manufacturing data is representative of the year 2011 based on total windows manufactured that year. Data include process energy and water consumption. Electricity was reported for material preparation and window assembly, and natural gas was reported for heating and drying ovens. The facility totals were normalized to one window. These data are an average and not specific for the exact window(s) being modeled. For confidentiality purposes, the data are not shared in this documentation, however, they have been included in the models for all the window types.

\subsubsection{Transportation to the Building Site, Use and Maintenance}

Transportation of the window to the building site is modeled using an average of $805 \mathrm{~km}$ (500 mi) by heavy-duty diesel fuel-powered truck.

Installing windows is primarily a manual process; no energy or emissions are included in the model. Windows come to the construction site fully assembled and custom-ordered to fit so there is generally no installation waste.

Maintenance of the windows includes weatherstripping and sealing. Weatherstrip is modeled as a thermoplastic elastomer. Data for the thermoplast, as ethylene propylene diene monomer (EPDM) rubber, come from ecoinvent (as synthetic rubber). For BIRDS, an EPDM weatherstrip has been modeled in the amount of $0.0064 \mathrm{~kg}$ per $0.3 \mathrm{~m}(0.014 \mathrm{lb}$ per $\mathrm{ft}$ ). Weatherstrip is assumed to perform at its optimal level an average of 7.5 years (Vigener and Brown 2012), so is modeled as replaced every 7.5 years. Different perimeter sealants can be used for different applications. For BIRDS, an acrylic latex sealant with silicone has been modeled in the amount of $0.029 \mathrm{~kg}$ per $\mathrm{m}(0.31 \mathrm{oz}$ per $\mathrm{ft}$ ), which is based on a $0.47 \mathrm{~cm}$ (0.19 in) diameter bead (DAP 2011). Data for the sealant is described in Section 3.3.8 and is modeled as being replaced every 15 years (Vigener and Brown 2012).

Other maintenance, such as glass and/or window frame cleaning, frame repainting or recoating, hardware adjustment or replacement, are not included in the analysis. All operational energy-related aspects of the window are addressed in other sections of this report.

The windows are modeled as having a lifetime of 30 years. Lifetime was set based on Earthsure's (2013) draft window industry PCR, even though it is acknowledged that realistically, the lifetime of windows can vary (based on frame type, weather conditions, maintenance, etc.), and that often windows have a longer service life than 30 years. 


\subsubsection{End-of-Life}

Wood clad and vinyl windows are modeled as landfilled at end-of-life. The frame of the aluminum window is modeled as recycled at end-of-life, and the " $0-100$ recycling methodology” has been applied. For this methodology, system expansion is applied; the production of the same amount of virgin aluminum that is in the frame is subtracted out of the system, crediting the system with an avoided burden based on the reduced requirement for virgin material production in the next life-cycle. Likewise, recycled content in the aluminum adds some of the burden to the product system in order to share the burden with the previous life-cycle. The "0-100 recycling methodology" is applied to valuable metal recovery in other product categories as well. For more information on the “0-100 recycling methodology” approach to modeling metals at end-of-life, see Atherton (2007) and World Steel Association (2011). The remaining parts of the window, including the IGU, are disposed of in a landfill.

End-of-life modeling includes transportation by diesel-fuel powered truck approximately $80 \mathrm{~km}$ (50 mi) to a C\&D landfill or to recycling. The portions of the window going to landfill are modeled based on ecoinvent end-of-life waste management process data.

\subsubsection{HVAC}

Residential BIRDS evaluates air conditioning systems and gas furnaces. BIRDS environmental performance data for these was provided on a per-unit (or per-system) basis as well as electric furnaces for future updates of the BIRDS new residential database. Figure 3-5 presents the general system boundaries for these as they are modeled for BIRDS.

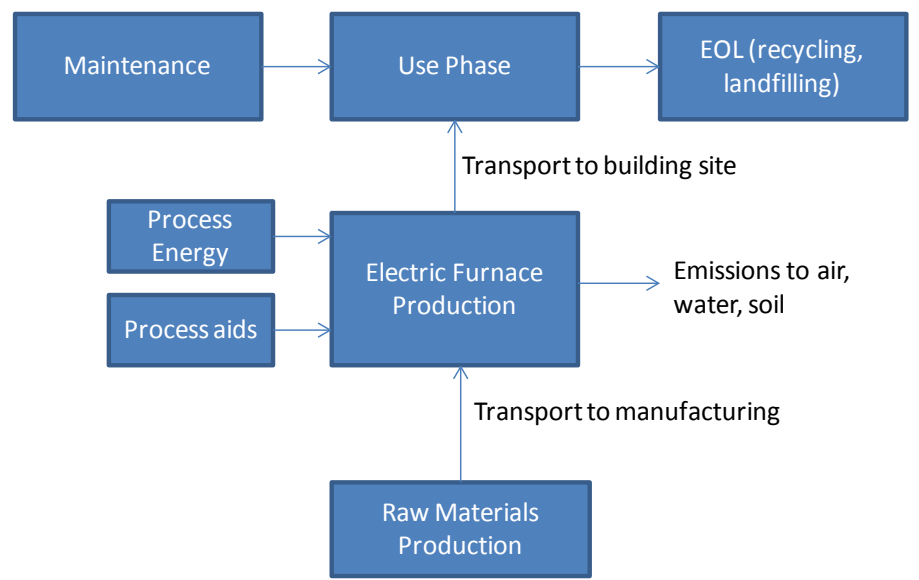

Figure 3-5 HVAC System Boundaries - Electric Furnace Example

\subsubsection{Natural Gas and Electric Furnaces}

\subsection{Upstream Materials Production through Manufacturing}

LCA practitioners often seek bill of materials data when conducting life-cycle assessments. However, there was no bill of materials data available for residential 
furnaces so proxy data were used. Athena Sustainable Materials Institute (2003) provided teardown data for a medium efficiency Lennox sealed combustion furnace, manufactured in 1985. These data were used with adjustments. The mass of the Lennox, $91 \mathrm{~kg}$ (200 lb), was normalized to the mass of an efficient natural gas furnace currently available on the market that weighs approximately $56 \mathrm{~kg}(124 \mathrm{lb})^{7,8}$. These data were supplemented by Yang, Zmeureanu et al. (2008), which provided data for a blower motor, replacing that of the older Lennox, to account for the more efficient furnace. Table 3-26 provides the materials in the natural gas furnace; the notes column identifies the adjustments made.

\section{Table 3-26 Natural Gas Furnace Bill of Materials}

\begin{tabular}{lccl} 
& \multicolumn{3}{c}{ Mass } \\
Material & kg & $\mathbf{l b}$ & Notes \\
Aluminum & 1.02 & 2.25 & $\begin{array}{l}\text { Yang (2008) air blower data, replacing the Al in } \\
\text { Athena (2003) }\end{array}$ \\
Brass & 0.05 & 0.11 & \\
Ceramic & 0.04 & 0.08 & \\
Circuit board, transistors & 0.05 & 0.11 & \\
Copper & 2.20 & 4.85 & Yang (2008) air blower data, replacing the Cu \\
Fiberglass insulation (foil- & & & in Athena (2003) \\
lined) & 0.27 & 0.60 & \\
Galvanized Steel & 21.86 & 48.19 & Steel paired down to meet the Rheem weight \\
PET & 0.38 & 0.83 & \\
PVC & 0.45 & 0.99 & \\
Powder coating & 0.19 & 0.42 & \\
Rubber & 0.02 & 0.04 & \\
Steel & 29.79 & 65.66 & Yang (2008) air blower and Athena (2003). \\
Total & 56.3 & $\mathbf{1 2 4 . 1}$ & \\
\hline
\end{tabular}

For the electric furnace, the mass of the Lennox was normalized down to the mass of the electric furnace in BIRDS, a unit currently on the market. ${ }^{9}$ Data for the blower motor were provided by Yang (2008). Table 3-27 presents the bill of materials with data adjustments.

\footnotetext{
${ }^{7}$ Weight of the Standard Rheem Classic 95 \% efficiency natural gas furnace (RGRC-07-RBGS) from Rheem Classic Series, Upflow Gas Furnaces, Physical Data and Specifications, Form No. G11-527, p.4. ${ }^{8}$ This source states a total shipping weight of $62.1 \mathrm{~kg}(137 \mathrm{lb})$. The mass of the equipment itself was assumed to be $91 \%$ of the total weight, based on other Rheem product published weights relative to their shipping materials.

${ }^{9}$ Rheem Air Handlers, Form No. H11-524 REV. 8, Unit Dimensions \& Weights, p.4, model 4221/4821.
} 
Table 3-27 Electric Furnace Bill of Materials

\begin{tabular}{|c|c|c|c|}
\hline \multirow[b]{2}{*}{ Material } & \multicolumn{2}{|c|}{ Mass } & \multirow[b]{2}{*}{ Notes } \\
\hline & kg & lb & \\
\hline Aluminum & 1.02 & 2.25 & Yang (2008), replacing the $\mathrm{Al}$ in Athena (2003) \\
\hline Brass & 0.05 & 0.11 & \\
\hline Ceramic & 0.04 & 0.08 & \\
\hline Circuit board, transistors & 0.05 & 0.11 & \\
\hline Copper & 2.20 & 4.85 & Yang (2008), replacing the Cu in Athena (2003) \\
\hline Fiberglass insulation (foil- lined) & 0.27 & 0.60 & \\
\hline Galvanized Steel & 34.04 & 75.04 & Steel paired down to meet the Rheem weight \\
\hline PET & 0.38 & 0.83 & \\
\hline PVC & 0.45 & 0.99 & \\
\hline Powder coating & 0.32 & 0.71 & $\begin{array}{l}\text { Model assumes } 0.095 \mathrm{~kg} \text { powder per } \mathrm{m}^{2} \text { (from } \\
\text { ecoinvent) }\end{array}$ \\
\hline Rubber & 0.02 & 0.04 & \\
\hline Steel & 29.17 & 64.31 & $\begin{array}{l}\text { Yang (2008) air blower and Athena (2003). Steel } \\
\text { paired down to meet the Rheem weight }\end{array}$ \\
\hline Total & 68.00 & 149.9 & \\
\hline
\end{tabular}

The steel is assumed to be cold-rolled; this and the galvanized steel come from World Steel Association (2011). Aluminum is modeled as a 50/50 mix of primary and secondary extruded aluminum using data from the U.S. LCI Database. Data for copper come from International Copper Association (ICA) (2012). Data for PET and PVC come from the US LCI database. Ecoinvent provided the data for brass, ceramics, integrated circuit boards, rubber (as synthetic rubber), and powder coating. The fiberglass insulation was modeled as described in the insulation section of this report.

Raw materials are modeled as transported to the manufacturing plant via diesel truck an assumed average distance of $805 \mathrm{~km}$ (500 mi).

Because no manufacturing data were available for residential furnaces, an ecoinvent data set for a 10-kW (34 MBH) oil boiler was used as a proxy (Ecoinvent 2007). The ecoinvent dataset description states that the $10 \mathrm{~kW}$ low- $\mathrm{NO}_{\mathrm{x}}$ or condensing boiler data may be applied for residential furnaces (Ecoinvent 2007). The production energy is stated to be estimated from a 1998 environmental report. Even though this proxy is considered not to be representative of current practice, its use is considered sufficient for comparison purposes.

Table 3-28 shows data for a boiler of approximately $150 \mathrm{~kg}(331 \mathrm{lb})$. Since manufacturing the smaller units is assumed to require less energy, these data were normalized based on the total weights of the natural gas and electric furnaces. 
Table 3-28 Furnace Manufacturing

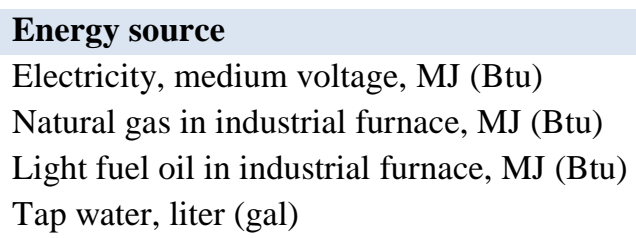

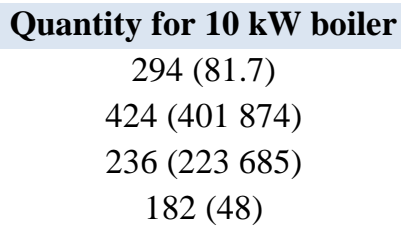

\subsection{Transportation to the Building Site through End-of-Life}

Transportation of the equipment to the building site is modeled using an assumed average of $644 \mathrm{~km}$ (400 mi) by heavy-duty diesel fuel-powered truck.

It is assumed that a qualified service technician comes to the building site to check and/or service the unit one time every three years to ensure optimal performance and lifetime. It is assumed that the qualified technician is within a $24 \mathrm{~km}(15 \mathrm{mi})$ service radius. This distance, driven in a gasoline-powered van, is allocated amongst other service visits, if the same technician is making more than one service call during that trip. Assuming the technician makes 5 service calls in one day, one-fifth of the impacts from driving $24 \mathrm{~km}$ (15 mi) are allocated to the product, or $4.8 \mathrm{~km}(3 \mathrm{mi})$. Environmental flow data associated with the operation of the van comes from ecoinvent. Unplanned service visits (i.e., unanticipated issues that require a service technician) are not included in the model under the assumption that the system will run as designed given the homeowner adequately follows the maintenance and care guidelines.

A lifetime of 16 years has been assumed for both gas and electric furnaces, based on the National Association of Home Builders (NAHB) Research Center (2007), a study on life expectancy of home components. ${ }^{10}$

At the end-of-life, it is assumed that the furnaces are sent for recycling to recover valuable metal using the " $0-100$ recycling methodology" discussed previously in Section 3.3.4.7. What cannot be recovered, i.e., any non-metallic parts, are modeled as landfilled, assuming a distance of $48 \mathrm{~km}(30 \mathrm{mi})$ to the land fill with transport via heavy-duty diesel truck. The landfill is modeled based on ecoinvent end-of-life waste management process data.

\subsubsection{Residential Air Conditioners}

Residential air conditioners for BIRDS are modeled as split systems with outdoor and indoor components that provide a condenser and evaporative heat exchanger, respectively. BIRDS includes LCA data for 3-ton residential air conditioners with SEERs of 13, 14, 18, and 21. SEER - Seasonal Energy Efficiency Ratio - is defined by the Air Conditioning, Heating, and Refrigeration Institute (AHRI) as total heat removed from the conditioned space during the annual cooling season divided by the total electrical energy

\footnotetext{
${ }^{10}$ NAHB (2007), Table 1, Section 15 gives furnaces a life expectancy range of 15 to 20 years.
} 
consumed by the air conditioner or heat pump during the same season, expressed in watthours (AHRI 2008). Eighteen SEER is considered to be a high rating relative to other models; based on informal discussions with industry members, only a small percentage of the market is currently at 18 SEER. An even smaller percentage is beyond 18 SEER, so 21 SEER is considered to be exceptionally high, providing an extremely efficient system.

\subsection{Upstream Materials Production through Manufacturing}

Bill of materials for the outside unit (condenser) shown in Table 3-29 came from De Kleine (2009). The condensing unit is based on a tear-down of a 3-ton, 10 SEER unit manufactured in approximately 2001. The components' materials were assumed by Four Elements, except where noted.

\section{Table 3-29 Condenser Unit Bill of Materials}

\begin{tabular}{llccl} 
Main & Material Breakdown & $\mathbf{k g}$ & $\mathbf{L b}$ & Notes \\
Component & & & & \\
Compressor & Aluminum & 0.53 & 1.16 & Compressor breakdown from (Biswas \\
& Cast iron & 24.74 & 54.54 & and Rosano 2011), Fig 1. \\
& Copper & 1.32 & 2.90 & \\
& Steel & 2.72 & 6.00 & \\
\hline Coil Assembly & Copper (tubing) & 3.95 & 8.71 & Approx. 50 \% copper tubing, 50 \% \\
& Aluminum (fins) & 3.95 & 8.71 & aluminum fins. (De Kleine, 2009) \\
\hline Fan Motor & Copper wire & 1.08 & 2.37 & Assumed to have a composition of 25 \\
& Steel & 3.10 & 6.83 & \% copper wire, 72 \% steel, and 3 \% \\
& Polyamide & 0.13 & 0.28 & polyamide (De Kleine 2009) \\
\hline Unit Wall & Galvanized steel & 3.10 & 6.83 & \\
\hline Base & Galvanized steel & 2.70 & 5.95 & \\
\hline Top Cover & Galvanized steel & 1.90 & 4.19 & \\
\hline Fan Guard & Stainless steel & 1.60 & 3.53 & \\
\hline Refrigerant & Brass (service valves) & 0.75 & 1.65 & \\
Line service & Rubber & 0.25 & 0.55 & \\
valve & Stainless steel & 0.80 & 1.76 & \\
\hline Wire Guard & Steel & 0.60 & 1.32 & \\
\hline Fan Blade & Steel & 0.30 & 0.66 & \\
\hline Misc Fasteners & Sheet metal (steel) & 0.30 & 0.66 & \\
\hline Capacitor & Copper wiring & 0.10 & 0.22 & Assumed to be 50 \% copper wiring and \\
\hline Relay Switch & Nylon polymer & 0.10 & 0.22 & 50 \% nylon polymer (De Kleine 2009) \\
\hline Copper Wiring & Copper wire & 0.20 & 0.44 & \\
\hline Total & & $\mathbf{5 4 . 2 0}$ & $\mathbf{1 1 9 . 4 9}$ & \\
\hline & & & & \\
\hline & & & \\
& & &
\end{tabular}

De Kleine (2009) performed a teardown for a SEER 10 unit, but the bill of materials for higher SEERs were required for the study. To do this, De Kleine (2009) created a weight 
function using survey data and manufacturer specification sheets on condenser units from several different brands ranging in efficiency from 10 SEER to 18 SEER and ranging in capacity from 1.5 tons to 5 tons of cooling. This weight function was used to calculate the mass of each of the condenser units in BIRDS as follows, enabling the adjustment of the bill of materials to the different masses as shown in Table 3-30. See De Kleine (2009) for more detail.

Table 3-30 Condenser Unit Masses

\begin{tabular}{lccccc} 
& SEER 10 & SEER 13 & SEER 14 & SEER 18 & SEER 21 \\
$\begin{array}{l}\text { Factor } \\
\text { Mass in kg }\end{array}$ & 1 & 1.36 & 1.49 & 1.98 & 2.34 \\
(lb) & & & & & \\
\hline
\end{tabular}

These values corresponded with De Kleine (2009), and are consistent with manufacturers' products of the same SEER ratings.

The evaporator coil indoor unit was modeled as being housed in the electric furnace. De Kleine (2009) approximated the inside coil assembly for a 13 SEER system to weigh 15.9 $\mathrm{kg}(35 \mathrm{lb})$ and be composed of $50 \%$ copper tubing and $50 \%$ aluminum fins. The refrigerant line, connecting the outdoor and indoor units, was modeled as 20 feet of copper tubing weighing $4.5 \mathrm{~kg}$ (9.9 lb) (De Kleine 2009). The air conditioning system uses R-410a refrigerant, and data for the quantity of refrigerant used in each of the SEERs studied (shown in Table 3-31) was calculated using refrigerant mass function developed by De Kleine (2009).

\section{Table 3-31 Refrigerant Quantities}

\begin{tabular}{lcccc} 
& SEER 13 & SEER 14 & SEER 18 & SEER 21 \\
$\mathbf{R}-410 a$ in kg (lb) & $3.3(7.3)$ & $3.6(7.9)$ & $5.0(10.9)$ & $6.5(14.4)$ \\
\hline
\end{tabular}

The steel data, assumed to be cold-rolled, and the galvanized steel data come from the World Steel Association (2011). Aluminum is modeled as a 50/50 mix of primary and secondary extruded aluminum using data from the U.S. LCI Database. Data for copper tube, sheet, and wire come from International Copper Association (ICA) (2012). Ecoinvent provided the data for the cast iron, stainless steel, brass, rubber (as synthetic rubber), and polyamide.

R-410a data are based on a 50/50 share of difluoromethane (R-32) and pentafluoroethane (R-125). Due to lack of available production data on both chemicals, proxies were implemented. Trifluoromethane (HFC-23) was used as a proxy for difluoromethane and 1,1,difluoroethane (HFC-152a) was used as proxy for R-125. Note: while proxies were used for the production aspect of the chemicals, any release of these was based on the release of R-32 and R-125, not the proxy chemicals, so that ozone depletion impact remains zero and climate change potential impact is calculated appropriate to R-410a. 
Raw materials are modeled as transported to the manufacturing plant via diesel truck an assumed average distance of $805 \mathrm{~km}$ (500 mi).

No manufacturing data were available for residential air conditioners, so as proxy, an ecoinvent data set for a $10 \mathrm{~kW}(34 \mathrm{MBH})$ oil boiler was used. Since manufacturing the smaller units is assumed to require less energy and resources than the $150 \mathrm{~kg}$ (331 lb) boiler, these data were normalized based on the total weights of the air conditioners.

\subsection{Transportation to the Building Site through End-of-Life}

Transportation of the equipment to the building site is modeled using a heavy-duty, diesel-powered truck is used and an average distance of $1287 \mathrm{~km}$ (800 mi) is travelled. This distance was estimated by De Kleine (2009) and is based on five manufacturing locations of major residential air conditioner manufacturers.

It is assumed that a qualified service technician comes to the building site to check and service the unit every three years to ensure optimal performance and lifetime. It is assumed that the qualified technician is within a $24 \mathrm{~km}$ (15 mi) service radius. This distance is driven in a gasoline-powered van and is shared amongst other service visits for that technician, assuming that the same technician is making more than one service call during that trip. Assuming the technician makes 5 service calls in one day, one-fifth of the impacts from driving $24 \mathrm{~km}(15 \mathrm{mi})$ are allocated to the product, or $4.8 \mathrm{~km}$ (3 mi). Data for a van come from ecoinvent. Unplanned service visits (i.e., unanticipated issues that require a service technician) are not included in the model under the assumption that the system will run as designed given the homeowner adequately follows the maintenance and care guidelines.

A lifetime of 15 years has been assumed for the air conditioners (National Association of Home Builders (NAHB) Research Center 2007). During use, refrigerant is assumed to escape at a rate of $2 \%$ per year of the total refrigerant (De Kleine 2009). It is recharged every three years during the maintenance visit.

At the end-of-life, it is assumed that the air conditioners are sent for recycling to recover valuable metal using the " 0 -100 recycling methodology discussed previously in Section 3.3.4.7. What cannot be recovered, i.e., any non-metallic parts, are modeled as landfilled assuming a distance of $48 \mathrm{~km}$ (30 mi) to the landfill with transport via heavy-duty diesel truck. The landfill is based on ecoinvent waste management process data. A study prepared for Air-Conditioning, Heating, and Refrigeration Technology Institute (AHRTI) assumes an overall loss of 15\% of the R-410a refrigerant (AHRTI 2011). This is based on "recovering $90 \%$ of the charge from $95 \%$ of the field units, but allowing for a $100 \%$ charge loss from about $5 \%$ of the field stock” (AHRTI 2011).

\subsubsection{Split System Heat Pump}

The Net-Zero Energy Residential Test Facility (NZERTF) uses a split system heat pump which can convert cooler outside air to warm inside air for heating, and vice versa for cooling. A split system is an air conditioner split by the air source condensing unit 
located on the outside of the building and an air handler inside the building. An air handler is an appliance used to condition and circulate air through a building as part of the building's HVAC system. The Aaon condensing unit (model CB-036) and corresponding heat pump air handler (model F1-036) are modeled in the NZERTF. By way of the reversible heap pump, the system provides cooling and heating with R-410A refrigerant. The refrigerant absorbs heat in the evaporator where it vaporizes, and releases heat where the refrigerant condenses, in the condenser. In heating mode, the outdoor coil serves as the evaporator, while the inside coil is the condenser. The refrigerant coming from the outdoor coil carries the thermal energy from outside air indoors. The indoor coil then transfers thermal energy to the indoor air, where it is distributed throughout the home by the air handler. In cooling mode, the cycle is reversed; similar to an air conditioner, the outdoor coil is the condenser and the indoor coil is the evaporator. In BIRDS, the split system heat pump's system boundaries are modeled as follows:

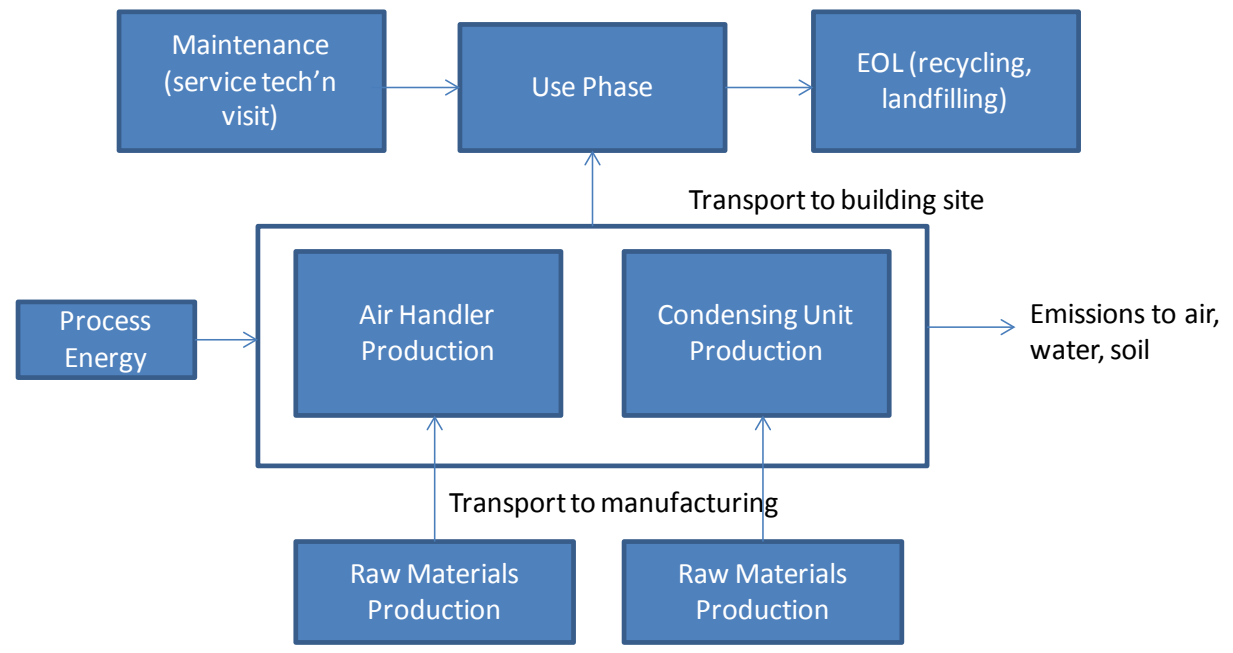

Figure 3-6 Split System Heat Pump System Boundaries

\subsection{Upstream Materials Production through Manufacturing}

Manufacturer-specific data was not available, so publicly-available sources of data were used as proxy and customized wherever possible using product specifications. Data for the bill of materials for the air handler comes from Nyman (2004) Table $2 .{ }^{11}$ The higher mass of the air handler in Nyman (2004) - $691 \mathrm{~kg}(1523 \mathrm{lb})$ - was scaled down to the mass of the $58.5 \mathrm{~kg}(129 \mathrm{lb})$ Aaon unit, and data are as follows in Table 3-32:

\footnotetext{
${ }^{11}$ The data for the small air-handling unit (AHU) w/ wheel was used.
} 
Table 3-32 F1 Air Handler Bill of Materials

\begin{tabular}{lccrl}
\multicolumn{1}{c}{ Material Breakdown } & Kg & Lb & \multicolumn{1}{c}{ \% } & Notes \\
Sheet metal and cast iron & 47.8 & 105.3 & $81.6 \%$ & Assume 75\% is galv. \\
Mineral wool & 4.9 & 10.8 & $8.4 \%$ & steel, 25\% cast iron \\
Fiberglass & 0.5 & 1.1 & $0.9 \%$ & \\
Copper & 1.3 & 2.8 & $2.2 \%$ & \\
Aluminum & 4.0 & 8.8 & $6.8 \%$ & \\
Natural rubber & 0.1 & 0.1 & $0.1 \%$ & \\
Total --> & $\mathbf{5 8 . 5}$ & $\mathbf{1 2 9 . 0}$ & $\mathbf{1 0 0} \%$ & \\
\hline
\end{tabular}

The galvanized steel comes from World Steel Association (2011). Aluminum is modeled as a 50/50 mix of primary and secondary extruded aluminum which come from the U.S. LCI Database. Data for copper tube comes from ICA (2012). Ecoinvent provided the data for the cast iron, glass fiber, mineral wool (as rock wool), and rubber.

No manufacturing data were available for the air handler, so as proxy, an ecoinvent data set for a $10 \mathrm{~kW}$ (34 MBH) oil boiler was used - see discussion above Table 3-32. Since manufacturing/assembling the smaller air handler is assumed to require less energy and resources than the $150 \mathrm{~kg}$ (331 lb) boiler, these data were scaled down on a mass basis.

For the condensing unit, the bill of materials for the residential air conditioner was used. Table 3-29 provides a detailed breakdown of components and materials for a 3-ton, 10 SEER condensing unit (De Kleine, 2009). The data in the table were increased by the 1.98 factor given in Table 3-30, to be more in line with the Aaon condensing unit, whose mass $(107.5 \mathrm{~kg}(237 \mathrm{lb}))$ corresponds almost perfectly with the data in Table 3-30. It should be noted that the Aaon unit provides an air conditioning rating of up to 17.3 SEER, not the SEER 18 in the table (Aaon 2016). Per an Aaon sales representative, ${ }^{12}$ the system is charged with $5.5 \mathrm{~kg}(12.1 \mathrm{lb}) \mathrm{R}-410 \mathrm{a}$ refrigerant. Data sources for all the materials in the condenser are given below Table 3-31.

As mentioned earlier in this documentation, no manufacturing data were available for residential air conditioners. However, the modeling of the materials in the equipment includes processing these materials into usable parts, i.e., tubing, wire, and sheet metal. While this does not include processes like punching, shearing, forming parts and general final assembly-related processing, it likely accounts for most environmental impacts. This unknown quantity is difficult to quantify without understanding the processes at this product's final manufacturing/assembly plant.

\subsection{Transportation to the Building Site through End of Life}

Transportation of the equipment to the building site is modeled using an assumed average of $2414 \mathrm{~km}$ (1500 mi) by heavy-duty diesel fuel-powered truck.

\footnotetext{
${ }^{12}$ Phone correspondence with Aaon in June, 2014.
} 
The air handler uses a $50.8 \times 50.8 \times 2.54 \mathrm{~cm}(20 \times 20 \times 1$ in) air filter that should be checked every 30 days and replaced or cleaned as necessary. Permanent type filters may be vacuumed and/or washed, and reinstalled when thoroughly dry. BIRDS includes a disposable air filter. An Aaon salesperson said that no specific filter is required and that it can be purchased locally. The filter that has been modeled for this system is a minimum efficiency reporting value (MERV) 11 filter, described in Table 3-36 and adjusted to 50.8 x $50.8 \mathrm{~cm}(20$ x 20 in).

Maintenance includes a qualified service technician coming to the building site to check and service the unit every three years to ensure optimal performance and lifetime. It is assumed that the technician is within a $24 \mathrm{~km}(15 \mathrm{mi})$ service radius. This distance is driven in a gasoline-powered van and is shared amongst other service visits for that technician, if the same technician is making more than one service call during that trip. Assuming the technician makes 5 service calls in one day, one-fifth of the impacts from driving $24 \mathrm{~km}$ (15 mi) are allocated to the product, or $4.8 \mathrm{~km}$ (3 mi). Data for a van come from ecoinvent. Unplanned service visits (i.e., unanticipated issues that require a service technician) are not included in the model under the assumption that the system will run as designed given the homeowner adequately follows the maintenance and care guidelines.

Per Aaon, ${ }^{13}$ the air handler has a lifetime of 15 yrs and the condensing unit has a lifetime of 16 yrs. These stated lifetimes are consistent with those listed in NAHB (2007) for those items. During use, refrigerant is assumed to escape at a rate of $2 \%$ per year. (De Kleine, 2009, Sec. 3.3). It is modeled as recharged every three years during the maintenance visit.

At the end of their life, it is assumed that the equipment is sent for recycling to recover valuable metal (see windows end-of-life in Section 3.3.4.7 for the recycling methodology used). What cannot be recovered is modeled as landfilled. A distance of $48 \mathrm{~km}$ (30 mi) to the landfill in a heavy-duty diesel truck has been modeled. The landfill is based on ecoinvent waste management process data. A study prepared for Air-Conditioning, Heating, and Refrigeration Technology Institute (AHRTI, 2011) assumes an overall loss of $15 \%$ of the R-410a refrigerant after decommissioning. This is based on "recovering 90 $\%$ of the charge from $95 \%$ of the field units, but allowing for a $100 \%$ charge loss from about $5 \%$ of the field stock”. (AHRTI, 2011, p.12)

\subsubsection{Heat Recovery Ventilator}

One of the featured technologies in the Net-Zero Energy Residential Test Facility (NZERTF) is a heat recovery ventilator (HRV). An HRV moves stale, contaminated air outside while bringing in fresh air, all the while extracting the hot energy from the indoor air and transferring it to the incoming air, so that there is little energy lost. HRV systems are especially important in newer, tightly sealed homes that do not have as much natural ventilation. The HRV unit modeled for the NZERTF and BIRDS is the Venmar EKO 1.5

\footnotetext{
${ }^{13}$ Phone correspondence with Aaon in June, 2014.
} 
HRV, a high-efficiency model that, per Venmar, uses high performance motors which enable it to significantly lower energy costs without affecting performance. The heat recovery core can retain up to $80 \%$ of a home's heating or cooling. ${ }^{14}$

In 2013, Venmar contributed data to BIRDS on the EKO 1.5 HRV, model 43900, to be used in the calculations in NZERTF and BIRDS. One HRV is evaluated in this system.

\subsection{Raw Material Production}

Venmar provided the detailed bill of parts and materials in the HRV system. The list of parts has been removed from this documentation to protect the proprietary nature of the data. Instead, the $22.6 \mathrm{~kg}(49.8 \mathrm{lb})$ unit's parts have been grouped in terms of likematerials, as presented in Table 3-33.

\section{Table 3-33 Venmar EKO 1.5 Bill of Materials}

$\begin{array}{lc}\text { Material } & \text { Percent in Product } \\ \text { Prepainted steel } & 41.3 \% \\ \text { Polypropylene (PP) } & 15.8 \% \\ \text { Motor: steel, alum, copper } & 12.0 \% \\ \text { Galvanized steel } & 8.1 \% \\ \text { Expanded polystyrene (EPS) foam } & 5.9 \% \\ \text { Aluminum } & 3.5 \% \\ \text { Steel, copper wire, leadwire } & 4.7 \% \\ \text { Polyvinyl chloride (PVC) } & 2.0 \% \\ \text { Acrylonitrile-butadiene-styrene copolymer (ABS) } & 1.7 \% \\ \text { Additional materials } & 5.0 \% \\ \text { Total } & \mathbf{1 0 0 \%}\end{array}$

Over 99\% of the reported materials were included in the model. Data for prepainted steel comes from the World Steel (2011) dataset for Finished Cold Rolled Coil (FCRC). Per Venmar, the motor is made up of approximately $45 \%$ steel, $45 \%$ aluminum, and $10 \%$ copper. The steel is based on World Steel (2011) LCI data on finished cold rolled steel (FCRC). The aluminum used in the motor and other parts of the unit is extruded aluminum, using a mix of secondary and primary aluminum, and this data comes from the U.S. LCI Database. The copper sheet data comes from ICA (2012). World Steel's (2011) data on hot-dip galvanized (HDG) steel is used for the galvanized steel.

The EPS is used as insulation within the unit. Foam production data come from ecoinvent. While the foam data is European-based, the polystyrene (PS) resin within the dataset was switched out with the U.S. LCI dataset for PS resin production. The resins of Polypropylene (PP), Polyvinyl chloride (PVC), and Acrylonitrile-butadiene-styrene copolymer (ABS) come from the U.S. LCI Database.

\footnotetext{
${ }^{14}$ Description of performance retrieved at: http://www.venmar.ca/110-air-exchangers-eko-1-5hrv.html\#!prettyPhoto
} 
Leadwire is tinned copper with PVC insulation. Copper wire (ICA (2012)) is assumed to make up $40 \%$ by mass, with the other $60 \%$ being the PVC.

Additional materials in the unit include: NBR foam (data for acrylonitrile and polymer foaming from ecoinvent); some electrical parts (from ecoinvent); high impact polystyrene (U.S. LCI Database), EPDM (modeled as synthetic rubber, from ecoinvent), and silicone sealant (based on data from ecoinvent).

The packaging, an additional $3.9 \mathrm{~kg}(8.7 \mathrm{lb})$, includes corrugated cardboard and cardboard (89 \% of packaging), EPS foam (10\%), and less than $1 \%$ each of steel, PVC, and low-density polyethylene (LDPE). The cardboard production data come from ecoinvent. The steel, PVC, and LDPE were not included in the model since, overall, they amounted to less than $0.01 \%$ of the total mass.

Transport distances and modes of transportation of the parts to Venmar's Drummondville, Quebec, facility were provided by Venmar. Most of the main suppliers are local, thus most the parts were reported to be within $100 \mathrm{~km}$ (62 mi). The parts within North America are modeled as transported by heavy-duty (combination) diesel-fueled truck. The few parts that come from Asia or Europe are modeled as transported by ocean freighter and heavy-duty truck. Data for the combination truck and ocean freighter come from the U.S. LCI database.

\subsection{Manufacturing}

Venmar's Drummondville, Quebec, facility produces HRVs and Energy Recovery Ventilators (ERVs) delivering airflow from $0.019 \mathrm{~m}^{3} / \mathrm{s}$ to $0.142 \mathrm{~m}^{3} / \mathrm{s}$ (40 cubic feet per minute (CFM) to 300 CFM). The Venmar facility is primarily an assembly plant: flat prepainted or galvanized steel sheet is transformed using an automated punching machine and hydraulic press brakes. Wiring in the units is connected. Most of the labor is manual assembly of components using either screw (pneumatic screwdrivers) or silicone for sealing parts. The facility is a "dry" assembly line. Thus, no water is used, nor is any solvent except for cleaning the working area and when a part or unit needs cleaning. Energy was reported on a full facility basis and has been normalized on a per-unit basis, as follows in Table 3-34:

\section{Table 3-34 HRV Production Energy Requirements}

\begin{tabular}{lll} 
Energy Source & \multicolumn{1}{c}{ Quantity } & Notes \\
$\begin{array}{l}\text { Electricity } \\
\text { (hydroelectricity) }\end{array}$ & $8.7 \mathrm{kWh}(0.0966 \mathrm{MMBtu})$ & $\begin{array}{l}\text { Lighting, hand tools, compressor, press brake and } \\
\text { automated punching machine, cooling and computers. } \\
\text { Natural gas }\end{array}$ \\
\hline
\end{tabular}

Data for the energy come from the U.S. LCI database. While solvent is used to clean areas or parts, its use, and any VOCs from this cleaning, are considered negligible and not included in th `e model. No waste or air emissions were reported. 


\subsection{Transportation to the Building Site through End of Life}

For BIRDS, which accounts for transport to customers throughout North America, a transportation distance of the unit to installation was modeled as $2414 \mathrm{~km}(1500 \mathrm{mi})$. Transportation is done by heavy-duty (combination) diesel-fueled truck, and these data come from the U.S. LCI Database. Modeling the customer driving to a store to purchase and bring the unit home is not included for the first purchase, with the assumption that this unit is installed when the home is built, so the unit is delivered by the builder (in a truck or van).

For maintenance, HRVs should undergo simple maintenance procedures, including cleaning the unit and filters, about every six months. This can be done by the homeowner.

The lifetime is expected to be 20 or more years, based on the stated lifetime of an HRV in NAHB (2007), Table 1, Sec. 15. At the end of life, it is assumed that the HRV is sent for recycling to recover valuable metal (see windows end of life in Section 3.3.4.7 for the recycling methodology used). The non-metal parts are modeled as landfilled. A distance of $48 \mathrm{~km}$ (30 mi) to the landfill in a heavy-duty diesel truck has been modeled. The landfill is based on ecoinvent waste management process data.

\subsubsection{Whole House Dehumidifier}

One of the energy technologies employed by the Net-Zero Energy Residential Test Facility (NZERTF) is a whole-house ventilating dehumidifier. Data for the Ultra-Aire Whole-House Ventilating Dehumidifier (model 70H) was used in the calculations in NZERTF and BIRDS. With a capacity of 70 pints/day, the Ultra-Aire $70 \mathrm{H}$ is designed to provide moisture control and air filtration for an area of up to $1800 \mathrm{sq}$. $\mathrm{ft}$. It has a MERV rating of 11 . Ultra-Aire contributed the data on the $70 \mathrm{H}$; one dehumidifier is evaluated in this system.

\subsection{Upstream Material Production}

Ultra-Aire provided the material composition of the dehumidifier in terms of percentage of materials, along with functions and/or parts of the main components. These data were used to construct a bill of materials, shown in Table 3-35. 
Table 3-35 Ultra-Aire 70H Whole-House Ventilating Dehumidifier Bill of Materials

\begin{tabular}{|c|c|c|c|}
\hline \multirow[b]{2}{*}{ Material } & \multicolumn{2}{|c|}{ Mass } & \multirow[b]{2}{*}{ Notes } \\
\hline & Lb & Kg & \\
\hline Steel & 37.7 & 17.1 & Housing, motors, and fasteners. \\
\hline Copper & 7.7 & 3.5 & Refrigerant tubing, motor windings, wiring \\
\hline $\begin{array}{l}\text { High density } \\
\text { polyethylene (HDPE) }\end{array}$ & 1.65 & 0.75 & Drain pan (assumed HDPE). \\
\hline $\begin{array}{l}\text { Polyvinyl Chloride } \\
\text { (PVC) }\end{array}$ & 1.1 & 0.5 & Electrical components, duct collars \\
\hline Rubber & 1.1 & 0.5 & Seals and trim. \\
\hline Foam insulation & 1.65 & 0.75 & Assumed expanded polystyrene (EPS) foam \\
\hline Aluminum & 2.75 & 1.25 & Heat exchanger fins \& plates \\
\hline R410a refrigerant & 0.81 & 0.37 & Actual quantity reported to be in a new unit. \\
\hline Compressor oil & 0.55 & 0.25 & \\
\hline Total & 55.01 & 24.97 & \\
\hline
\end{tabular}

Data for steel come from World Steel Association (2011). Data for the copper tubing and copper wiring come from ICA (2012). The data for the HDPE and PVC come from the U.S. LCI Database. The rubber comes from the ecoinvent database, as does the "foaming" process for the EPS insulation. The U.S. LCI Database supplied the data for production of the PS resin in the EPS. Aluminum is modeled as a 50/50 mix of primary and secondary extruded aluminum and comes from the U.S. LCI Database. The compressor oil was modeled as lubricating oil, which comes from the U.S. LCI database.

The Ultra-Aire 70H uses R410a in its refrigeration system to remove heat and moisture from incoming air and add heat to the air that is discharged. The R410a data is discussed in text following Table 3-31.

The transportation distance of components to the assembly plant in Madison, WI was assumed to be on average $805 \mathrm{~km}$ (500 mi), assuming some of the larger parts are relatively local and smaller parts may be transported greater distances. Transport is modeled as heavy-duty (combination) diesel-fueled truck. Data for the combination truck come from the U.S. LCI Database.

\subsection{Manufacturing}

Components, materials, and sub-assemblies are shipped to Ultra-Aire's Madison, WI, facility. The dehumidifier is assembled in batches on an assembly line in the plant dedicated to the product platform. The product is primarily assembled by hand with a few assembly stations utilizing automation. The finished product is held in and shipped from Ultra-Aire's distribution center that adjoins the plant. It is assumed that some electricity is used and that there are probably some ancillary materials, such as solvents or degreasers for cleaning the working area or perhaps parts or units. No manufacturing data were provided for this equipment but proxy data on electricity use for assembly of a similar size of HVAC equipment was used. 


\subsection{Transportation to the Building Site through End of Life}

Transportation distance of the unit to installation was modeled as $1368 \mathrm{~km}$ (850 mi), based on Ultra-Aire's average shipping distance to customers in North America.

Transportation is modeled as heavy-duty diesel-fueled truck, and these data come from the U.S. LCI Database.

A lifetime of 19 years was modeled based on a recent analysis by the U.S. Department of Energy (DOE) that determined whole house dehumidifiers to have a 19-year life. (DOE, 2015, Table 8.2.25) This longer life finding is fairly consistent with Ultra-Aire whole house dehumidifiers; Ultra-Aire introduced this product line in 1996 and, anecdotally speaking, there are originals still in use.

The only maintenance that needs to be done is to regularly inspect it and clean or replace the air filter. Seasonal maintenance should include drain line inspection/cleaning. The unit uses a MERV-11 (or optionally MERV-14) filter, and it is recommended by the manufacturer that the filter be replaced every 3-6 months. The replacement of the MERV 11 filter every six months was included in the model, and included the homeowner trip to the store as well as the mass of the materials in the filter. The bill of materials of the MERV 11 filter was obtained by purchasing a MERV 11 media filter of size 22.9 x 27.9 x $2.54 \mathrm{~cm}(9 \times 11 \times 1$ in) (P/N 4030671), then disassembling it and weighing the parts. The bill of materials was compiled as follows in Table 3-36:

\section{Table 3-36 MERV-11 Filter Bill of Materials}

\begin{tabular}{lccl} 
& \multicolumn{2}{c}{ Mass } & \\
Part and/or Material & Lb & $\mathbf{g}$ & Notes \\
\hline Plastic stretch wrap (packaging) & 0.002 & 1.0 & LDPE \\
Cardboard "frame" & 0.08 & 37.0 & Bleached \\
Rubber/plastic in the pleats & 0.12 & 55.0 & 11 rows, 5 g per row \\
Synthetic fiber & 0.075 & 34.0 & Assume PET \\
Total & $\mathbf{0 . 2 8}$ & $\mathbf{1 2 7}$ & \\
\hline
\end{tabular}

The data for the LDPE comes from the U.S. LCI Database, and ecoinvent provides the data for the cardboard. The plastic in the pleats is modeled as polypropylene. The synthetic fiber was modeled as a spun-bonded polyethylene terephthalate (PET). The PET comes from the U.S. LCI Database, and the data for the spunbonding process -0.76 kWh (2.73 MJ) per kg comes from EA (2011), Table 4.2. Filters are landfilled after they are replaced.

At the end of life of the dehumidifier, it is assumed that it is sent for recycling to recover valuable metal (see windows end of life in Section 3.3.4.7 for the recycling methodology used). The non-metal parts are modeled as landfilled. A distance of $48 \mathrm{~km}$ (30 mi) to the landfill in a heavy-duty diesel truck has been modeled. The landfill is based on ecoinvent waste management process data. The model assumes most of the refrigerant is recovered at end of life. This is supported by a study prepared for Air-Conditioning, Heating, and Refrigeration Technology Institute (AHRTI) that assumes an overall loss of 15\% of the 
R-410a refrigerant (based on "recovering $90 \%$ of the charge from $95 \%$ of the field units, but allowing for a $100 \%$ charge loss from about $5 \%$ of the field stock"). (AHRTI, 2011, p.12)

\subsubsection{Residential Water Heaters}

\subsubsection{Conventional and Tankless Water Heaters}

Conventional electric and gas-powered water heaters with 189-liter (50-gal) storage tanks were included in BIRDS. A Rinnai R75LSi gas tankless water heater was evaluated for use in the Net-Zero Energy Residential Test Facility (NZERTF). Per Rinnai, the tankless unit uses "up to 40 percent less energy than a traditional tank." ${ }^{15}$

\subsection{Upstream Materials Production through Manufacturing}

No manufacturer-specific data was available, so publicly-available sources of data were used as proxy. A comprehensive study on the eco-design of water heaters (VHK, 2007) was consulted for the bill of materials data for the water heaters in BIRDS.

Electric water heater. Table B.9 in VHK (2007) provided bills of materials for several electric water heaters; the heater with $200 \mathrm{~L}$ (53 gal) storage tank was used, as its size is closest to the $189 \mathrm{~L}$ (50 gal) needed for BIRDS. Since the Material Groups listed in Table B.9 were general, these data were supplemented by more detailed parts and materials provided by Table B.10 in VHK (2007) to develop the data shown in Table 3-37. Any assumptions made are noted.

\section{Table 3-37 Electric Water Heater Bill of Materials}

\begin{tabular}{|c|c|c|c|}
\hline \multirow[b]{2}{*}{ B.9 Material Group } & \multicolumn{2}{|c|}{ Mass } & \multirow[b]{2}{*}{ Parts, Materials \& Assumptions } \\
\hline & kg & lb & \\
\hline 3-Ferro & 40.5 & 89.2 & $\begin{array}{l}\text { Tank, mounting plate, screws. Tank assumed to be } \\
\text { stainless steel }\end{array}$ \\
\hline 2-TecPlastics & 1.5 & 3.3 & $\begin{array}{l}\text { Rubber gasket (assume } 25 \% \text { ), PVC pipe protection and } \\
\text { pipe collar, PVC thermal control (assume } 75 \% \text { ) }\end{array}$ \\
\hline 1-BlkPlastics - & 1.2 & 2.7 & Assume EPS insulation \\
\hline 7-Misc & 1.2 & 2.7 & $\begin{array}{l}\text { Portion of the Misc. category; part unknown. Assuming } \\
\text { packaging, based on Table B.10. Not included in this } \\
\text { analysis. }\end{array}$ \\
\hline 7-Misc & 0.3 & 0.7 & Portion of the Misc. category; Assume resistance heater \\
\hline 5-Coating & 3.1 & 6.7 & Assume enamel \\
\hline 4-Non-ferro & 0.2 & 0.5 & Assume copper \\
\hline 6-Electronics & 0.06 & 0.1 & Assume wiring, thermal control \\
\hline TOTAL & 48.1 & 106.0 & \\
\hline
\end{tabular}

\footnotetext{
${ }^{15}$ Rinnai product information retrieved from https://www.rinnai.us/tankless-water-heater. This was based on the average cost to run an electric tank water heater per the Department of Energy Average Energy Costs (www.doe.gov).
} 
Gas water heater. Bill of materials for the gas water heater and its storage tank shown in Table 3-38 are based on Table B.8 in VHK (2007), which contains materials for a generic water storage tank and the natural gas component of a water heater. Since a $189 \mathrm{~L}$ (50 gal) storage tank was not offered by VHK (2007), the data for the $150 \mathrm{~L}$ (39.6 gal) tank was scaled on a mass basis. The data for the gas heating/storage component was left the same.

\section{Table 3-38 Gas Water Heater Bill of Materials}

\begin{tabular}{lccl} 
Parts & \multicolumn{2}{c}{ Mass } & Materials \\
Generic tank & kg & $\mathbf{l b}$ & \\
Tank & 26.0 & 57.3 & Galvanized steel \\
Enamel & 4.7 & 10.3 & Enamel \\
Insulation & 9.1 & 20.0 & Rigid PUR foam \\
Mantle & 11.7 & 25.9 & Galvanized steel \\
Top/bottom & 0.3 & 0.6 & Polypropylene \\
Diptube & 2.1 & 4.7 & Galvanized steel \\
Fitting & 1.3 & 2.8 & Brass \\
Mounting & 0.6 & 1.4 & Galvanized steel \\
Subtotal & 55.8 & 122.9 & \\
Gas storage component & & & \\
Burner & 1.5 & 3.3 & Galvanized steel \\
H Ex & 3.5 & 7.7 & Galvanized steel \\
Flue parts & 2.7 & 6.0 & Galvanized steel \\
Gas valve & 1.4 & 3.1 & Aluminum diecast \\
Brass parts & 1.0 & 2.2 & Brass \\
Various steel parts & 41.0 & 90.4 & Galvanized steel \\
Subtotal & 51.1 & 112.7 & \\
Total & $\mathbf{1 0 6 . 9}$ & $\mathbf{2 3 5 . 6}$ & \\
\hline
\end{tabular}

Tankless water heater. Bill of materials for the $22.7 \mathrm{~kg}(50 \mathrm{lb})$ Rinnai R75LSi unit shown in Table 3-39 are derived from VHK (2007) Table B.6, which contains materials for instantaneous gas water heaters of varying power and weights. The basis for these data is the $20 \mathrm{~kW}$ gas-fired low temperature boiler evaluated in earlier VHK work on Methodology for the Ecodesign of Energy-using Products (MEEuP), corrected for typical product weights of gas instantaneous water heaters. ${ }^{16}$

\footnotetext{
${ }^{16}$ See VHK (2007) for more information.
} 
Table 3-39 Tankless Water Heater Bill of Materials

\begin{tabular}{lccc} 
Material & $\mathbf{k g}$ & $\mathbf{l b}$ & $\mathbf{\%}$ \\
Galvanized steel & 13.96 & 30.78 & $61.6 \%$ \\
Copper tube, sheet & 2.16 & 4.77 & $9.5 \%$ \\
ABS & 1.84 & 4.06 & $8.1 \%$ \\
Stainless steel, 18/8 coil & 1.36 & 2.99 & $6.0 \%$ \\
Die cast aluminum & 0.99 & 2.18 & $4.4 \%$ \\
Brass, CuZn38 cast & 0.83 & 1.83 & $3.7 \%$ \\
Cast Iron & 0.60 & 1.32 & $2.6 \%$ \\
Insulation ceramic, ferrite & 0.41 & 0.91 & $1.8 \%$ \\
Electronics, controller board & 0.35 & 0.76 & $1.5 \%$ \\
Others, not specified & 0.18 & 0.41 & $0.8 \%$ \\
Total & $\mathbf{2 2 . 6 8}$ & $\mathbf{5 0 . 0 0}$ & $\mathbf{1 0 0 . 0}$ \\
\hline
\end{tabular}

All steel and galvanized steel data come from World Steel Association (2011). Aluminum is modeled as a 50/50 mix of primary and secondary extruded aluminum which come from the U.S. LCI Database. Data for copper tube, sheet and wire come from ICA (2012). U.S. LCI Database provided the production data for ABS, PVC and PP. Ecoinvent provided the data for the stainless steel, brass, rubber (as synthetic rubber), EPS, PUR foam, enamel, and electronics. The unspecified "other" materials in the tankless water heater data amount to less than one percent; no assumptions were made as to the materials, so this mass was not accounted for in the model.

Raw materials are modeled as transported to the manufacturing plant via diesel truck an assumed average distance of $805 \mathrm{~km}$ (500 mi). Data come from the U.S. LCI Database.

No manufacturing data were available for residential water heaters, so as proxy, the ecoinvent data set for a $10 \mathrm{~kW}(34 \mathrm{MBH})$ oil boiler was used - see discussion above Table 3-28. Since manufacturing the smaller units is assumed to require less energy and resources than the $150 \mathrm{~kg}$ (331 lb) boiler, these data were scaled down based on the total weights of the water heaters.

\subsection{Transportation to the Building Site through End-of-Life}

Transportation of the water heaters to the building site is modeled using an assumed average of $644 \mathrm{~km}$ (400 mi) by heavy-duty diesel fuel-powered truck. The Rinnai tankless unit is modeled as transported $2414 \mathrm{~km}$ (1500 mi) by heavy-duty diesel fuelpowered truck. The difference is that the Rinnai unit is manufacture-specific so comes from one location, while the other water heaters are modeled as generic so are manufactured in many locations around the U.S., reducing the overall distance transported.

It is assumed that a qualified service technician comes to the building site to check and service the units every three years to ensure optimal performance and lifetime. It is assumed that the technician is within a $24 \mathrm{~km}$ (15 mi) service radius. This distance, driven in a gasoline-powered van, is shared amongst other service visits for that 
technician, assuming that the same technician is making more than one service call during that trip. Assuming the technician makes 5 service calls in one day, one-fifth of the impacts from driving $24 \mathrm{~km}(15 \mathrm{mi})$ are allocated to the product, or $4.8 \mathrm{~km}(3 \mathrm{mi})$. Data for a van come from ecoinvent. Unplanned service visits (i.e., unanticipated issues that require a service technician) are not included in the model under the assumption that the system will run as designed given the homeowner adequately follows the maintenance and care guidelines.

Lifetimes of 11 and 10 years have been assumed for the electric and gas-fired water heaters, respectively. (NAHB, 2007 Table 1, Section 1) The lifetime of the tankless water heater is modeled as 20 years. (NAHB, 2007, Table 1, Section 15) At the end-of-life, it is assumed that the water heaters are sent for recycling to recover valuable metal (see Section 3.3.4.7 for the recycling methodology used). What cannot be recovered is modeled as landfilled. A distance of $48 \mathrm{~km}$ (30 mi) to the landfill in a heavy-duty diesel truck has been modeled. The landfill is based on ecoinvent waste management process data.

\subsubsection{Heat Pump Water Heater}

The Net-Zero Energy Residential Test Facility (NZERTF) is equipped with a Rheem hybrid water heater. The water heater uses air source heat pump technology, extracting heat from warm air, intensifying the heat with a compressor, delivering the heat to the water, and exhausting the cooler air. It is an efficient way to heat water because it uses ambient air temperature to do much of the work. Manufacturer-specific data was not available, so publicly-available sources of data were used as proxy and customized wherever possible using product specifications. One heat pump water heater is evaluated in this system.

\subsection{Upstream Materials Production through Manufacturing}

A combination of electric water heater and air conditioner data from BIRDS was used. Adjustments were made to the bills of materials based on Rheem literature, including the addition of refrigerant, switching insulation quantities, and scaling the unit weights to the Rheem unit.

Rheem did not provide specific weight data for its hybrid heat pump water heater, so the weight was estimated based on information on other Rheem products. The heat pump water heater weight was assumed to be the same as a Rheem 50 gallon water heater; the heat pump part of the unit was calculated to be: total heat pump tank weight minus the electric water heater weight, as shown in Table 3-40: 
Table 3-40 Heat Pump Water Heater Weight Estimation

\begin{tabular}{|c|c|c|c|}
\hline Unit & kg & Lb & Notes \\
\hline Rheem Model HP50ES 50 gallon heat pump tank & 89.3 & 197.0 & \\
\hline $\begin{array}{l}\text { Rheem model RHE PRO52-2 } 50 \text { gallon electric } \\
\text { tank }\end{array}$ & 41.2 & 90.8 & $\begin{array}{l}\text { Shipping weight only was given, so } \\
\text { this represents a portion of the total. }\end{array}$ \\
\hline Assumed weight of heat pump part of unit & 48.2 & 106.2 & \\
\hline Assumed weight of hot water tank & 41.2 & 90.8 & $\begin{array}{l}\text { Assumed to be same weight as the } \\
\text { Rheem RHE PRO52-2 }\end{array}$ \\
\hline
\end{tabular}

The bills of materials are described in terms of the individual components. Data for the Rheem hot water tank portion was based on VHK (2007) Table B.9 electric water heater data. Data for the $200 \mathrm{~L}$ (53 gal) storage tank was used as its size closely aligns with the Rheem's 189 L (50 gal) capacity. As was done for the generic water heater chapter earlier in this document, the data were supplemented by more detailed parts and materials provided by VHK (2007) Table B.10 materials’ quantities, especially those over $1 \%$ weight by mass, have been adjusted to meet the weight of the Rheem unit. Any assumptions made are noted in Table 3-41.

\section{Table 3-41 Rheem Hot Water Tank Portion Bill of Materials}

\begin{tabular}{|c|c|c|c|}
\hline \multicolumn{3}{|c|}{ Mass } & \multirow[b]{2}{*}{ Parts, Materials \& Assumptions } \\
\hline B.9 Material Group & Kg & $\mathbf{L b}$ & \\
\hline 3-Ferro & 35.36 & 77.96 & $\begin{array}{l}\text { Tank, mounting plate, screws. Tank assumed to be } \\
\text { stainless steel }\end{array}$ \\
\hline 2-TecPlastics & 0.32 & 0.71 & Rubber gasket \\
\hline 2-TecPlastics & 1.02 & 2.25 & $\begin{array}{l}\text { PVC pipe protection and pipe collar, PVC thermal control } \\
\text { Previously EPS insul. This tank insulated with } 21 / 2 "\end{array}$ \\
\hline $\begin{array}{l}\text { 1-BlkPlastics - } \\
\text { Insulation }\end{array}$ & 1.21 & 2.68 & $\begin{array}{l}\text { polyol-based non-CVC foam insulation. }{ }^{17} \text { Polyol modeled } \\
\text { as PUR rigid foam insulation (density } 36.8 \mathrm{~kg} / \mathrm{m} 3 \text { ). }\end{array}$ \\
\hline 7-Misc & 0.30 & 0.66 & Portion of the Misc. category; Assume resistance heater \\
\hline 5-Coating & 2.67 & 5.89 & Assume enamel \\
\hline 4-Non-ferro & 0.24 & 0.54 & Assume copper \\
\hline 6-Electronics & 0.06 & 0.13 & Assume copper wiring, thermal control \\
\hline TOTAL --> & 41.20 & 90.82 & \\
\hline
\end{tabular}

Data for the Rheem heat pump portion was based on the bill of materials for the condensing unit described in the air conditioner subchapter of this report (Section 3.3.5.2). The unit is based on a tear-down of a 3-ton, 10 SEER unit. The quantities of materials have been scaled down to the weight of the Rheem unit, and some materials have been added, under Notes in Table 3-42.

\footnotetext{
${ }^{17}$ Based on communications with a Rheem technical support person via phone.
} 
Table 3-42 Rheem Heat Pump Portion Bill of Materials

\begin{tabular}{|c|c|c|c|c|}
\hline \multirow[b]{2}{*}{ Main Component } & \multirow[b]{2}{*}{ Material Breakdown } & \multicolumn{2}{|c|}{ Mass } & \multirow[b]{2}{*}{ Notes } \\
\hline & & Kg & Lb & \\
\hline \multirow[t]{4}{*}{ Compressor } & Aluminum & 0.45 & 0.99 & \multirow{4}{*}{$\begin{array}{l}\text { Compressor breakdown from Biswas (2011) } \\
\text { Fig } 1 .\end{array}$} \\
\hline & Cast iron & 21.20 & 46.73 & \\
\hline & Copper & 1.13 & 2.49 & \\
\hline & Steel & 2.33 & 5.14 & \\
\hline \multirow[t]{2}{*}{ Coil Assembly } & Copper (tubing) & 3.38 & 7.46 & \multirow{2}{*}{$\begin{array}{l}\text { Approx } 50 \% \text { copper tubing, } 50 \% \text { aluminum } \\
\text { fins. (De Kleine, 2009, Sec. 3.1.4) }\end{array}$} \\
\hline & Aluminum (fins) & 3.38 & 7.46 & \\
\hline \multirow[t]{3}{*}{ Fan Motor } & Copper wire & 0.92 & 2.03 & \multirow{3}{*}{$\begin{array}{l}\text { Assumed to have a composition of } 25 \% \text { copper } \\
\text { wire, } 72 \% \text { steel, and } 3 \% \text { polyamide (De } \\
\text { Kleine, } 2009 \text {, Sec. } 3.1 .4 \text { ) }\end{array}$} \\
\hline & Steel & 2.65 & 5.85 & \\
\hline & Polyamide & 0.11 & 0.24 & \\
\hline Unit Wall & Galvanized steel & 2.66 & 5.86 & \\
\hline Base & Galvanized steel & 2.31 & 5.10 & \\
\hline Top Cover & Galvanized steel & 1.63 & 3.59 & \\
\hline Fan Guard & Stainless steel & 1.60 & 3.53 & \\
\hline \multirow{2}{*}{$\begin{array}{l}\text { Refrigerant Line } \\
\text { service valve }\end{array}$} & Brass (service valves) & 0.75 & 1.65 & \\
\hline & Rubber & 0.25 & 0.55 & \\
\hline Wire Guard & Stainless steel & 0.80 & 1.76 & \\
\hline Fan Blade & Steel & 0.60 & 1.32 & \\
\hline Misc Fasteners & Steel & 0.30 & 0.66 & \\
\hline Capacitor & Sheet metal (steel) & 0.30 & 0.66 & \\
\hline \multirow[t]{2}{*}{ Relay Switch } & Copper wiring & 0.10 & 0.22 & \multirow{2}{*}{$\begin{array}{l}\text { Assumed to be } 50 \% \text { copper wiring and } 50 \% \\
\text { nylon polymer (De Kleine, 2009, Sec. 3.1.4) }\end{array}$} \\
\hline & Nylon polymer & 0.10 & 0.22 & \\
\hline Copper Wiring & Copper wire & 0.20 & 0.44 & \\
\hline Refrigerant & $\mathrm{R} 410 \mathrm{~A}$ & 0.68 & 1.49 & Added here. Data from Rheem tech support \\
\hline Powder coating & steel powder coating & 0.35 & 0.77 & $\begin{array}{l}\text { Added here based on assumption that the basic } \\
\text { volume of the appliance is powder coated. } \\
\text { Assumes } 0.095 \mathrm{~kg} / \mathrm{m} 2 \text {, per Ecoinvent powder } \\
\text { coating process. }\end{array}$ \\
\hline Total & & 48.18 & 106.23 & \\
\hline
\end{tabular}

The steel, assumed to be cold-rolled, and the galvanized steel come from World Steel Association (2011). Aluminum is modeled as a 50/50 mix of primary and secondary extruded aluminum which come from the U.S. LCI Database. Data for copper tube, sheet, and wire come from ICA (2012). U.S. LCI Database provided the production data for PVC and PP. Ecoinvent provided the data for the cast iron, stainless steel, brass, rubber (as synthetic rubber), polyamide, enamel, and powder coating. The R410a data is discussed in text following Table 3-31.

Raw materials are modeled as transported to the manufacturing plant via diesel truck an assumed average distance of $805 \mathrm{~km}$ (500 mi).

No manufacturing data were available for this unit, so as proxy, the ecoinvent data set for a $10 \mathrm{~kW}$ (34 MBH) oil boiler was used - see discussion above Table 3-28. Since 
manufacturing the smaller units is assumed to require less energy and resources than the $150 \mathrm{~kg}$ (331 lb) boiler, these data were scaled down based on the total weight of the Rheem water heater.

\subsection{Transportation to the Building Site through End-of-Life}

Transportation to the building site is modeled using an assumed average of $2414 \mathrm{~km} \mathrm{(1}$ $500 \mathrm{mi}$ ) by heavy-duty diesel fuel-powered truck, assuming that one Rheem facility is manufacturing / assembling this particular unit.

Per a wholesaler of Rheem appliances, the water heater should be inspected for damaged components at least annually by a qualified service technician. ${ }^{18}$ Thus, a qualified service technician is assumed to come to the home annually to ensure optimal performance and lifetime. It is assumed that the technician is within a $24 \mathrm{~km}(15 \mathrm{mi})$ service radius. This distance, driven in a gasoline-powered van, is shared amongst other service visits for that technician, if the same technician is making more than one service call during that trip. Assuming the technician makes 5 service calls in one day, one-fifth of the impacts from driving $24 \mathrm{~km}$ (15 mi) are allocated to the product, or $4.8 \mathrm{~km}$ (3 mi). Data for a van come from ecoinvent. Unplanned service visits (i.e., unanticipated issues that require a service technician) are not included in the model under the assumption that the system will run as designed given the homeowner adequately follows the maintenance and care guidelines.

Given that the unit comes sealed and pre-charged with refrigerant, it is assumed that there are no refrigerant leaks during the life of the unit.

A lifetime of 15 years has been assumed for the Rheem unit, accounting for a 16-yr lifetime of a heat pump and relatively shorter lifetime of an electric water heater (11 yrs). (NAHB, 2007, Table 1, Section 1) At the end of life, it is assumed that the unit is sent for recycling to recover valuable metal (see Section 3.3.4.7 for the recycling methodology used). What cannot be recovered is modeled as landfilled. Given its small charge, it is assumed that the refrigerant is not recovered at end of life. A distance of $48 \mathrm{~km}$ (30 mi) to the landfill in a heavy-duty diesel truck has been modeled. The landfill is based on ecoinvent waste management process data.

\subsubsection{Lighting}

Three lighting alternatives were included in BIRDS: incandescent, compact fluorescent lamp (CFL), and light-emitting diode (LED). These were calculated on a per one $\mathrm{W} / \mathrm{h}$ basis so that BIRDS could calculate the energy needed for lighting based on time used. Figure 3-7 presents the lighting system boundaries for a CFL example.

\footnotetext{
${ }^{18}$ Email communication with Justin U, Gensco wholesaler of HVAC products in the western US, 24 January 2013.
} 


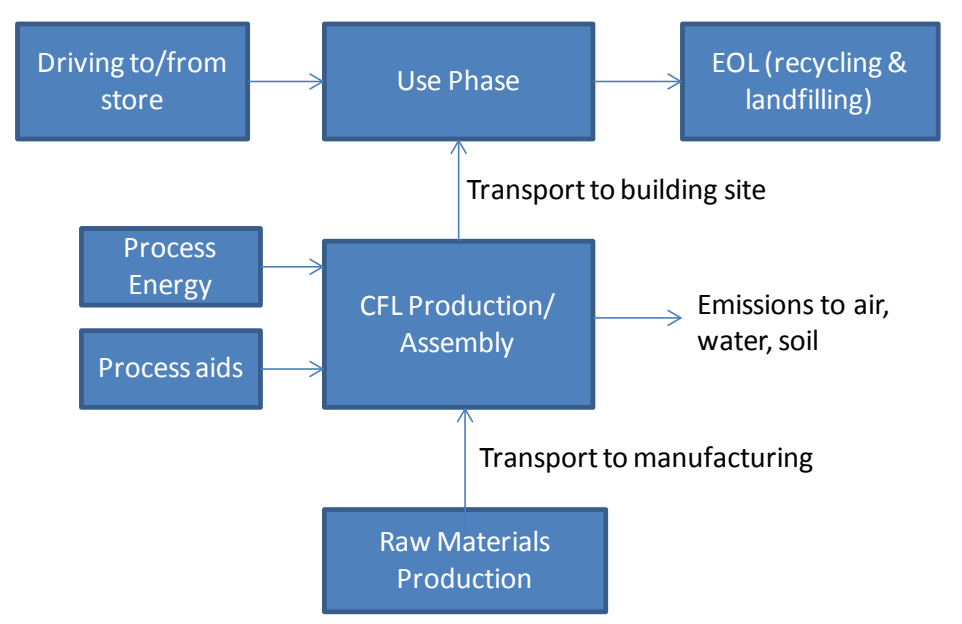

Figure 3-7 Lighting System Boundaries - CFL Example

In order to model the lighting alternatives on the basis of functional equivalency, the model must account for an equivalent or comparable lumen output, i.e., measure of brightness. The lighting characteristics from Energy Efficiency and Renewable Energy (EERE) (2012) were used to define the BIRDS' lighting systems' functional equivalency. Table 4.1 in Energy Efficiency and Renewable Energy (EERE) (2012), reproduced in part in Table 3-43, summarizes the average characteristics of the lamps analyzed within existing lighting LCA literature (at the time) in terms of lumen output, wattage, and lifetime. For the continuously-improving LED technology, a lumen output available in 2011 was used, which was higher than lumens from earlier studies.

Table 3-43 Performance of Lighting Technologies in BIRDS

\begin{tabular}{lcccc} 
Lamp Type & Watts & Lumens & $\begin{array}{c}\text { Operating } \\
\text { Lifetime (hr) }\end{array}$ & $\begin{array}{c}\text { Number of Equiv. } \\
\text { Systems }\end{array}$ \\
\hline Incandescent & 60 & 900 & 1000 & 25 \\
CFL & 15 & 900 & 8500 & 2.9 \\
LED (2011) & 12.5 & 800 & 25000 & 1 \\
\hline
\end{tabular}

\subsubsection{Upstream Materials Production through Manufacturing}

The bills of materials for all three alternatives come from U.K. Department for Environment (2009). These bills of materials are based on Ramroth (2008) but with more detail/aggregation provided.

\subsection{Incandescent}

The bill of materials shown in Table 3-44 is based on a $100 \mathrm{~W}$ (soft white) incandescent bulb manufactured by General Electric. Other sources provided data available for $60 \mathrm{~W}$ incandescent bulbs ${ }^{19}$, but Table B-12 of U.K. Department for Environment (2009) was used since its data is based on a detailed tear-down for a widely available product.

\footnotetext{
19 See, for example, Parsons (2006).
} 
Furthermore, when factoring in use phase energy, the BOM differences between $60 \mathrm{~W}$ and $100 \mathrm{~W}$ are negligible.

\section{Table 3-44 Incandescent Light Bulb Bill of Materials}

\begin{tabular}{lccl} 
Parts and Materials & \multicolumn{2}{c}{ Mass } & \multicolumn{2}{l}{ Notes } \\
Ballast & $\mathbf{g}$ & $\mathbf{l b}$ & \\
Black glass insulation & 2.0 & $4.4 \mathrm{E}-3$ & Modeled as foam glass \\
Internal filler & 1.0 & $2.2 \mathrm{E}-3$ & Modeled as foam glass \\
\hline Lamp & & & \\
Tin plate base & 2.0 & $4.4 \mathrm{E}-3$ & \\
Tungsten filament & $2.0 \mathrm{E}-2$ & $4.4 \mathrm{E}-5$ & Modeled as chromium \\
Internal glass & 2.0 & $4.4 \mathrm{E}-3$ & Modeled as borosilicate glass tube \\
\hline Lens & & & \\
Globe (glass) & 20.0 & $4.4 \mathrm{E}-2$ & Modeled as borosilicate glass tube \\
Packaging & & & \\
\hline Corrugated board & 4.0 & $8.8 \mathrm{E}-3$ & \\
Total & $\mathbf{3 1 . 0}$ & $\mathbf{6 . 8}$ E-2 & \\
\hline
\end{tabular}

The data sets used to model the incandescent system's parts and materials come from ecoinvent. U.K. Department for Environment (2009) used proxy data for materials not available in ecoinvent or other publicly-available data or databases. These proxies were also used for BIRDS, and are indicated in the table notes. Raw materials are modeled as transported to the manufacturing plant via diesel truck an assumed average distance of $805 \mathrm{~km}$ (500 mi).

No manufacturing data were available, but the parts forming (wire drawing, injection molding, extrusion, etc.) have been included with the upstream raw materials, accounting for at least some of the production energy.

\subsection{Compact Fluorescent Lamp (CFL)}

The bill of materials in Table 3-45 is based on a 23 W Philips Marathon Mini CFL. Other data were available for an $18 \mathrm{~W} \mathrm{CFL}^{20}$ which might have been preferable in terms of wattage identified in Table 3-45, but Tables B.10-B.11 of U.K. Department for Environment (2009) were used since the tear-down was quite detailed and for a widely available product. Furthermore, the difference in mass between the two sources was $3 \%$ to $5 \%$, with a similar bill of materials. Factoring in use phase energy, this difference becomes negligible.

${ }^{20}$ Ibid. 


\section{Table 3-45 CFL Bill of Materials}

\begin{tabular}{|c|c|c|c|}
\hline \multirow{2}{*}{$\begin{array}{l}\text { Parts and Materials } \\
\text { Ballast }\end{array}$} & \multicolumn{2}{|c|}{ Mass } & \multirow[t]{2}{*}{ Notes } \\
\hline & g & lb & \\
\hline PUR foam (rigid) & 3.0 & $6.6 \mathrm{E}-3$ & \\
\hline Plastic base (Polyvinyl chloride, PVC) & 17.0 & $3.7 \mathrm{E}-2$ & \\
\hline Printed wiring board & 4.0 & 8.8 E-3 & \\
\hline \multicolumn{4}{|l|}{ Printed board assembly (PBA) - } \\
\hline Polypropylene (PP) caps & 4.0 & $8.8 \mathrm{E}-3$ & \\
\hline PBA- inductor (cast iron) & 7.0 & $1.5 \mathrm{E}-2$ & \\
\hline PBA- inductor (copper) & 4.5 & 9.9 E-3 & \\
\hline PBA - transistor (ABS copolymer) & 1.0 & 2.2 E-3 & \\
\hline \multirow[t]{2}{*}{ PBA - transistor (Aluminum) } & 3.5 & $7.7 \mathrm{E}-3$ & \\
\hline & & & Modeled as a logic type \\
\hline PBA - resistors, diodes, HV capacitor & 1.0 & $2.2 \mathrm{E}-3$ & integrated circuit \\
\hline PBA - torus magnet (cast iron) & 1.0 & $2.2 \mathrm{E}-3$ & \\
\hline \multicolumn{4}{|l|}{ Lamp } \\
\hline Electrode assembly - mercury gas & 4.0 E-3 & 8.8 E-6 & \\
\hline Electrode assembly - chromium & 2.0 & 4.4 E-3 & \\
\hline Copper pins & 2.0 & 4.4 E-3 & \\
\hline Tin base plate & 5.0 & $1.1 \mathrm{E}-2$ & \\
\hline Black glass insulation & 5.0 & $1.1 \mathrm{E}-2$ & Modeled as foam glass \\
\hline \multicolumn{4}{|l|}{ Lens } \\
\hline Glass tube & 34.0 & $7.5 \mathrm{E}-2$ & $\begin{array}{l}\text { Modeled as borosilicate } \\
\text { glass tube }\end{array}$ \\
\hline \multicolumn{4}{|l|}{ Packaging } \\
\hline Corrugated board & 4.0 & 8.8 E-3 & \\
\hline Total & 98.0 & $2.2 \mathrm{E}-1$ & \\
\hline
\end{tabular}

The U.S. LCI Database provided data for the polyvinyl chloride base, polypropylene caps, acrylontrile-butadiene-styrene (ABS) copolymer transistor, and aluminum (as an average mix of primary and secondary aluminum). Data for copper sheet and wire come from International Copper Association (ICA) (2012). The remaining data sets come from ecoinvent. U.K. Department for Environment (2009) used proxy data for materials and/or parts not available in ecoinvent or other publicly-available data or databases. These proxies were also used for BIRDS, and are indicated in the table notes. Raw materials are modeled as transported to the manufacturing plant via diesel truck an assumed average distance of $805 \mathrm{~km}$ (500 mi).

No manufacturing data were available, but the parts forming (wire drawing, injection molding, extrusion, etc.) and manufacture of the individual electronics components have been included with the upstream raw materials, accounting for at least some of the production energy. For assembly, U.K. Department for Environment (2009) used data provided by ecoinvent - assembly of an LCD screen - which the authors determined to be a suitable proxy for CFL manufacturing. Per U.K. Department for Environment (2009), this surrogate was selected because an LCD screen is also a complex electrical 
product, involving circuits and components that are assembled, and the impacts were expressed on a per $\mathrm{kg}$ basis so the assembly of the lighting systems could be modeled based on their respective weights. This was a conservative assumption on the part of U.K. Department for Environment (2009) Four Elements tested this assumption with sensitivity analysis, which showed that it did not make a significant difference to the overall results. BIRDS used this same assumption, applying the assembly data to a $98.0 \mathrm{~g}$ (0.22 lb) system.

\subsection{Light-Emitting Diode (LED)}

The integrated LED system from Table B.2 and Table B.3 in U.K. Department for Environment (2009) was modeled, giving the LED system the opportunity to be retrofitted into existing lighting infrastructure. The LED inventory shown in Table 3-46 factored in 10 LED die.

\section{Table 3-46 LED Bill of Materials}

\begin{tabular}{|c|c|c|c|}
\hline \multirow{2}{*}{$\begin{array}{l}\text { Parts and Material } \\
\text { Ballast }\end{array}$} & \multicolumn{2}{|c|}{ Mass } & \multirow[t]{2}{*}{ Notes } \\
\hline & g & lb & \\
\hline PUR foam (rigid) & 3.0 & $6.6 \mathrm{E}-3$ & \\
\hline Inductor (cast iron) & 6.0 & $1.3 \mathrm{E}-2$ & \\
\hline Inductor $(\mathrm{Cu})$ & 4.0 & 8.8 E-3 & \\
\hline Zener Diodes & 0.1 & $2.2 \mathrm{E}-4$ & Modeled as an unspecified diode \\
\hline Capacitors (aluminum) & 5.0 & $1.1 \mathrm{E}-2$ & \\
\hline Resistor & 10.0 & $2.2 \mathrm{E}-2$ & \\
\hline Transistor & 3.0 & $6.6 \mathrm{E}-3$ & \\
\hline PCB (aluminum machined tooled block) & 100.0 & $2.2 \mathrm{E}-1$ & Modeled as aluminum \\
\hline Wiring $(\mathrm{Cu})$ & 2.0 & 4.4 E-3 & \\
\hline Solder paste (used for electronics) & 1.0 & $2.2 \mathrm{E}-3$ & \\
\hline Polypropylene (PP) housing & 35.0 & $7.7 \mathrm{E}-2$ & \\
\hline Integrated circuit & 1.0 & $2.2 \mathrm{E}-3$ & \\
\hline Polyethylene terephthalate (PET) film & 2.0 & 4.4 E-3 & \\
\hline \multicolumn{4}{|l|}{ Lamp } \\
\hline Black glass insulation & 6.0 & $1.3 \mathrm{E}-2$ & Modeled as foam glass \\
\hline Tinplate base & 3.0 & 6.6 E-3 & Modeled as a low-alloyed steel \\
\hline Copper pins & 0.1 & $2.2 \mathrm{E}-4$ & \\
\hline Base contacts $(\mathrm{Cu})$ & 0.4 & $8.8 \mathrm{E}-4$ & \\
\hline Base contacts (solder paste for electronics) & 0.2 & 4.4 E-4 & \\
\hline Plastic base (PVC) & 16.0 & $3.5 \mathrm{E}-2$ & \\
\hline Light emitting diodes (LED, 10 total) & 19.0 & 4.2 E-2 & \\
\hline \multicolumn{4}{|l|}{ Lens } \\
\hline Glass & 20.0 & 4.4 E-2 & Modeled as borosilicate glass tube \\
\hline Coating (aluminum) & 1.0 & $2.2 \mathrm{E}-3$ & \\
\hline \multicolumn{4}{|l|}{ Packaging } \\
\hline Corrugated board & 3.0 & $6.6 \mathrm{E}-3$ & \\
\hline Total & 240.8 & $5.3 \mathrm{E}-1$ & \\
\hline
\end{tabular}


The U.S. LCI Database provided data for the PVC base, PP housing, PET film, and aluminum (as average production mix). Data for copper sheet and wire come from International Copper Association (ICA) (2012). The remaining data sets, including the production of the LEDs, come from ecoinvent. U.K. Department for Environment (2009) used proxy data for materials not available in ecoinvent or other publicly-available data or databases. These proxies were also used for BIRDS, and are indicated in the table notes. Raw materials are modeled as transported to the manufacturing plant via diesel truck an assumed average distance of $805 \mathrm{~km}$ (500 mi).

Data for LED die manufacturing comes from OSRAM Opto Semiconductors GmbH. (2009). Primary data were collected on the two main process stages to produce OSRAM's Golden Dragon Plus: the front end, where the $1 \mathrm{~mm}^{2}\left(1.6 \mathrm{E}-3 \mathrm{in}^{2}\right)$ semiconductor chip is fabricated, and back end, where the chip is contacted and packaged. See OSRAM Opto Semiconductors GmbH. (2009), pp.9-11, for more qualitative detail and schematics on the manufacture of the LED. Figure 6 in OSRAM Opto Semiconductors GmbH. (2009) presents the primary energy to produce one LED: approximately $0.41 \mathrm{kWh}$. Given that the other categories of data in the figure include materials production, an assumption was made that "common consumption" is energy at manufacturing, amounting to approximately $0.27 \mathrm{kWh}$ per LED, or $2.7 \mathrm{kWh}$ for 10 LEDs. No other manufacturing data could be gleaned from this study, but the ecoinvent data set on assembly of an LCD screen was used for assembly (see above discussion), and parts forming data were applied to other parts and materials listed in the table.

\subsubsection{Transportation to the Building Site through End-of-Life}

Several the LCA studies mentioned China or Asia in general as being the main manufacturing location for incandescents. For their study, Energy Efficiency and Renewable Energy (EERE) (2012), p.32, assumed that an incandescent lamp is either manufactured in the northeastern U.S. or Shanghai, China, while also acknowledging that production occurs all over the world. BIRDS assumed $25 \%$ of production of incandescents to be produced in the northeast U.S., and 75 \% in Shanghai, China.

BIRDS modeled CFLs as manufactured in China (Parsons 2006, Ramroth 2008, U.K. Department for Environment 2009, Energy Efficiency and Renewable Energy (EERE) 2012).

Energy Efficiency and Renewable Energy (EERE) (2012) stated that LED lighting market is highly fragmented, with several firms focusing on a specific part within the LED supply chain (this was seen with OSRAM Opto Semiconductors GmbH. (2009)). BIRDS adopted EERE's approach to simplifying the sourcing logistics as follows: "the complete LED package is produced in Taiwan and then is assembled into the finished LED lamp product in Taiwan or the United States. In the second scenario, LED packages are produced in Taiwan and then shipped to the southeast region of the U.S. where they 
are assembled into complete LED lamp products” (Energy Efficiency and Renewable Energy (EERE) 2012).

For Asia manufacturing, transportation includes the ocean freighter transport to a port in California, plus heavy duty diesel truck an assumed $2414 \mathrm{~km}$ (1500 mi), an average distance traveled from California to other parts of the United States. For U.S. manufacturing, transport is modeled an assumed average of $2414 \mathrm{~km}$ (1500 mi) by heavy-duty diesel fuel-powered truck. Intermediate transportation (i.e., from LED production to lamp assembly) is also included.

For every light bulb purchased and needing to be replaced, customer driving to and from the retail store has been included.

How these lighting systems affect operating energy during the home's use phase is addressed in other sections of this report.

At end-of-life, each of the lighting alternatives was modeled as $20 \%$ recycling (and material recovery), and $80 \%$ landfill. A distance of $48 \mathrm{~km}$ (30 mi) traveled via a heavyduty diesel truck to the landfill or recycler has been assumed for waste and recycling transport.

\subsubsection{Sealants}

LCAs of an interior and exterior sealant have been included in BIRDS. The interior sealant is modeled as an aluminum foil-backed multi-purpose tape designed for taping joints and seams against moisture and vapor on ductwork. The exterior sealant, an acrylic latex caulk with silicone, is used to minimize air infiltration around windows, door frames, and other areas on the building envelope. The LCAs are based on one linear foot of each type of sealant (boundaries shown in Figure 3-8).

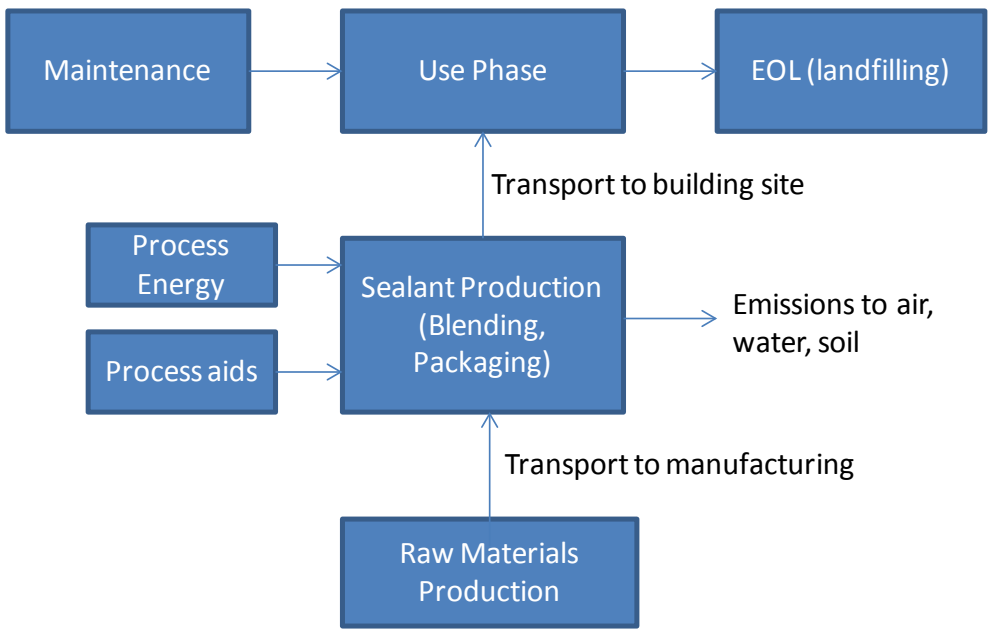

Figure 3-8 Sealants System Boundaries - Exterior Sealant Example 
Both types of sealants have been modeled based on products that are readily available and whose published product literature provided sufficient data to model their production without the need to make too many assumptions. It should be reminded that there are many products on the market that can perform the same sealing functions, and that the products described herein are not considered endorsements.

\subsubsection{Upstream Materials Production through Manufacturing}

\subsection{Ductwork Sealant}

The ductwork sealant modeled for BIRDS is modeled as a multi-purpose foil-backed tape. The 0.13-mm (5.0-mil) thick tape contains three distinct layers: a 0.05-mm (2.0-mil) thick aluminum foil layer, a synthetic rubber layer for the adhesive, and an unbleached natural Kraft paper layer for the liner (Nashua Tape Products 2013). One roll of $46 \mathrm{~m}$ (151 ft) long by $48 \mathrm{~mm}(0.16 \mathrm{ft})$ wide tape, or $2.2 \mathrm{~m}^{2}\left(23.8 \mathrm{ft}^{2}\right)$ of tape, weighed $0.55 \mathrm{~kg}$ (1.2 lb), or $3.64 \mathrm{~g}(0.13 \mathrm{oz})$ per linear foot. ${ }^{21}$ Based on this weight, the material components were broken down as shown in Table 3-47, with assumptions noted.

\section{Table 3-47 Foil Tape Bill of Materials}

\begin{tabular}{lccl} 
Tape material & \multicolumn{2}{c}{ Mass } & \multicolumn{1}{l}{ Notes } \\
& g & $\mathbf{o z}$ & \\
Aluminum & 2.01 & 0.071 & Based on $0.05 \mathrm{~mm}(2.0 \mathrm{mil})$ \& density of $2.7 \mathrm{~g} / \mathrm{cm}^{3}$ \\
Unbleached Kraft & 0.16 & $5.8 \mathrm{E}-3$ & Assumed $10 \%$ of remaining weight \\
Synthetic rubber & 1.39 & 0.049 & Assumed $85 \%$ of remaining weight \\
Cardboard core & 0.08 & $2.9 \mathrm{E}-3$ & Assumed $5 \%$ of remaining weight \\
LDPE* film (packaging) & negl. & negl. & \\
Total & 3.64 & 0.13 & \\
\hline *LDPE = Low Density Polyethylene Film & &
\end{tabular}

Production data for the foil is modeled as 50/50 primary and secondary aluminum from the U.S. LCI Database, plus sheet rolling (ecoinvent). Data for the remaining materials were supplied by ecoinvent. Assembly of the tape was assumed to consist of layering and laminating the materials, rolling, and cutting. The electricity-only portion of the ecoinvent data set for "laminating foil (with an acrylic binder)" was used, which was reported as $0.0183 \mathrm{kWh} / \mathrm{m}^{2}\left(0.0017 \mathrm{kWh} / \mathrm{ft}^{2}\right)$ laminated. This value is likely underestimated since cutting and rolling are not included in this dataset.

\footnotetext{
${ }^{21}$ Weight taken by Four Elements.
} 


\subsection{Exterior Sealant}

The exterior sealant was modeled based on composition information for an MSDS of a commonly used acrylic latex sealant with silicone (DAP 2005). The amount modeled for

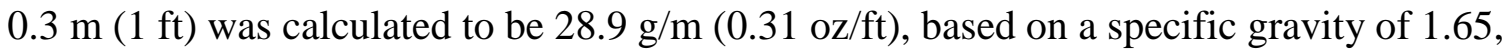
coverage of $17 \mathrm{~m}(56 \mathrm{ft})$ per $298 \mathrm{~cm}^{3}(10.1 \mathrm{fl} \mathrm{oz})$, and a bead diameter of $0.47 \mathrm{~cm}(0.19$ in) (DAP 2011). Since composition was provided in the customary percentage ranges, the quantities of each ingredient modeled were estimated based on best-guess assumptions (see Table 3-48).

\section{Table 3-48 Exterior Sealant Bill of Materials}

\begin{tabular}{lcccl} 
& \multicolumn{4}{c}{ Mass Percentage } \\
Components & Low \% & High \% & \% Modeled & Notes \\
Non-hazardous polymer & 10 & 30 & 30 & Acrylic polymer assumed \\
Water & 10 & 30 & 18 & “82 \% solids” (DAP 2011) \\
Calcium carbonate & 40 & 70 & 46 & \\
Phthalate ester & 1 & 5 & 3 & \\
Titanium dioxide & 0.1 & 1 & 0.55 & \\
Ethylene glycol & 0.1 & 1 & 0.55 & \\
Crystalline silica & 0.1 & 1 & 1 & \\
Carbon black & 0 & 1.5 & 0.75 & \\
Ammonia & & 0.01 & 0.01 & \\
Formaldehyde & & 0.02 & 0.02 & \\
Ethyl acrylate & & 0.009 & 0.009 & \\
Acetaldehyde & & 0.002 & 0.002 & \\
Acrylonitrile & & 0.0003 & 0.0003 & \\
Total & & & $\mathbf{1 0 0}$ &
\end{tabular}

The mass of the high-density polyethylene (HDPE) squeeze tube packaging was

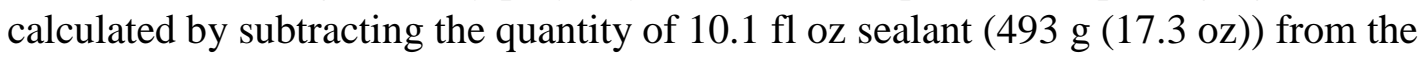
weighed product (539 g (19.0 oz)). Thus, HDPE amounted to $46 \mathrm{~g}(1.6 \mathrm{oz})$, or $2.7 \mathrm{~g} / \mathrm{m}$ $(0.029 \mathrm{oz} / \mathrm{ft})$.

The U.S. LCI Database provided production data for HDPE, calcium carbonate, and ethylene glycol. Ecobilan (2001) provided the inventory data on the phthalate ester, and ecoinvent provided the remaining data. Manufacturing data were limited; the electricityonly portion of an ecoinvent data set for acrylic filler production - likely mixing energy were used, which amounted to $1.8 \mathrm{E}-3 \mathrm{kWh} / \mathrm{kg}(1.6 \mathrm{E}-5 \mathrm{kWh} / \mathrm{ft})$.

Raw materials for both products are modeled as transported to the manufacturing plant via diesel truck an assumed average distance of $805 \mathrm{~km}$ (500 mi).

\subsubsection{Transportation to the Building Site through End-of-Life}

Transportation of the equipment to the building site is modeled assuming an average of 483 km (300 mi) traveled via heavy-duty diesel fuel-powered truck. 
The tape is assumed to be replaced every 10 years. The exterior sealant is modeled as being replaced every 15 years (Vigener and Brown 2012). At the end of each of their respective lives, it is assumed that they are landfilled. Data on the landfill is based on ecoinvent end-of-life waste management process data. A distance of $48 \mathrm{~km}$ (30 mi) to the landfill in a heavy-duty diesel truck has been assumed.

\subsubsection{Solar Photovoltaic}

Photovoltaics (PV) is the term used to describe the method of generating direct current electricity from solar energy. PV panels, or solar panels, are composed of solar cells that supply usable solar power. A PV inverter converts the direct current electricity produced by solar cells into an alternating current that can be fed into an electrical grid or used offgrid.

The Net-Zero Energy Residential Test Facility (NZERTF) uses a 10.2 kW PV system. Thirty-two SunPower SPR-320E-WHT-U solar PV panels are installed on the roof of the NZERTF in four horizontal strings of eight panels each. Two strings are connected to a SunPower 5000m LUT inverter for a total of two inverters. One SunPower 320 solar panel delivers a conversion efficiency of $19.9 \%$ (SunPower, 2013a). With a mass of 18.6 kg (41 lb), it has 96 monocrystalline solar cells which are built on a solid copper foundation. Its frame is black anodized material, and the glass is high transmission, tempered, anti-reflective glass.

The LCA for the BIRDS model includes one solar panel and one PV inverter; the total number of panels and inverters put into use by the NZERTF are multiplied within the BIRDS tool. Figure 3-9 presents the PV system boundaries.

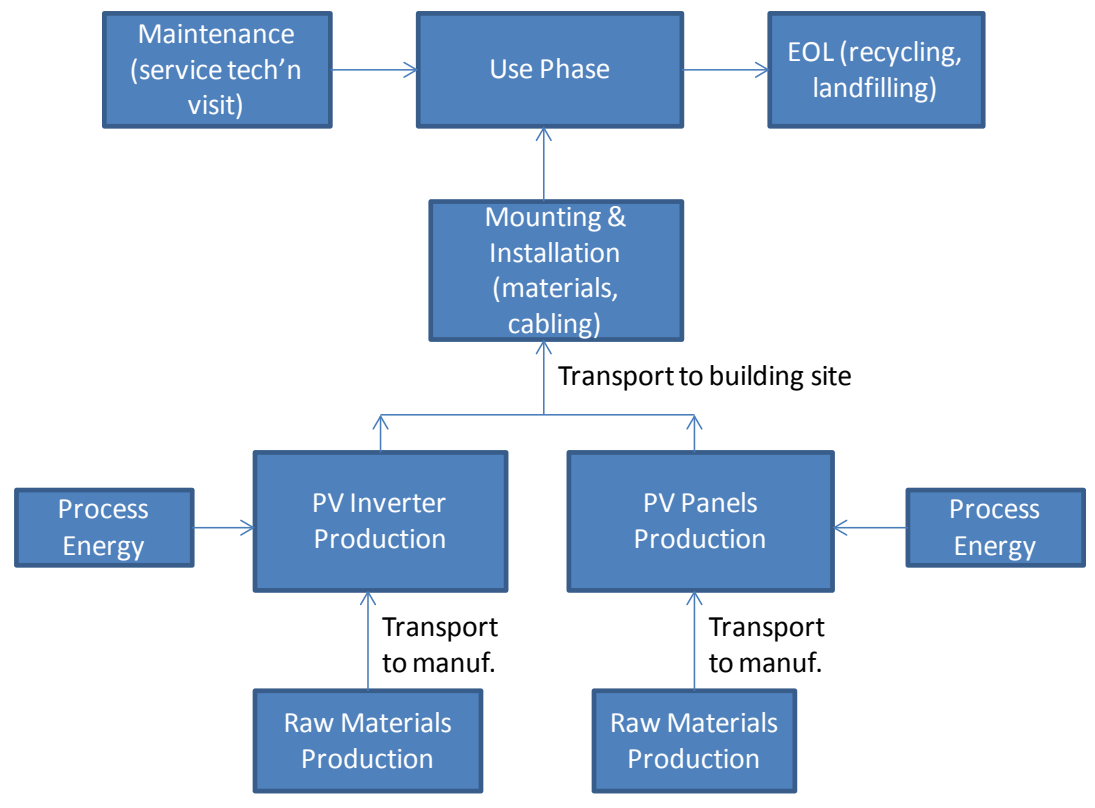

Figure 3-9 PV System Boundaries 


\subsubsection{Upstream Materials Production through Manufacturing}

Manufacturer-specific data was not available, so publicly-available sources of data were used as proxy. The inventories of the crystalline silicon PV panel, PV inverter, and associated cabling are based on research by Mariska De Wild and Erik Alsema which is summarized in IEA (2011). ${ }^{22}$ Ecoinvent data sets have been used to build the LCA model for BIRDS, as it has incorporated the IEA (2011) data into its own database, adding additional elements to account for standard ecoinvent inventory and data quality requirements (Jungbluth 2007a).

\subsubsection{Photovoltaic Panel}

These data were provided by industry and are a reliable representation of crystalline silicon module production technology for 2005/2006 and is based on Western Europe production. Due to the very detailed nature of the PV panel's bill of materials, the data are not recreated in this report. To aid in the system boundaries within the source that are included here, Figure 3-10 has been created to present the processes described in IEA (2011) that cover the monocrystalline Si PV panel.

For the BIRDS model, ecoinvent datasets that correspond to the information in IEA (2011) were used. Since the data are based on Western Europe, wherever possible, data representing North American production were used to customize the data more to North American conditions; U.S. LCI Database and other North American data sets were used to replace some of the process energy, transportation, and upstream materials data sets (e.g., framing materials, auxiliary materials, etc.). The interested reader is encouraged to refer to the tables listed in Figure 3-10 and/or Jungbluth (2007a).

\footnotetext{
${ }^{22}$ M.J. de Wild-Scholten, Energy research Center of the Netherlands, Petten, The Netherlands and E.A. Alsema, Copernicus Institute for Sustainable Development and Innovation, Utrecht University, The Netherlands.
} 


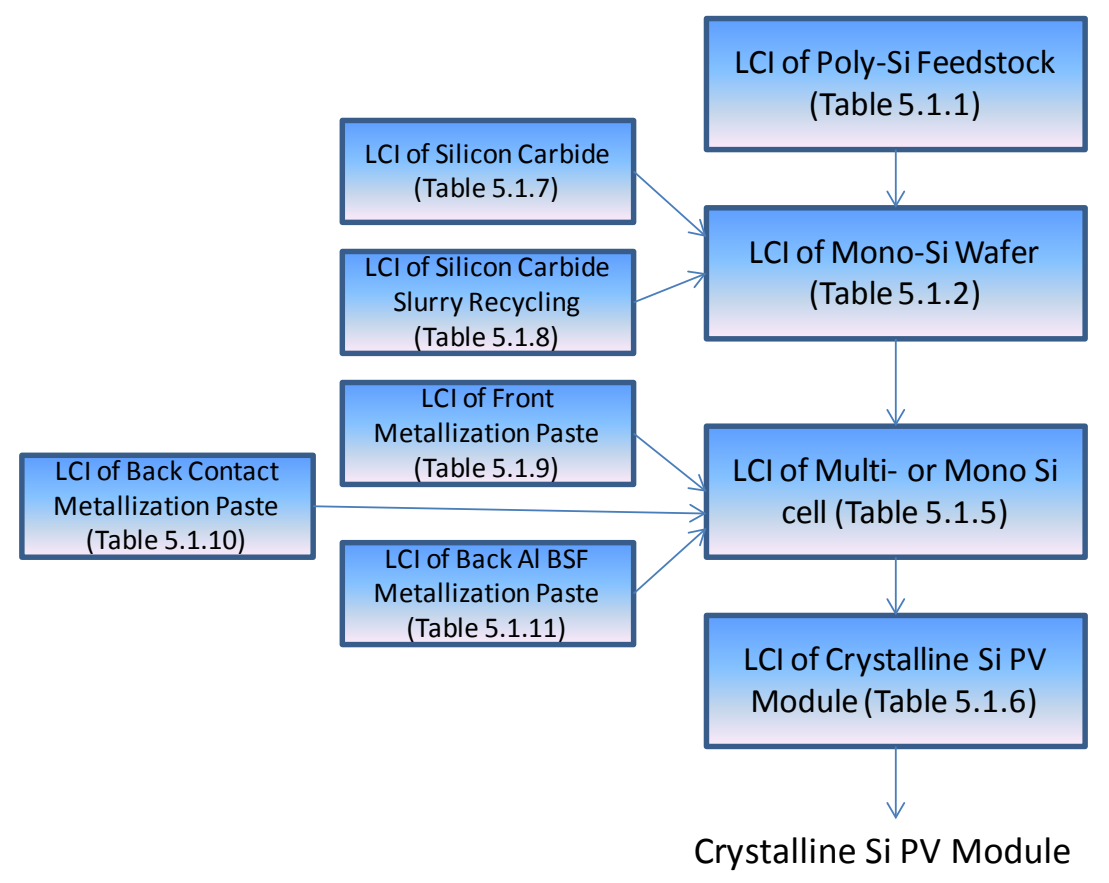

Figure 3-10 PV Module Data Sets Provided in IEA (2011)

While the data in IEA (2011) may be good quality and some of the geographical data has been customized to North American conditions, there are still limitations to its use as a proxy for the SunPower panel, for example:

- SunPower PV panels have 96 solar cells while the IEA panels have 60 cells;

- SunPower PV panels are backed with a solid copper foundation while IEA panels are modeled as having back-contact metallization paste;

- The construction of the SunPower PV panels enables it to have a higher conversion efficiency than the "14\%" average efficiency of other monocrystalline silicon PV panels (IEA, 2011, p.31).

SunPower was not available for consultation to reconcile some of these differences and enable some adjusting of the inventory, so the model remains more of an industry average panel, and not customized more to the SunPower unit. Given the application of the data in this setting where the data is expected to be representative of any installed solar photovoltaic system, an industry average inventory is more appropriate.

\subsubsection{Photovoltaic Inverter}

The SunPower 5000m LUT PV inverter was modeled based on a tear-down of a $2500 \mathrm{~W}$ ac PV inverter. The SunPower inverter has a $5000 \mathrm{~W}$ continuous power output, and its 67 $\mathrm{kg}$ (148 lb) mass is approximately 3.6 times greater than the one featured in IEA (2011). To make up for the mass difference, the materials and parts presented in IEA (2011) Table 5.5.1.4 were scaled up proportionally to the SunPower's mass. One exception is the scaling factor for the printed circuit board, which was doubled, assuming its weight is not 
directly proportional to its performance within the system. It should be noted that Table 3-49 is fairly simplistic, and that the corresponding ecoinvent module contains more detail as to the transformers, wiring, packaging, etc.

\section{Table 3-49 SunPower 5000m LUT PV Inverter Bill of Materials}

\begin{tabular}{lcccc} 
& $\mathbf{2 5 0 0} \mathbf{~ W}$ & \multicolumn{2}{c}{ SunPower $\mathbf{5 0 0 0} \mathbf{~ W}$} & \\
Parts / Materials & $\mathbf{K g}$ & $\mathbf{K g}$ & $\mathbf{L b}$ & Notes \\
\hline Steel & 9.8 & 37.2 & 82.0 & As casing \\
Aluminum & 1.4 & 5.3 & 11.7 & As casing \\
Transformers, wire- & & & & \\
wound & 5.5 & 20.9 & 46.0 & \\
Printed circuit board & 1.8 & 3.6 & 7.9 & \\
Total & $\mathbf{1 8 . 5}$ & $\mathbf{6 7 . 0}$ & $\mathbf{1 4 7 . 7}$ & \\
\hline
\end{tabular}

The steel data come from World Steel Association (2011). Aluminum is modeled as a $50 / 50$ mix of primary and secondary extruded aluminum which come from the U.S. LCI Database. The electronics data come from the ecoinvent database. Raw materials are modeled as transported to the manufacturing plant via diesel truck an assumed average distance of $805 \mathrm{~km}$ (500 mi). Data come from the U.S. LCI Database.

\subsubsection{Transportation to the Building Site through End of Life}

Transportation of the SunPower PV panels, the PV inverter, and mounting materials to the building site is modeled using an assumed average of $2414 \mathrm{~km}$ (1 $500 \mathrm{mi}$ ) by heavyduty diesel fuel-powered truck.

Specific mounting data were not available from SunPower literature, so the industry weighted-average materials and processes in IEA (2011) Table 5.4.2 were used. The data are provided for $1 \mathrm{~m}^{2}\left(10.8 \mathrm{ft}^{2}\right)$ of a mounted PV module on a slanted roof. This was multiplied by 1.6 to install the SunPower panel. Data for electrical cabling for module interconnection and AC-interface is provided in IEA (2011) Table 5.5.1.1, and was modeled for on-roof installation as follows:

Table 3-50 Solar Panel Mounting Materials and Cabling

\begin{tabular}{lccl} 
Mounting Material & $\begin{array}{c}\text { Kg per 1.6 } \\
\text { m2 }\end{array}$ & $\begin{array}{c}\text { Lb per 1.6 } \\
\text { m2 }\end{array}$ & Notes \\
Aluminum & 4.54 & 10.02 & plus section bar rolling \\
Corrugated board & 0.02 & 0.05 & \\
Polyethylene & 0.002 & 0.005 & \\
Polystyrene & 0.01 & 0.02 & \\
Low-alloyed steel & 2.40 & 5.29 & plus steel sheet rolling \\
Cabling Material & & & \\
Copper & 0.16 & 0.35 & 2.2 m DC cable and 0.1 m AC cable \\
Thermoplastic elastomer & 0.10 & 0.21 & \\
\hline
\end{tabular}


Copper wire data come from ICA (2012). U.S. LCI Database provided the data for the polyethylene and polystyrene. Data for the thermoplast, modeled as ethylene propylene diene monomer (EPDM) rubber, come from ecoinvent, as does the low-alloyed steel and corrugated board.

It is assumed that a qualified service technician comes to the building site once annually to check the PV system to ensure optimal performance and lifetime. It is assumed that the technician is within a $24 \mathrm{~km}$ (15 mi) service radius. This distance, driven in a gasolinepowered van, is shared amongst other service visits for that technician, if the same technician is making more than one service call during that trip. Assuming the technician makes 5 service calls in one day, one-fifth of the impacts from driving $24 \mathrm{~km}$ (15 mi) are allocated to the product, or $4.8 \mathrm{~km}$ (3 mi). Data for a van come from ecoinvent. Unplanned service visits (i.e., unanticipated issues that require a service technician) are not included in the model under the assumption that the system will run as designed given the homeowner adequately follows the maintenance and care guidelines.

Over time, PV panels can degrade at a rate of one percent per year. The SunPower modules were found to degrade at a rate of 0.25 percent per year. (SunPower, 2013a) With a useful life defined as "99 out of 100 panels operating at more than $70 \%$ of rated power," SunPower panels are shown in its product literature to have a useful life of 40years (SunPower, 2013a, 2013b). The Solar Energy Industries Association (SEIA) states that the lifespan of PV panels can last from 20 to 30 years (SEIA, 2015). A useful life of 30 years has been conservatively modeled; while product literature indicates a longer lifetime, SunPower provides 25 years in its warranty. SEIA (2015) states a lifetime of 10 years for the inverter; this is supported by the 10-year warranty given by SunPower for the 5000m LUT (SunPower Inverter Limited Warranty).

At end of life, materials from PV panels are assumed to be sent for recycling for material recovery. The recycling process for silicon based modules can be described as follows: "For silicon-based modules, aluminium frames and junction boxes are dismantled manually.... The module is subsequently crushed and its several components are separated, allowing recovering up to $80 \%$ of the panel."${ }^{23}$ An LCA screening study by Fraunhofer (2012) demonstrated that valuable materials like aluminum frames, copper, and glass cullet can be successfully recovered at a flat glass recycling facility. At the time of this writing, in the U.S., recycling of PV panels is not mandated. However, it is expected that as recycling of PV panels becomes a streamlined operation and as PV panels begin to graduate out of their useful lives, recycling will be industry standard practice. It should be noted that PV panels are required to be recycled in the EU today. ${ }^{24}$

\footnotetext{
${ }^{23}$ See: http://www.solarwaste.eu/collection-and-recycling/.

${ }^{24}$ In 2012, PV panels fell under the scope of the Directive on waste electrical and electronic equipment (WEEE), which means that producers of PV panels are required to fund collection, treatment, and recycling of WEEE and divert it from landfills.
} 
A distance of $48 \mathrm{~km}(30 \mathrm{mi})$ to the landfill or a recycler in a heavy-duty diesel truck has been modeled. The landfill is based on ecoinvent waste management process data.

\subsubsection{Solar Thermal Water Heating}

The Net-Zero Energy Residential Test Facility (NZERTF) is equipped with two closedloop solar water heating systems. Each system uses two Heliodyne Gobi 406001 solar thermal panels or collectors and a solar storage tank with heat exchanger (the Helio-Pak or HPAK 016) attached. The system works as follows: solar fluid in the collector is heated by the sun and then pumped through the heat exchanger which then heats the water in the storage tank. The solar fluid circulates back to the collector, where it is then reheated by the sun. The solar storage tanks are equipped with a backup electrical heating element when the sun is not able to provide energy.

The LCA for the BIRDS model includes one collector, one heat exchanger, and the two water storage tanks used for the two systems: $303 \mathrm{~L}$ (80 gal) and $454 \mathrm{~L}$ (120 gal) tanks. One Gobi 406001 collector has a gross area of $2.5 \mathrm{~m}^{2}\left(26.9 \mathrm{ft}^{2}\right)$ and a mass of $33.5 \mathrm{~kg}$ (74 lb). The number of collectors and auxiliary equipment needed for any given performance requirement in BIRDS are multiplied within BIRDS.

Figure 3-11 presents the system boundaries for the solar water heating system.

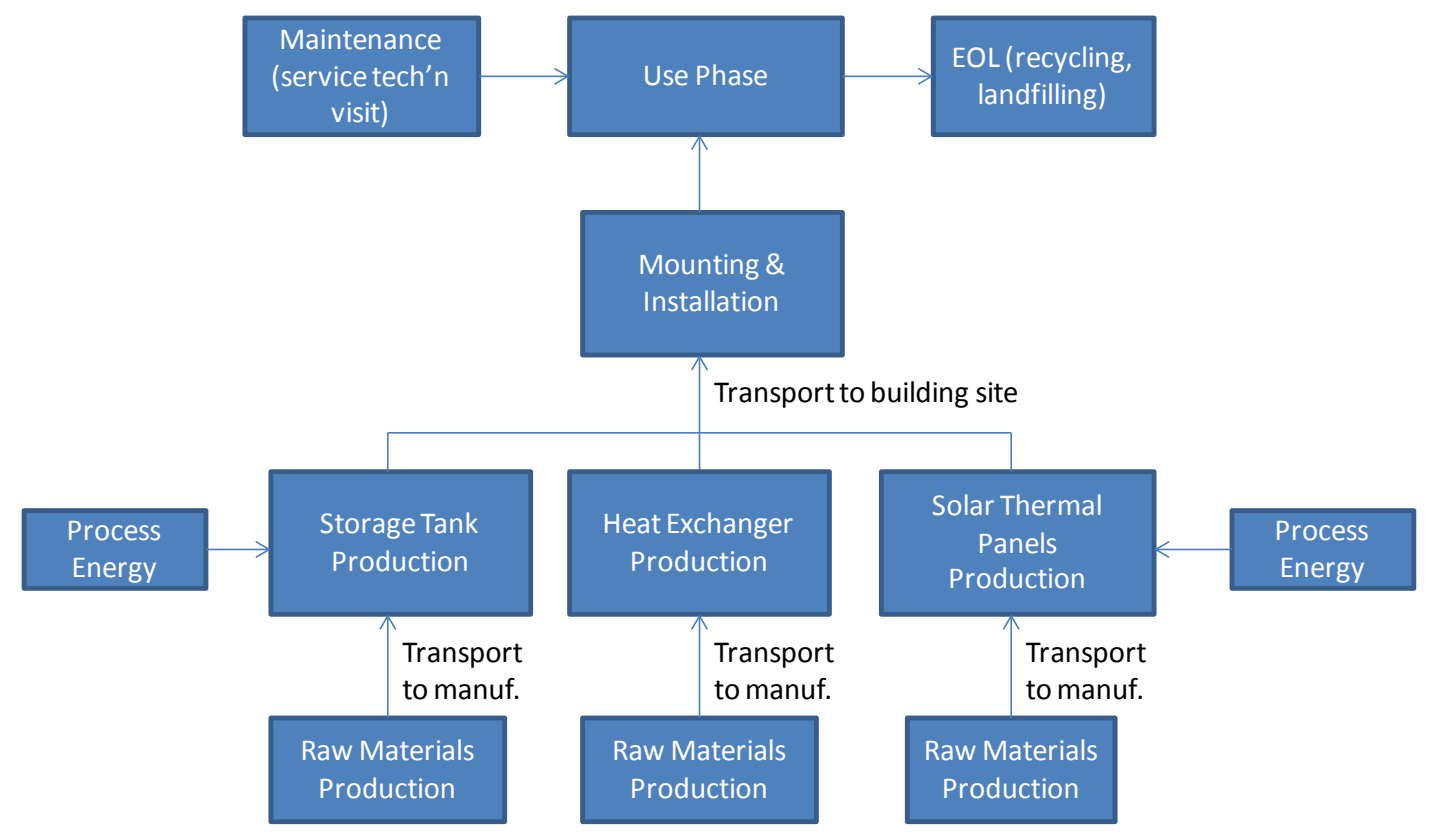

Figure 3-11 Solar Water Heating System Boundaries 


\subsubsection{Upstream Materials Production through Manufacturing}

\subsubsection{Solar Collector Panels}

Manufacturer-specific data was not available, so publicly-available sources of data were used as proxy and customized wherever possible using product specifications. Data for the solar collector comes from ecoinvent and is described in Stucki (2012) and Jungbluth (2007b). The data cover the assembly of a flat plate collector with a copper absorber coated with a black chrome coating. Data are based on Swiss production in 2002 and include materials, water use, and production energy. One collector has an active area of $2.72 \mathrm{~m}^{2}\left(29.3 \mathrm{ft}^{2}\right)$ and an empty weight of $52 \mathrm{~kg}$ (115 lbs). The technology is considered by ecoinvent to still be current. Some North American datasets and U.S. energy datasets from the U.S. LCI database were used to customize the European geography to more North American conditions. Nevertheless, the older data and the relatively smaller size of the ecoinvent collector are limitations to the data.

The data in Stucki (2012) is copyrighted so the bill of materials cannot be recreated here, but the interested reader is encouraged to go to the source or download the inventory datasets which are produced in EcoSpold1 format, at www.lc-inventories.ch (at no charge), or found within ecoinvent.

\subsubsection{Heat Transfer Liquid}

The closed-loop solar system requires $2.2 \mathrm{~L}$ (0.6 gal) of heat transfer liquid consisting of $40 \%$ to $50 \%$ inhibited propylene glycol (Dyn-o-flo HD) and water. The mixture was modeled using $45 \%$ propylene glycol and $55 \%$ water. (Heliodyne Installation Guide, Table 1.5).

\subsubsection{Heat Transfer Appliance}

No data were available on the HPAK or similar apparatus so the $24.9 \mathrm{~kg}$ (55 lb) bill of materials was estimated using a combination of published Heliodyne information on parts and materials in drawings, technical specifications (HelioPak Technical Specifications), and the Heliodyne HPAK installation guide, as follows in Table 3-51:

\section{Table 3-51 HPAK Bill of Materials}

\begin{tabular}{lcccl} 
Material & $\mathbf{\%}$ & $\mathbf{K g}$ & $\mathbf{l b}$ & Notes \\
Steel & $46.0 \%$ & 11.5 & 25.3 & \\
Copper & $30.0 \%$ & 7.48 & 16.5 & \\
Acrylic & $8.0 \%$ & 2.00 & 4.4 & $\begin{array}{l}\text { polymethyl methacrylate, for acrylic } \\
\text { (PMMA) (cover) }\end{array}$ \\
EPDM rubber & & & & Insulation by Armaflex \\
insulation & $7.0 \%$ & 1.75 & 3.85 & \\
Bronze & $5.0 \%$ & 1.25 & 2.75 & \\
Expanded PP foam & $3.0 \%$ & 0.75 & 1.65 & Casing \\
EPDM & $1.0 \%$ & 0.25 & 0.55 & Other parts \\
Total & $\mathbf{1 0 0 . 0} \%$ & $\mathbf{2 4 . 9}$ & $\mathbf{5 5 . 0}$ & \\
\hline
\end{tabular}


The steel, assumed to be galvanized, comes from World Steel Association (2011). Data for copper tube and wires come from ICA (2012). U.S. LCI Database provided the production data for polymethyl methacrylate (PMMA, for acrylic) and polypropylene (PP). The PP foaming process comes from ecoinvent. Ecoinvent provided the data for the bronze and the ethylene propylene diene monomer (EPDM) rubber.

No manufacturing data was available for this type of appliance. However, the modeling of the upstream materials includes processing into usable parts, e.g., copper tubing. While this does not include full forming of parts and general final assembly, it likely accounts for most environmental impacts. Nonetheless, this uncertainty in impact is difficult to quantify without understanding the processes at this product's final manufacturing/assembly plant.

\subsubsection{Solar Water Tanks}

The Heliodyne storage tanks consider the solar storage components along with an electric component for auxiliary or backup heating. VHK (2007) provided these data; Table 3-52 uses data extrapolated from VHK (2007) Table B.9; the data for the 200 L (53 gal) storage tank was scaled up and the solar components from VHK (2007) Table 3.2 were incorporated into the materials list to meet the total published weights of the Heliodyne units. As described in a previous chapter, since the Material Groups listed in VHK (2007) Table B.9 were general, these data have been supplemented by more detailed parts and materials provided by VHK (2007) Table B.10. Assumptions made are noted. Data for the materials are described in the subchapter on hot water heaters.

\section{Table 3-52 Heliodyne Solar Water Storage Tanks Bill of Materials}

\begin{tabular}{|c|c|c|c|c|c|}
\hline \multirow[b]{2}{*}{$\begin{array}{l}\text { B.9 Material } \\
\text { Group }\end{array}$} & \multicolumn{2}{|c|}{ 80-gal } & \multicolumn{2}{|c|}{ 120-gal } & \multirow[b]{2}{*}{ Parts, Materials \& Assumptions } \\
\hline & kg & $\mathbf{L b}$ & Kg & $\mathbf{L b}$ & \\
\hline 3-Ferro & 84.7 & 186.8 & 124.4 & 274.3 & $\begin{array}{l}\text { Tank, mounting plate, screws. Tank assumed to be } \\
\text { stainless steel }\end{array}$ \\
\hline 2-TecPlastics & 3.1 & 6.9 & 4.6 & 10.2 & $\begin{array}{l}\text { Rubber gasket (assume } 25 \% \text { ), PVC pipe protection and } \\
\text { pipe collar, PVC thermal control (assume } 75 \% \text { ) }\end{array}$ \\
\hline 1-BlkPlastics - & & & & & Assume EPS insulation \\
\hline & 2.5 & 5.5 & 3.7 & 8.1 & \\
\hline 7-Misc & 2.5 & 5.5 & 3.7 & 8.1 & $\begin{array}{l}\text { Portion of the Misc. category; part unknown. Assuming } \\
\text { packaging, based on Table B.10. Not included in this } \\
\text { analysis. }\end{array}$ \\
\hline 7-Misc & & & & & Portion of the Misc. category; Assume resistance heater \\
\hline & 0.6 & 1.4 & 0.9 & 2.0 & \\
\hline 5-Coating & & & & & Assume enamel \\
\hline & 6.5 & 14.3 & 9.5 & 21.0 & \\
\hline 4-Non-ferro & & & & & Assume copper \\
\hline & 0.4 & 0.9 & 0.6 & 1.4 & \\
\hline 6-Electronics & 0.1 & 0.3 & 0.2 & 0.4 & Assume wiring, thermal control \\
\hline
\end{tabular}


Solar Storage Parts and Materials (based on Table 3.2)

\begin{tabular}{|c|c|c|c|c|c|}
\hline Feed Pump & 3.8 & 8.3 & 5.0 & 11.0 & Stainless steel (assumption) \\
\hline Heat exchanger & - & - & - & - & $\begin{array}{l}\text { This line item removed as the Heliodyne system } \\
\text { uses an external heat exchanger (HPAK) }\end{array}$ \\
\hline 3-way valve & 1.5 & 3.3 & 2.0 & 4.4 & Aluminum diecast (assumption) \\
\hline Piping & 3.0 & 6.6 & 4.0 & 8.8 & Copper (assumption) \\
\hline TOTAL --> & 108.8 & 239.8 & 158.6 & 349.7 & \\
\hline
\end{tabular}

No manufacturing data were available for these tanks, so as proxy, the same data used for the water heaters in this documentation was used for this tank.

\subsubsection{Transportation to the Building Site through End of Life}

Transportation of the Heliodyne solar heating system to the building site is modeled using an assumed average of $2414 \mathrm{~km} \mathrm{(1500} \mathrm{mi)} \mathrm{by} \mathrm{heavy-duty} \mathrm{diesel} \mathrm{fuel-powered}$ truck.

The installation of the solar collectors accounts for mounting the solar panels on a slanted roof and installation of copper pipes. Collectors can be mounted flush against the roof using steel clips and hardware, or rack-mounted using aluminum channel shoes and legs. For the NZERTF, the collectors are assumed to be flush on the roof, and it is assumed that $1.4 \mathrm{~kg}(3.0 \mathrm{lb})$ of stainless steel hardware is used per collector. Data for stainless steel come from ecoinvent, and ICA (2012) provides the data for the copper pipes. It should be noted that the copper pipes need only to be installed one time during the 40year study period, as once installed, they are used for other solar collector replacements.

It is assumed that a qualified service technician comes to the building site once annually to check the system and ensure optimal performance and lifetime. During maintenance, the heat transfer liquid is tested for freeze protection and correct $\mathrm{pH}$ level. It is assumed that the liquid is replaced every 10 years. After use, it is sent to a municipal wastewater treatment. It is assumed that the technician is within a $24 \mathrm{~km}$ (15 mi) service radius. This distance, driven in a gasoline-powered van, is shared amongst other service visits for that technician, if the same technician is making more than one service call during that trip. Assuming the technician makes 5 service calls in one day, one-fifth of the impacts from

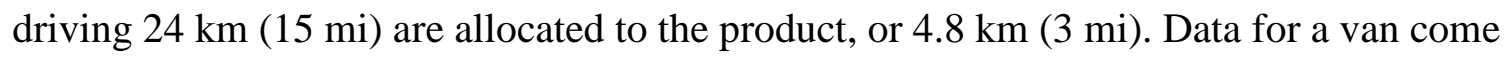
from ecoinvent. Unplanned service visits (i.e., unanticipated issues that require a service technician) are not included in the model under the assumption that the system will run as designed given the homeowner adequately follows the maintenance and care guidelines.

The solar collectors are modeled as having a 20-year lifetime, based on product literature. At end of life, they are assumed to be recycled (see discussion in the PV chapter). A lifetime of 10 years has been assumed for the Helio-Pak, based on the warranty. (HPAK Installation Guide, Sec.7). Lifetimes of 11 years have been assumed for the solar water heaters. (NAHB, 2007, Table 1, Section 1) At the end of life, it is assumed that these pieces of equipment are sent for recycling to recover valuable metal (see Section 3.3.4.7 
for the recycling methodology used). What cannot be recovered is modeled as landfilled. A distance of $48 \mathrm{~km}$ (30 mi) to the landfill in a heavy-duty diesel truck has been modeled. The landfill is based on ecoinvent waste management process data. 


\section{Software Development}

The development of BIRDS NEST and associated OpenStudio (OS) Measure was completed through a collaboration between NIST's Engineering Laboratory (EL) (Applied Economics Office (AEO) and EL Data, Security, and Technology (ELDST)) and NREL's OS Team. NREL developed the OS Measure while EL developed BIRDS NEST. This section gives an overview of the information exchange and a detailed description of the OS Measure and BIRDS NEST, including the software tools and programming languages implemented.

\subsection{Information Exchange}

\subsubsection{Overview}

As was discussed in Section 1.3, OS was selected as the initial software for which BIRDS NEST would be designed because of its capabilities to exchange all the necessary information required to develop LCIAs for a customized building design with an API hosted on an independent server, including the ability to run the API and display its results without leaving the OS application. The information exchanged and flow of information between OS and BIRDS NEST is shown in Figure 4-1.

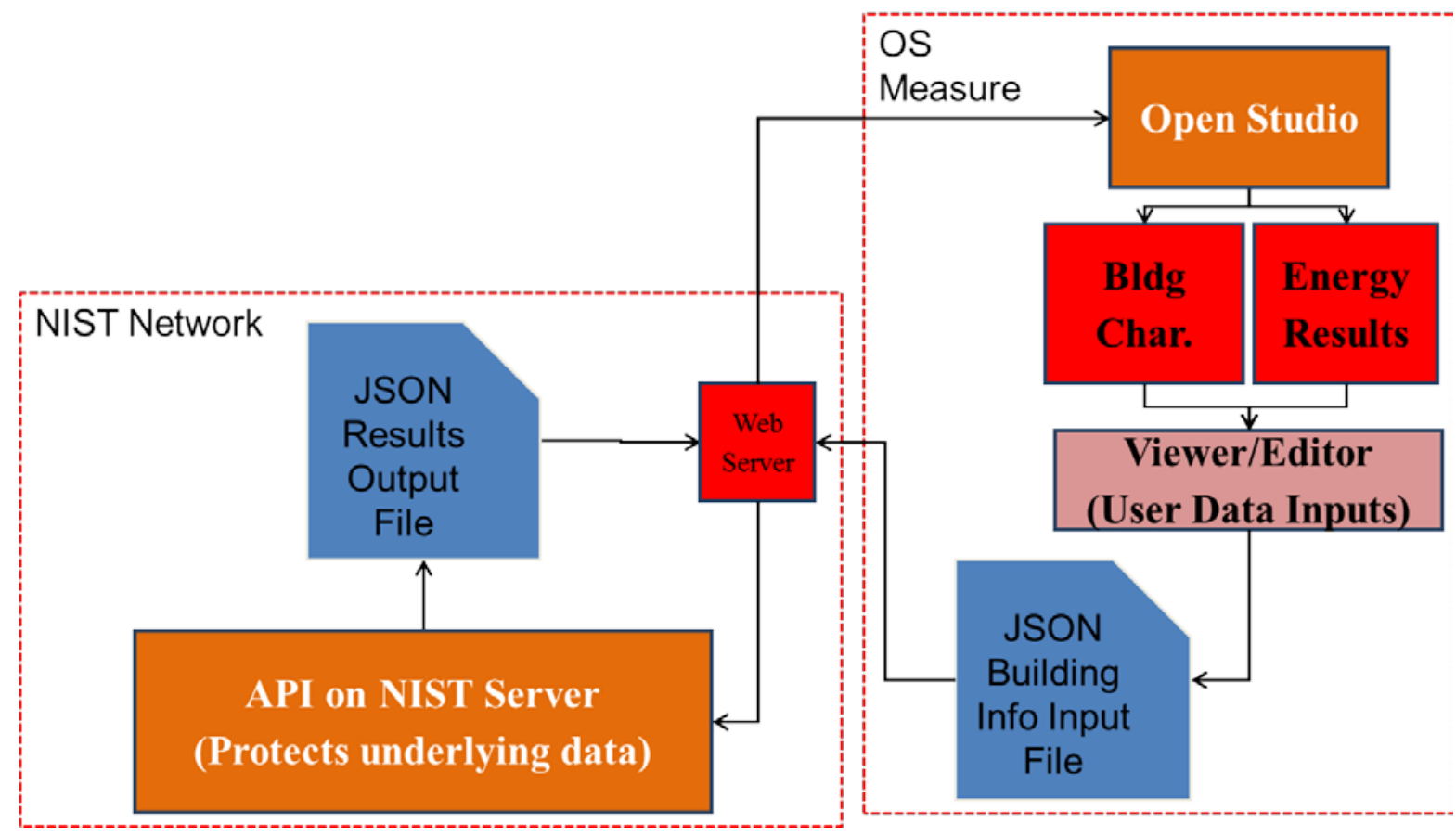

Figure 4-1 Information Exchange between OS and BIRDS API

The transfer of information from OS to the BIRDS NEST is completed using JavaScript Object Notation (JSON)-formatted files. OS generates a JSON-formatted input file that is sent through HTTP to the BIRDS NEST, which is waiting for a JSON input file. As soon as an input file is received, the API parses the file into its parameters and uses the values 
to generate LCIA estimates for the building design. The set of values are aggregated into a JSON-formatted output file and sent back to OS using HTTP. OS awaits the return of a JSON-formatted output file that it reads and parses into an OS Measure Report. The report displays a set of tables and graphs in the OS Results tab.

A user that has developed a building design within the OS application can add the BIRDS NEST OS Measure to their model using the OS Measure tab as shown in Figure 4-2. The BIRDS NEST OS Measure can be downloaded from the Building Component Library (BCL).

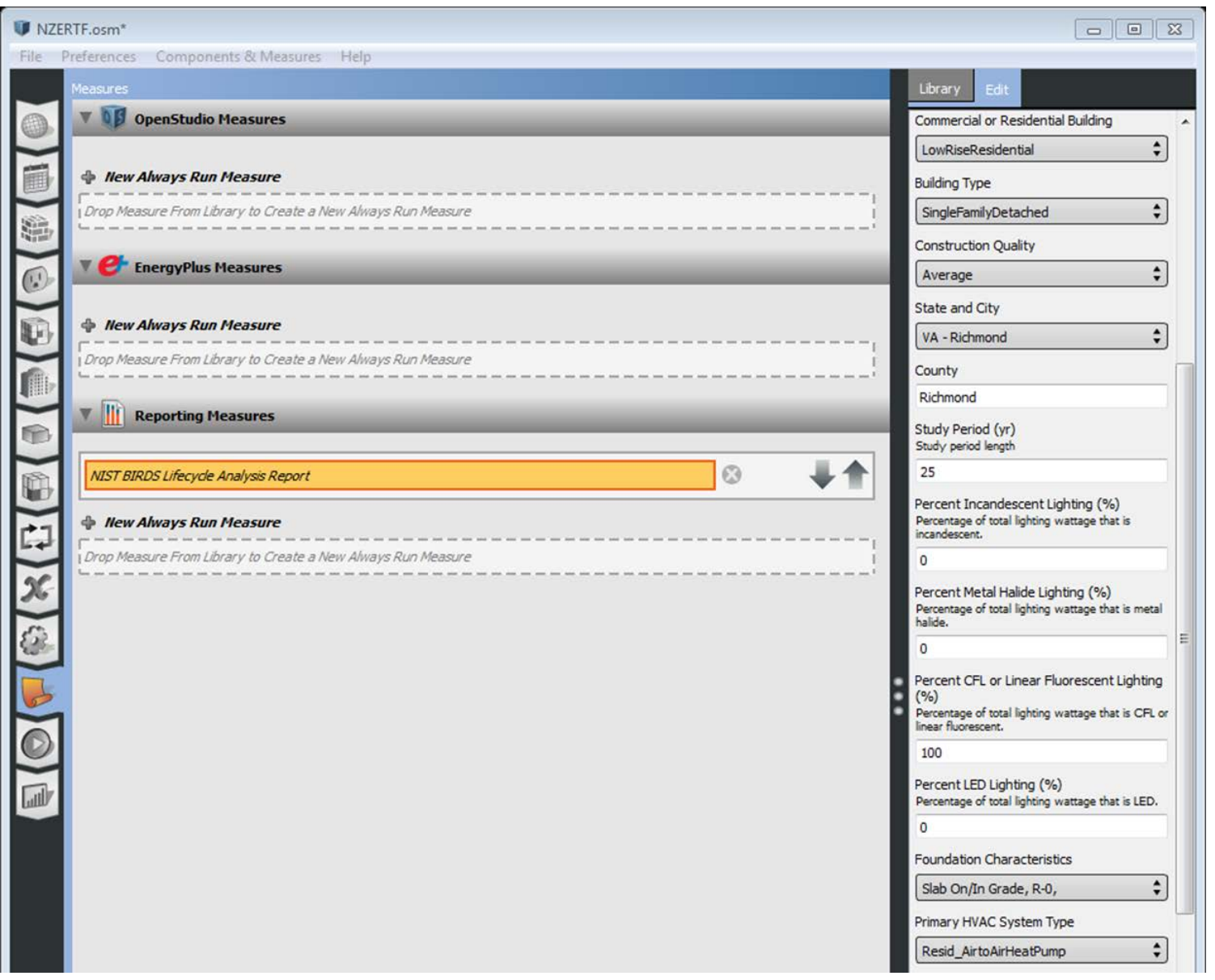

Figure 4-2 OpenStudio Measure - User Inputs

After reviewing and/or changing the user inputs for the BIRDS NEST OS Measure to match the user's building design and preferences, the user runs the OS model that executes any OS Measure and the $\mathrm{E}+$ simulation that generates annual performance data on the building (e.g., energy use, thermal comfort). After the $\mathrm{E}+$ simulation has finished running (but before OS reports a completed run), information on the building characteristics and annual performance data are formatted into a JSON "input" file and sent to BIRDS NEST. 
The BIRDS NEST API, hosted on a NIST server, is constantly waiting for an input file. As soon as the input file is received, the API parses the file into its parameters and uses the values to generate LCIA estimates for the building design. The LCIA values along with key building characteristics and generated warnings are aggregated into a JSON-formatted "output" file that is sent back to OS - all of which occurs in a manner of seconds without leaving the OS Run tab. OS awaits the return of an output file that it reads and parses into a CSV file. An OS Measure Report (labeled BIRDS NEST Measure Report) is generated and displays the data from the CSV file as a set of tables and graphs. The report is viewable in the OS Results tab as shown in Figure 4-3.

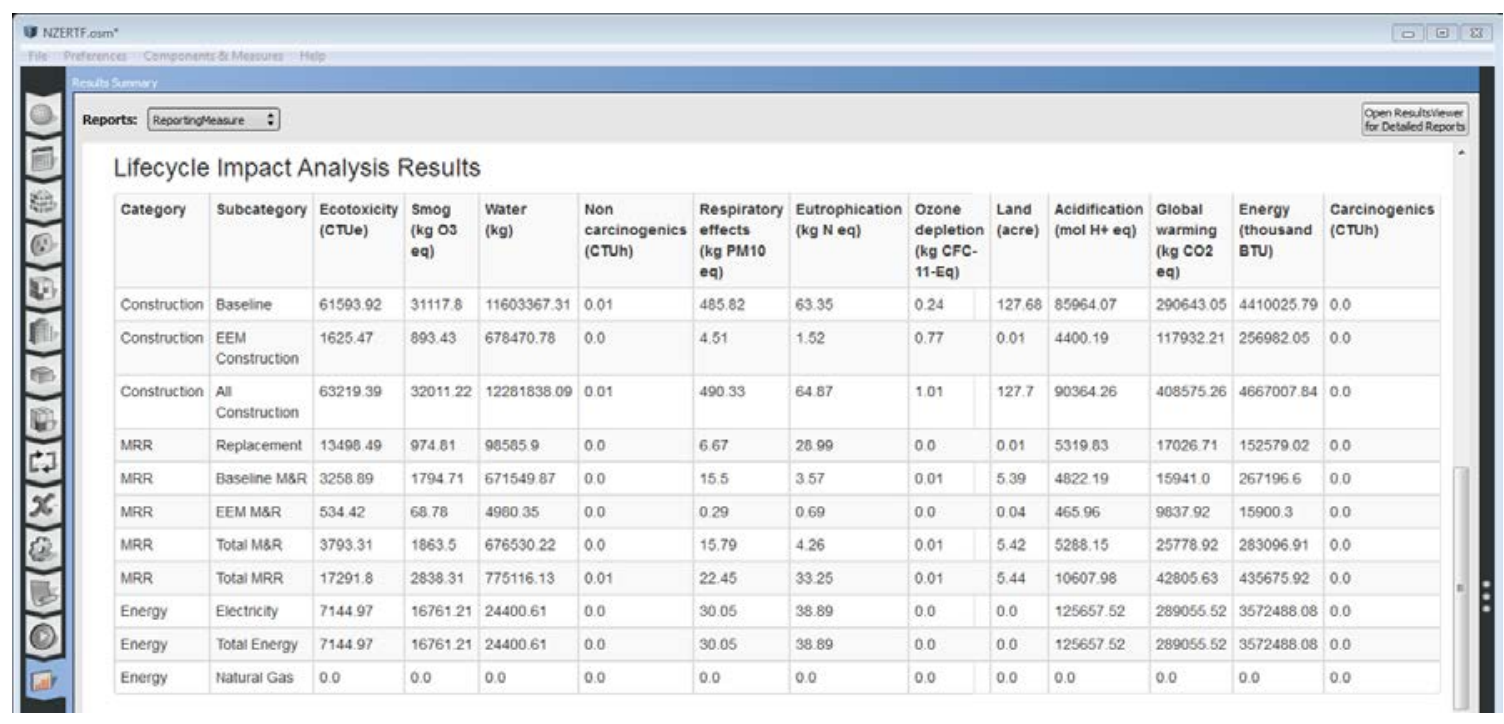

Figure 4-3 OpenStudio Measure BIRDS Report

\subsubsection{Information Exchange Format}

The ability to exchange information between OS and BIRDS NEST requires common definitions and value restrictions of each input and output parameter to successfully associate information about the OS model and E+ results with the LCIA calculations. Even though OS Measures are written using Ruby and BIRDS NEST is written in Python, it is possible to transfer information seamlessly between the two using a library of enumerations for each of the input and output parameters created using Protocol Buffers, which are a language-neutral, platform-neutral extensible mechanism for serializing structured data and referred to as "Protobuf." Each input file is initially tested to ensure the values in the input file generated by OS are consistent with enumerations defined in Protobuf. Note that the use of Protobuf generalizes the input file to a common format for submitting to BIRDS NEST. A general format allows not just OS, but any software tool to submit an input file to the API to generate LCIA results for a building design if it is submitted consistent with the Protobuf enumeration library and includes values for all required information. 


\subsection{OpenStudio Measure}

The BIRDS NEST OS Measure requires a combination of automated input extraction from the OS model (e.g., conditioned floor area, perimeter, wall construction and insulation levels) and E+ results (e.g., electricity and natural gas consumption) and user inputs that are either not defined or cannot currently be identified within the OS model (e.g., study period, environmental impact weighting, HVAC equipment types). A complete list of parameter values is listed in Table 4-1. Each of these input types are discussed in greater detail in the appropriate subsection below.

\section{Table 4-1 OpenStudio Measure Parameter Values}

\begin{tabular}{|l||c|}
\hline $\begin{array}{l}\text { Building Geometry \& } \\
\text { Envelope Construction }\end{array}$ & $\begin{array}{c}\text { Building Equipment \& } \\
\text { Operation }\end{array}$ \\
\cline { 2 - 2 } $\begin{array}{l}\text { Number of Stories } \\
\text { Conditioned Floor Area } \\
\text { Exterior Wall Area }\end{array}$ & $\begin{array}{c}\text { Lighting Wattage } \\
\text { Daylighting Controls } \\
\text { HVAC Coil Specifications } \\
\text { Window Area }\end{array}$ \\
$\begin{array}{l}\text { Window Specifications Photovoltaic } \\
\text { Infiltration ACH }\end{array}$ \\
$\begin{array}{l}\text { Wall Construction } \\
\text { Assembly } \\
\text { Attic Construction } \\
\text { Assembly } \\
\text { Foundation Type }\end{array}$ \\
\hline
\end{tabular}

\begin{tabular}{|c|}
\hline User-Specified \\
\hline Building Category \\
Building Type \\
Construction Quality \\
Location \\
Lighting Technology \\
Foundation \\
Characteristics \\
Primary HVAC Type \\
Secondary HVAC Type \\
\hline Study Period \\
\hline Environmental Weighting \\
Environmental Allocation \\
\hline
\end{tabular}

\subsubsection{Automated Input Extraction}

The automated input values that are extracted by the BIRDS NEST OS Measure includes building characteristics from the OS file and annual building operational performance from the E+ results file as shown in Table 4-2. The geometry parameter values include the number of stories and conditioned floor area by story. Construction assembly information includes window specifications, exterior wall assembly materials, and attic construction assembly materials as well as the area of each. The equipment parameters include the lighting wattage and daylighting controls, heating and cooling (air and water) coil specifications, and solar thermal and solar photovoltaic systems. The operational parameters include consumption by fuel source and electricity production. 
Table 4-2 OpenStudio Measure Parameter Values - Automated Extraction

\begin{tabular}{lcc}
\hline $\begin{array}{l}\text { Geometry and Construction } \\
\text { Parameters }\end{array}$ & Equipment Parameters & Operational Parameters \\
\hline Number of Stories & Lighting Wattage & Electricity Consumption \\
$\begin{array}{l}\text { Conditioned Floor Area } \\
\text { Foundation Type }\end{array}$ & Daylighting Controls & Natural Gas Consumption \\
$\begin{array}{l}\text { Window Area and } \\
\text { Specifications }\end{array}$ & HVAC Coil Specifications & Electricity Production \\
\cline { 2 - 2 } $\begin{array}{l}\text { Exterior Wall Construction } \\
\text { Area and Assembly }\end{array}$ & Domestic Hot Water Heater \\
$\begin{array}{l}\text { Attic Construction and Area } \\
\text { Assembly }\end{array}$ & Solar Thermal System \\
\hline
\end{tabular}

\subsubsection{User Input Selection}

Although it is possible to extract a large amount of information from the OS and E+ files, there remain parameter values that cannot currently be extracted from the model. The user input values shown in Table 4-3 are related to building characteristics, but are not currently extractable include the building category, building type, quality of construction, building location, lighting technology, foundation characteristics, and HVAC system types. A user's preferences are also required for the study period, environmental weighting approach, and environmental allocation method.

Table 4-3 OpenStudio Measure Parameter Values - User-Specified

\begin{tabular}{lc}
\hline Unidentifiable Parameters & User Preference Parameters \\
\hline Building Category & Study Period \\
Building Type & Environmental Weighting \\
Construction Quality & Environmental Allocation \\
Location & \\
\hline Lighting Technology & \\
Foundation Characteristics & \\
Primary HVAC Type & \\
Secondary HVAC Type & \\
\hline
\end{tabular}

\subsection{BIRDS NEST}

BIRDS NEST was developed based on the same framework and building component options used in developing the BIRDS Low-Energy Residential Database as well as additional options to account for alternatives not yet included in BIRDS. The API completes a closest match to the input values from the JSON input file generated by OS using the building envelope and building system options described in following subsections. 


\subsubsection{Baseline Building}

LCIAs for the baseline building are estimated for both its initial construction and maintenance and repairs over the study period. The baseline building construction is estimated using the following building characteristics: building type, number of stories, finished floor area, wall construction, foundation construction, and construction quality. Options for each of these characteristics is shown in Table 4-4. The baseline maintenance and repair LCIAs are estimated based on the year of operation and the finished floor area of the building.

Table 4-4 Baseline Building Characteristic Options

\begin{tabular}{|c|c|c|c|c|}
\hline Characteristic & \multicolumn{4}{|c|}{ Options } \\
\hline Building Type & \multicolumn{4}{|c|}{ Single-Family Dwelling } \\
\hline Stories & \multicolumn{2}{|c|}{1} & \multicolumn{2}{|c|}{2} \\
\hline Finished Floor Area & \multicolumn{4}{|c|}{ Continuous Function } \\
\hline Wall & Wood & Brick & Stucco & Masonry \\
\hline Foundation & \multicolumn{2}{|c|}{ Slab/Crawlspace } & Basement-Finished & Basement-Unfinished \\
\hline Quality & \multicolumn{2}{|c|}{ Average } & Custom & Luxury \\
\hline
\end{tabular}

\subsubsection{Building Envelope Component Options}

The building envelope accounts for five of the ten building components that are evaluated by BIRDS NEST. The thermal performance of the wall, attic, and foundation assemblies is changed by altering the materials in those assemblies, such as the framing and insulation.

Table 4-5 shows the 70 wall assemblies for which LCIA estimates are calculated across four wall structure types based on requirements across editions of IECC (ICC 2006, ICC 2009, ICC 2012, ICC 2015) and additional options included in the BIRDS Low-Energy Residential Database: wood-framed (11), mass - concrete (16), mass - concrete masonry unit (16), and steel-framed (27). The wood-framed assembly options include combinations of framing, cavity insulation, and exterior wall insulation. The mass wall assemblies (concrete and concrete masonry unit) assume the use of the same options that include cavity insulation, interior rigid insulation, or exterior insulation. The steel-framed assemblies include combinations of cavity and exterior rigid insulation. 
Table 4-5 Wall Assembly Options

\begin{tabular}{|crrr|}
\hline Wood & & & \\
\hline & & Cavity & \multicolumn{2}{l|}{ Ext. Rigid } \\
OC & Thickness & R & \multicolumn{1}{l|}{ R } \\
\hline 16 & 4 & 13 & 0 \\
16 & 4 & 13 & 5 \\
16 & 4 & 13 & 10 \\
16 & 4 & 19 & 0 \\
16 & 4 & 21 & 0 \\
24 & 6 & 20 & 0 \\
24 & 6 & 21 & 0 \\
24 & 6 & 20 & 5 \\
24 & 6 & 20 & 10 \\
24 & 6 & 20 & 12 \\
24 & 6 & 20 & 24 \\
\hline $1 \mathrm{R}\left(\mathrm{ft}^{2}{ }^{\circ} \mathrm{F} \mathrm{hr} / \mathrm{Btu}\right)=0.176 \mathrm{R}_{\mathrm{SI}}\left(\mathrm{m}^{2}{ }^{\circ} \mathrm{K} / \mathrm{W}\right)$ \\
$1 \mathrm{in}=2.54 \mathrm{~cm}$ \\
\hline \multicolumn{4}{|l}{} \\
\hline
\end{tabular}

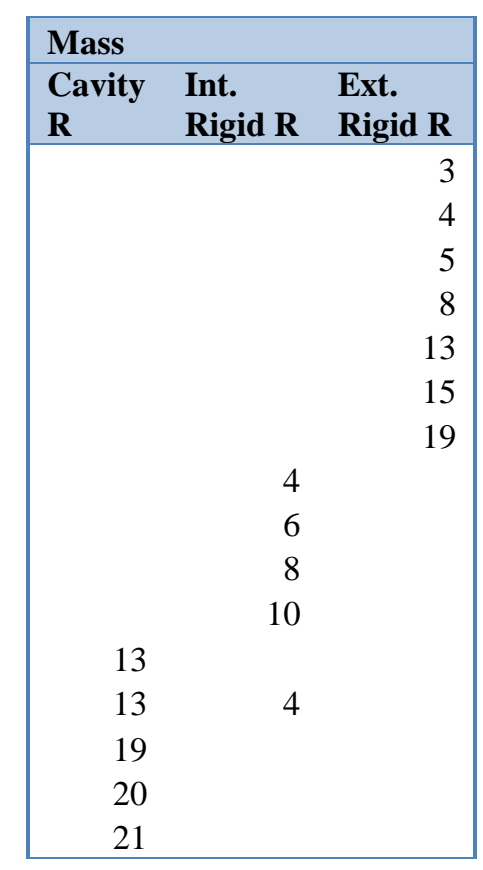

\begin{tabular}{|lr|}
\hline \multicolumn{1}{|l|}{ Steel } & \\
\hline Cavity & \multicolumn{1}{l|}{ Ext. } \\
R & \multicolumn{1}{l|}{ Rigid R } \\
\hline 0 & 9.3 \\
0 & 10 \\
0 & 14 \\
13 & 4.2 \\
13 & 5 \\
13 & 8.9 \\
13 & 9 \\
13 & 10 \\
13 & 12.7 \\
15 & 3.8 \\
15 & 4 \\
15 & 8.5 \\
15 & 12.3 \\
19 & 2.1 \\
19 & 6.2 \\
19 & 7.8 \\
19 & 8 \\
19 & 9 \\
19 & 11.6 \\
21 & 2.8 \\
21 & 3 \\
21 & 3.1 \\
21 & 7.5 \\
21 & 11.3 \\
25 & 7 \\
25 & 8 \\
25 & 10.9 \\
&
\end{tabular}

Foundations can include floor, slab, and/or wall insulation depending on the assembly. The 11 foundation floor/slab alternatives shown in Table 4-6 include three foundation types (basement, crawlspace, and slab) and floor/slab insulation based on requirements in editions of IECC (ICC 2006, 2009, 2012, 2015) and additional options included in the BIRDS Low-Energy Residential Database. A slab foundation includes three options based on the insulation value and depth of installation. The crawlspace assemblies include a combination of both floor and wall insulation levels using rigid insulation for the wall and fiberglass batt insulation for the floor. The basement assemblies include a combination of two foundation slab insulation and six foundation wall insulation options. 
Table 4-6 Foundation Assembly Options

\begin{tabular}{|lr|}
\hline Wall & Rigid R \\
Basement & 0 \\
& 5 \\
& 8 \\
& 10 \\
& 15 \\
& 22 \\
Crawlspace & 0 \\
& 5 \\
& 10 \\
Slab & 0 \\
\hline
\end{tabular}

\begin{tabular}{|lrr|}
\hline Floor/Slab & R-value & \multicolumn{1}{c|}{ Depth } \\
Basement & 0 & NA \\
& 10 & NA \\
Crawlspace & 13 & NA \\
& 19 & NA \\
& 30 & NA \\
& 38 & NA \\
Slab & 0 & 0 \\
& 10 & 2 \\
& 10 & 4 \\
\hline
\end{tabular}

The 14 attic assemblies shown in Table 4-7 include two framing types (wood and steel) and two locations for insulation installation (attic floor assembly and roof assembly). Insulation on the attic floor is assumed to be blown-in cellulose while insulation in the roof assembly includes a combination of cellulose in the rafters and exterior rigid insulation. Insulation levels are based on requirements in editions of IECC (ICC 2006, 2009, 2012, 2015) and other options included in the BIRDS Low-Energy Residential Database.

\section{Table 4-7 Attic Assembly Options}

\begin{tabular}{lrrr} 
Insulation & Ceiling R & Cavity R & \multicolumn{2}{c}{ Rigid R } \\
Attic Floor & 30 & 0 & 0 \\
& 38 & 0 & 0 \\
& 49 & 0 & 0 \\
\hline \multirow{2}{*}{ Roof } & 0 & 45 & 5 \\
& 0 & 45 & 16 \\
& 0 & 45 & 32 \\
\hline
\end{tabular}

The building envelope air leakage rates $\left(7.0 \mathrm{ACH}_{50}, 3.0 \mathrm{ACH}_{50}\right.$, and $\left.0.63 \mathrm{ACH}_{50}\right)$ shown in Table 4-8 are based on rates defined in editions of IECC (ICC 2006, 2009, 2012, 2015) as well as the performance of the NZERTF based on air changes per hour estimated using a blower door test at $50 \mathrm{~Pa}\left(\mathrm{ACH}_{50}\right)$. Table 4-8 shows the materials used in estimating the LCIAs for decreasing the air leakage rates. 
Table 4-8 Air Leakage Rate Options

\begin{tabular}{|c|c|c|c|c|}
\hline ACHNAT $_{\text {NC }}$ & ACH50 $_{\mathbf{5}}$ & \multicolumn{3}{|c|}{ Method(s) } \\
\hline$>0.35$ & 7.00 & Envelope Sealant & & \\
\hline$<0.15$ & 3.00 & Envelope Sealant & Envelope Sealant & \\
\hline NZERTF & 0.63 & Envelope Sealant & Air Barrier & Spray Foam in Joists \\
\hline
\end{tabular}

The 19 window assemblies shown in Table 3-19 are based on LCIAs for double hung windows that meet or exceed the window specifications defined in editions of the IECC (ICC 2006, 2009, 2012, 2015) and additional options included in the BIRDS Low-Energy Residential Database as shown in Table 4-9.

\section{Table 4-9 Window Assembly Options}

\begin{tabular}{|cc|}
\hline U-Value & SHGC \\
NR & 0.25 \\
1.2 & 0.3 \\
0.75 & 0.4 \\
0.65 & $\mathrm{NR}$ \\
0.65 & 0.4 \\
0.65 & 0.3 \\
0.5 & $\mathrm{NR}$ \\
0.5 & 0.3 \\
0.45 & 0.6 \\
0.4 & $\mathrm{NR}$ \\
0.4 & 0.6 \\
0.4 & 0.25 \\
0.35 & $\mathrm{NR}$ \\
0.35 & 0.6 \\
0.35 & 0.4 \\
0.35 & 0.25 \\
0.32 & $\mathrm{NR}$ \\
0.32 & 0.55 \\
0.2 & 0.25 \\
\hline $1 \mathrm{Btu} / \mathrm{ft}^{2} \cdot{ }^{\circ} \mathrm{F} \cdot \mathrm{h}=5.69 \mathrm{~W} / \mathrm{m}^{2} \cdot \mathrm{K}$ \\
\hline
\end{tabular}

\subsubsection{Building System Component Options}

The building systems account for 5 building components that can be varied within BIRDS NEST, four of which use a relatively straight forward approach to match to LCIA data as shown in Table 4-10. For the lighting system, any combination of incandescents, compact fluorescent lamps (CFLs), linear fluorescents (LFs), light-emitting diodes (LEDs), and metal halide can be evaluated based on converting the fraction of wattage to 
total wattage for each bulb type. Linear fluorescents are assumed to be equivalent to CFLs on a per watt basis. The DHW system includes four water heater alternatives and a solar thermal system. The solar PV system is calculated on a continuous basis per installed watt.

\section{Table 4-10 Lighting and DHW Options}

\begin{tabular}{|l|l|l|l|l|}
\hline \multicolumn{1}{|c|}{ System } & \multicolumn{3}{c|}{ Options } \\
\hline Lighting & Metal Halide & Incandescents & CFL/LF & LED \\
\hline Storage Water Heater & Electric (0.90) & Electric (0.95) & Gas & Heat Pump \\
\hline Solar Thermal & None & 2 panel; 80 gal. tank \\
\hline Solar PV & Continuous Per Watt & \multicolumn{3}{|c|}{} \\
\hline
\end{tabular}

The HVAC equipment options are more complicated due to the need to complete a best match on the type, capacity, and efficiency of the heating and cooling equipment as well as the type, if any, of mechanical ventilation. The ductwork for the heating and cooling system is assumed to be incorporated into the baseline building LCIA estimates. BIRDS NEST currently assumes that there can only be one heating, one cooling, and one mechanical ventilation option that match the system the user selected within the OS Measure. The first item in the input file that matches the expected item type (e.g., heating coil) for each will be used while other coils of that same type or any unmatched type will be ignored.

The HVAC system types are shown in Table 4-11, each of which is matched to the closest of 6 capacity values ranging from 1.0 ton to 5.0 tons and a minimum of two efficiency levels for both heating and cooling. Mechanical ventilation options include no ventilation, dedicated outdoor air (through heating and cooling ductwork), and a separate outdoor air system with a heat recovery ventilator (HRV).

\section{Table 4-11 Heating and Cooling Systems}

\begin{tabular}{lcccc}
\multicolumn{1}{c}{ System } & Capacity (tons*) & SEER & HSPF & EF \\
AC Unit with Furnace - Electric & 1.5 to 5.0 & 13 to 16 & & 0.98 \\
AC Unit with Furnace - Gas & 1.5 to 5.0 & 13 to 16 & & 0.80 to 0.96 \\
Air-to-Air Heat Pump (Electric Back-Up) & 1.0 to 5.0 & 13 to 16 & 7.7 to 9.9 & 0.98 \\
Air-to-Air Heat Pump (Gas Back-Up) & 1.0 to 5.0 & 13 to 16 & 7.7 to 9.9 & 0.80 to 0.96 \\
Water-to-Air Heat Pump & Not Yet Available & & & \\
\hline
\end{tabular}

$* 1$ ton of refrigerant $=3516.85 \mathrm{~W}$

\subsubsection{Building Performance}

The building performance is currently evaluated using the estimated annual energy consumption (electricity and natural gas) and production (electricity) from the E+ simulation results. The net annual electricity consumption is used to estimate the net 
LCIA for electricity based on the source emissions rates for the user-specified location. Annual Solar PV performance degradation is assumed to be $0.5 \%$ of total electricity production. The natural gas source emissions rate is constant across locations because the emissions from burning natural gas are the same regardless of the location. 


\section{Planned Release, Limitations, and Future Capabilities}

\subsection{Release of BIRDS NEST Beta}

The current (beta) version of BIRDS NEST will be released in late 2017. BIRDS NEST API and independent host web server is fully operational. The BIRDS NEST OS Measure is available for download from OS's Building Component Library (BCL) and will be accompanied by this technical manual, and a detailed tutorial with multiple use cases showing the capabilities of BIRDS NEST including example OpenStudio Model (.OSM) files, example JSON-formatted input and output files, and Protobuf enumerations list. This suite of documents should assist BIRDS NEST users as well as potential tool developers that want to understand how they might leverage BIRDS NEST for other software packages.

\subsection{Limitations}

There are limitations to the current beta version that should be clearly expressed to potential users for transparency purposes.

First, analysis based on the estimated energy performance is susceptible to the limitations and variations among current whole building energy simulation tools (e.g., E+ and OS) as well as variations among different users in creating building representations with the tools. As the development and application of simulation software improves in accuracy and uncertainty, the LCIA estimates related to the modeling should improve as well.

Second, some of the LCIA data is dated and/or is not location specific. The wholebuilding LCIAs are developed using I-O LCIA data that is not based on the most upto-date Environmentally Extended I-O Tables (2002 versus 2007). The regional electricity source emissions are based on eGRID data from 2008 while new data is currently being developed by the EPA. The building component data is based on national average LCA data.

Third, the building component LCIA data is available for a limited number of building component alternatives. As new LCIAs are developed, new building component alternatives can be added as options. However, some building components have been consistently difficult to obtain detailed source data with which to develop complete LCIAs.

Fourth, no uncertainty analysis is included in the LCIA estimates as required by international standards (International Organization for Standardization (ISO) 2006a, International Organization for Standardization (ISO) 2006b). Incorporating uncertainty analysis is problematic due to a lack of underlying uncertainty data, but this omission should be brought into the interpretation of the BIRDS results in the future, particularly in categories with a lack of scientific consensus such as some of the human health-related impact categories. A distribution of potential impacts will be more informative than the current single mid-point estimate. 
Fifth, the Environmental Problems approach that BIRDS uses for impact assessment does not offer the same degree of relevance for all environmental impacts. For global and regional effects (e.g., climate change and acidification) the method may result in an accurate description of the potential impact. For impacts dependent upon local conditions (e.g., smog, ecological toxicity, and human health impacts) it may result in an oversimplification of the actual impacts because the indices are not tailored to localities.

Sixth, during the interpretation step of the BIRDS LCAs, environmental impact results are optionally combined into a single environmental performance score using relative importance weights. These weights necessarily incorporate values and subjectivity. BIRDS users should routinely test the effects on the environmental impact scores of changes in the set of importance weights by completing their analysis with more than one weighting approach.

Seventh, life-cycle impact assessment is a rapidly evolving science. Assessment methods unheard of a decade ago have since been developed and are now being used routinely in LCAs. While BIRDS incorporates state-of-the-art impact assessment methods, the science will continue to evolve and methods in use today - particularly those for land and water use - are likely to change and improve over time. Future versions of BIRDS should incorporate these improved methods and resources as they become available.

\subsection{Future Capabilities}

Current options have been limited to ensure functionality for the current version of BIRDS NEST. Future versions will introduce new capabilities. The building types will be expanded to include not only low-rise apartment buildings, but also non-low rise residential buildings and commercial buildings (based on PNNL's Commercial Prototype Building Models). Additional building performance metrics will be incorporated, such as thermal comfort, indoor air quality, energy costs, building life-cycle costs, and costs of environmental impacts. As OS capabilities expand, so will those for BIRDS NEST, including the ability to automate additional input values that currently require user specification within the OS Measure. Additionally, feedback received from BIRDS NEST beta users will be prioritized and incorporated based on feasibility and potential impact on industry. 


\section{References}

AA (2013). Aluminum Association (AA), 2013, The Environmental Footprint of Semi-Finished Aluminum Products in North America, a Life Cycle Assessment Report. Retrieved from: http://www.aluminum.org.

Aaon (2016). Aaon CB Series Condensing Units. Document No. CB • R66640 • 090515, Accessed in 2016. Retrieved at www.aaon.com

AF \& PA (2001). American Forest \& Paper Association (AF\&PA), Details for Conventional Wood Frame Construction.

AHRI (2008). ANSI/AHRI 210/240-2008: 2008 Standard for Performance Rating of Unitary AirConditioning \& Air-Source Heat Pump Equipment.

AHRTI (2011). Life-cycle Climate Performance Model for Residential Heat Pump Systems, AHRTI Report No. 09003-01.

ASTM (2011). Standard Practice for Applying the Analytic Hiearchy Process Multiattribute Decision Analysis of Investments Related to Buildings and Building Systems, ASTM Designation E1765-11. West Conshohocken, PA.

Athena Sustainable Materials Institute (2003). Exploratory Life-cycle Analysis of Residential Operating Energy Systems.

Atherton, J. (2007). "Declaration by the Metals Indusctry on Recycling Principles." The International Journal of Life-cycle Assessment 12(1): 59-60.

Atlas Roofing Corporation (2012). Energy Shield/Energy Shield Plus/Cavity Wall Material Safety Data Sheet.

AWPA P5-09 (2010). American Wood Protection Association (AWPA), Standard P5-09.

Standard for Waterborne Preservations.

Bare, J. (2011). "TRACI 2.0: the tool for the reduction and assessment of chemical and other environmental impacts 2.0." Clean Technologies and Environmental Policy 13(5): 687-696.

Bare, J., et al. (2006). "Development of the method and US normalization database for life cycle impact assessment and sustainability metrics." Environmental Science \& Technology 40(16): 5108-5115.

Bayer MaterialScience (2008). Energy and Environmental Benefits of Insulating Commercial Buildings with Polyiso.

Bayer MaterialScience (2011). Life-Cycle Assessment of Polyiso Insulation - Final Report, Bayer MaterialSchienve.

Biswas, W. and M. Rosano (2011). "A life cycle greenhouse gas assessment of remanufactured refrigeration and air conditioning compressors." International Journal of Sustainable Manufacturing 2(2-3): 222-236.

CORRIM (2004). Bowyer, J., et. al., 2004, Phase I Final Report: Life Cycle Environmental Performance of Renewable Building Materials in the Context of Residential Construction. (Seattle, WA: Consortium for Research on Renewable Industrial Materials (CORRIM, 
Inc.)/University of Washington). Retrieved from:

http://www.corrim.org/pubs/reports/2005/phase1/MainRepAugust24.pdf.

CORRIM (2013a). Puettmann, M., et al., 2013, Cradle to Gate Life Cycle Assessment of Softwood Lumber Production from the Pacific Northwest (Corvallis: WoodLife Environmental Consultants, Consortium for Research on Renewable Industrial Materials (CORRIM), University of Washington, and others). Found at http://www.corrim.org/reports.

CORRIM (2013b). Puettmann, M., et al., 2013, Cradle to Gate Life Cycle Assessment of Softwood Lumber Production from the Southeast (Corvallis: WoodLife Environmental Consultants, Consortium for Research on Renewable Industrial Materials (CORRIM), University of Washington and others, 2013). Found at http://www.corrim.org/reports.

DAP (2005). Alex Plus Acrylic Latex Caulk Plus Silicone Material Safety Data Sheet.

DAP (2011). Technical Bulletin for ALEX PLUS Acrylic Latex Caulk Plus Silicone.

De Kleine, R. (2009). Life-cycle Optimization of Residential Air Conditioner Replacement, Report No. CSS09-12, University of Michigan, Ann Arbor.

Earthsure (2013). Window Product Category Rule [Draft for Review]. Earthsure PCR No. 30171600.

Ecobilan (2001). Eco-profile of high-volume commodity phthalate esters (DEHP/DINP/DIDP).

Ecoinvent (2007). "Life-Cycle Inventory Database." from http://www.ecoinvent.org/database/.

Energy Efficiency and Renewable Energy (EERE) (2012). Life-Cycle Assessment of Energy and Environmental Impacts of LED Lighting Products Part 1: Review of the Life-Cycle Energy Consumption of Incandescent , Compact Fluorescent, and LED Lamps, U.S. Department of Energy.

Faithful+Gould (2012). Residential Energy Efficiency Measures: Prototype Estimate and Cost Data Revision 6.0, National Renewable Energy Laboratory.

Fraunhofer (2012). Executive Summary: Life Cycle Assessment (LCA) screening of the Maltha recycling process for Si-PV modules. Retrieved from: http://www.pvcycle.org/.

Gloria, T. P., et al. (2007). "Life-Cycle Impact Assessment Weights to Support Environmentally Preferable Purchasing in the United States." Environmental Science \& Technology 41(21): 75517557.

Goedkoop, M., et al. (2008). "A Life-Cycle Impact Assessment Method which Comprises

Harmonised Category Indicators at the Midpoint and the Endpoint Level. Report I:

Characterisation. ." from www.lcia-recipe.net.

Guinée, J. B. (2002). "Handbook on Life-Cycle Assessment Operational Guide to the ISO Standards." The International Journal of Life Cycle Assessment 7(5): 311-313.

Heliodyne Helio-Pak Heat Transfer Appliance, Technical Specifications. Document no. PTLS 000005 042308. No date.

Heliodyne Installation Guide: HPAK Systems v.2.1.1. No date. 
Hendrickson, C., et al. (2006). Environmental Life-Cycle Assessment of Goods and Services: An Input-Output Approach, Resources for the Future Press.

IEA (2011). Fthenakis, H. C. Kim, R. Frischknecht, M. Raugei, P. Sinha, M. Stucki, 2011, Life Cycle Inventories and Life Cycle Assessment of Photovoltaic Systems, International Energy Agency (IEA), Photovoltaic Power Systems Programme (PVPS) Task 12, Report T12-02:2011.

Intergovernmental Panel on Climate Change (IPCC) (2005). IPCC/TEAP Special Report: Safeguarding the Ozone Layer and the Global Climate System.

International Code Council (ICC) (2006). 2006 International Energy Conservation Code. Washington, DC, International Code Council.

International Code Council (ICC) (2009). 2009 International Energy Conservation Code. Washington, DC, International Code Council.

International Code Council (ICC) (2012). 2012 International Energy Conservation Code. Washington, DC, International Code Council.

International Code Council (ICC) (2015). 2015 International Energy Conservation Code. Washington, DC, International Code Council.

International Copper Association (ICA) (2012). Life-cycle Assessment of Primary Copper Cathode.

International Organization for Standardization (ISO) (2006a). Environmental Management -Life-Cycle Assessment -- Principles and Framework, International Standard 14040.

International Organization for Standardization (ISO) (2006b). Environmental Management -Life-Cycle Assessment -- Principles and Framework, International Standard 14044.

Jungbluth, N and Tuchschmid, M. (2007a). "Photovoltaics”. In Dones, R. (Ed.) et al. Sachbilanzen von Energiesystemen: Grundlagen fur den okologischen Vergleich von Energiesystemen und den Einbezug von Energiesystemen in Okobilanzen fur die Schweiz. ecoinvent report No. 6-XII, Swiss Centre for Life Cycle Inventories, Dubendorf, CH.

Jungbluth, N. (2007b). “Sonnenkollektor-Anlagen”. In Dones, R. (Ed.) et al. Sachbilanzen von Energiesystemen: Grundlagen fur den okologischen Vergleich von Energiesystemen und den Einbezug von Energiesystemen in Okobilanzen fur die Schweiz. ecoinvent report No. 6-XI, Swiss Centre for Life Cycle Inventories, Dubendorf, $\mathrm{CH}$.

Kneifel, J. and P. Lavappa (2015). "Building Industry Reporting and Design for Sustainability (BIRDS) New Residential Database Technical Manual." NIST Technical Note 1878.

Kneifel, J. et al (2017). " BIRDS v3.1 Low-Energy Residential Database Technical Manual." NIST Technical Note 1956.

Levin, L. (1996). Best Sustainable Indoor Air Quality Practices in Commercial Buildings. Third International Green Building Conference and Expostion - 1996, Gaithersburg, MD, NIST.

Lippiatt, B., et al. (2013). "Building Industry Reporting and Design for Sustainability (BIRDS) Technical Manual and User Guide." NIST Technical Note 1814. 
Lippke, B., et al. (June 2004). CORRIM: Life-Cycle Environmental Performance of Renewable Building Materials, Journal - Forest Products, Vol. 54, No. 6. Retrieved from:

http://www.corrim.org/pubs/articles/2004/FPJ_Sept2004.pdf

McCulloch, A. (2009). "Life Cycle Inventory Analysis of the Production of a High-performance Foam Blowing Agent HFC-245fa (1, 1, 1, 3, 3-pentafluoropropane)." Journal of Cellular Plastics.

Nashua Tape Products (2013). 322 Multi-Purpose Foil Tape specification sheet prepared by Berry Plastics Corporation.

National Association of Home Builders (NAHB) Research Center (2007). Study of Life

Expectancy of Home Components, National Association of Home Builders.

National Renewable Energy Laboratory (NREL) (2012). "U.S. Life-Cycle Inventory Database (LCI)." from http://www.nrel.gov/lci/.

NIST (2010). Building for Environmental and Economic Sustainability (BEES) Online Software, Applied Economics Office, Engineering Laboratory, http://ws680.nist.gov/Bees/.

NIST (2017). Building Industry Reporting and Design for Sustainability (BIRDS) Software, Applied Economics Office, Engineering Laboratory, http://ws680.nist.gov/Birds.

NREL (2017). OpenStudio. Alliance for Sustainable Energy, LLC. https://www.openstudio.net/.

Nyman, Mikko, and Carey J. Simonson (2004). Life-Cycle Assessment (LCA) of Air-Handling Units with and without Air-to-Air Energy Exchangers, ASHRAE Transactions: Symposia, AN04-4-2, pp. 399-409.

OSRAM Opto Semiconductors GmbH. (2009). Life-cycle Assessment of Illuminants - A

Comparison of Light Bulbs, Compact Fluorescent Lamps and LED Lamps (Executive Summary).

Parsons, D. (2006). "The environmental impact of compact fluorescent lamps and incandescent lamps for Australian conditions." The Environmental Engineer 7(2): 8-14.

PE International (2010). Eco-Profile of Aromatic Polyester Polyols (APP).

PE International (2011). GaBi Database.

PE International (2012). Life-Cycle Assessment of Spray Polyurethane Foam Insulation Products, Spray Polyurethane Foam Alliance (SPFA).

Ramroth, L. (2008). "Comparison of life-cycle analyses of compact fluorescent and incandescent lamps based on rated life of compact fluorescent lamp." Rocky Mountain Institute: 11-12.

Rosenbaum, R. K., et al. (2011). "USEtox human exposure and toxicity factors for comparative assessment of toxic emissions in life cycle analysis: sensitivity to key chemical properties." The International Journal of Life Cycle Assessment 16(8): 710-727.

ROXUL (2013). "ComfortBatt Technical Product Information Sheet." from http://www.roxul.com/files/RX-NA_EN/pdf/Technical\%20Data\%20Sheets\%20updated/COMFORTBATT-USAwithSS.pdf.

RS Means (2017). from https://www.rsmeansonline.com.

Salazar, J. (2007). Life-cycle Assessment Case Study of North American Residential Windows, University of British Columbia. 
SEIA (2015). Solar Energy Industries Association (SEIA) website text, accessed in 2015: http://www.seia.org/policy/environment/pv-recycling.

SFPA (2014). Southern Forest Products Association (SFPA), Pressure-Treated Southern Pine Standards - Specifications - Applications, 2014 ed. Retrieved from:

http://www.southernpine.com/publications/.

SPFA (2012). "Life-Cycle Assessment of Spray Polyurethane Foam Insulation for Residential and Commercial Building Applications." from http://www.sprayfoam.org/files/docs/SPFA\%20LCA\%20Long\%20Summary\%20New.pdf.

Stucki, M and N. Jungbluth (2012), Update of the Life Cycle Inventories of Solar Collectors. ESU-services Ltd.

Suh, S. (2005). "Developing a sectoral environmental database for input-output analysis: the comprehensive environmental data archive of the US." Economic Systems Research 17(4): 449469.

Suh, S. (2010). Comprehensive Environmental Data Archive (CEDA). The Sustainability Practictioner's Guide to Input-Output Analysis. J. Murray and R. Wood, Common Ground Publishing.

Suh, S. and G. Huppes (2005). "Methods for life cycle inventory of a product." Journal of Cleaner Production 13(7): 687-697.

Suh, S., et al. (2004). "System boundary selection in life-cycle inventories using hybrid approaches." Environmental Science \& Technology 38(3): 657-664.

Suh, S. and B. C. Lippiatt (2012). "Framework for hybrid life cycle inventory databases: a case study on the Building for Environmental and Economic Sustainability (BEES) database." The International Journal of Life Cycle Assessment 17(5): 604-612.

SunPower (2013a). SunPower E-Series Solar Panels, 2013a, Document \# 504860 Rev B /LTR_EN, Retrieved at www.sunpowercorp.com.

SunPower (2013b). “SunPower Module 40-Year Useful Life”, white paper, Feb 2013.

SunPower Limited Warranty for SPRm PV Inverters, Document \#001-16799 Rev *B. No date. Retrieved from: http://us.sunpower.com/sites/sunpower/files/media-library/warranties/wrsunpower-limited-warranty-sprm-pv-inverters.pdf.

TWC (2011). Bolin, Christopher and Stephen Smith, 2011, Life Cycle Assessment: Procedures and Findings for ACQ-Treated Lumber (Centennial, CO), performed for the Treated Wood Council (TWC).

U.K. Department for Environment, Food and Rural Affairs (Defra), (2008). Life-cycle Assessments of Natural Fibre of Natural Fibre Insulation Materials, Final Report.

U.K. Department for Environment, Food and Rural Affairs (Defra), (2009). Life-cycle Assessment of Ultra-Efficient Lamps.

U.S. Department of Energy (DOE) (2015). EnergyPlus Simulation Software Version 8.3.0, Building Technologies Program (BTP). 
U.S. EPA Science Advisory Board (1990). Reducing Risk: Setting Priorities and Strategies for Environmental Protection, SAB-EC-90-021. Washington, DC.

U.S. EPA Science Advisory Board (2000). Toward Integrated Environmental Decision-Making, EPA-SAB-EC-00-011. Washington, DC.

UL Environment (2011). Product Category Rule (PCR) for Building Envelope Thermal Insulation, Product Category Rule Number UL 110116.

UL Environment (2013). Spray Polyurethane Foam Insulation and Roofing Systems, Declaration \#13CA29310.101.1.

United Nations Environment Programme (UNEP) (2005). Report of the Technology and Economi Assessment Panel (TEAP).

VHK (2007). Van Holsteijn en Kemna, B. Prepatory Study on Eco-Design of Water Heaters, Task 5 Report (Final).

Vigener, N. and M. A. Brown (2012). "Building Envelope Design guide - Windows." from http://www.wbdg.org/design/env fenestration winphp.

World Steel Association (2011). Methodology report - Life-cycle Inventory Study for Steel Products.

Yang, L., et al. (2008). "Comparison of environmental impacts of two residential heating systems." Building and Environment 43(6): 1072-1081. 